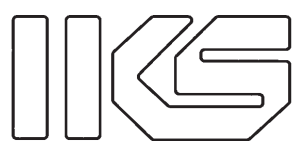

Instituut voor

Kern- en Stralingsfysica

Departement Natuurkunde

Faculteit Wetenschappen

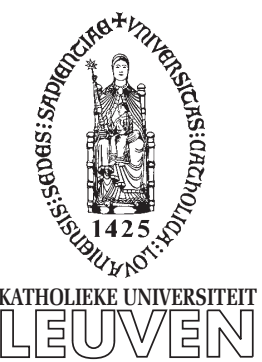

\title{
The beta decay of neutron-deficient rhodium and ruthenium isotopes
}

Promotoren:

Prof. Dr. M. Huyse

Prof. Dr. P. Van Duppen
Proefschrift ingediend tot het behalen van de graad van doctor in de wetenschappen door

Sarah Dean 



\section{Acknowledgements}

This work exists as a testament to the fortitude of my promoters Mark Huyse and Piet Van Duppen and to them I am particularly indebted. For help with experiments and other such convivialities thanks are due to the present members of the spectroscopy group viz. Hilde, Paul, Riccardo, Johnny, Karen, Ivan, Oleg, Marius, Yuri, Pascale, Farouk, Jarno, Jan, Daniel and Jean-Charles as well as past members - Astrid, Jan and Andrei. The help provided by the secretarial staff Josee, Katia and Sally is also appreciated.

Outside the institution - the contribution of Magda Górksa now at GSI is gratefully acknowledged. Thanks are also due to Messrs. Grawe, Roeckl and Brukard also from GSI. Thanks to the various obliging members of workshops and labs whose efforts have eased my modest progress through physics.

Lastly, thanks to the jury members for their careful reading of this text and helpful comments. 


\section{Contents}

1 Introduction 1

2 Theory and motivation $\quad 3$

2.1 Nuclear structure . . . . . . . . . . . . . . . . . . . . 3

2.1.1 The nuclear shell model . . . . . . . . . . . . 6

2.1.2 Shell model calculations . . . . . . . . . . . . . 7

2.1.3 Collective excitations . . . . . . . . . . . . . . . . 9 9

2.2 Nuclear beta decay . . . . . . . . . . . . . . . . . . . 11

2.2.1 Fermi and Gamow-Teller decay . . . . . . . . . . . . . . 13

2.2.2 Fermi and Gamow-Teller strength . . . . . . . . . . . . . . 14

2.2.3 Quenching of the Gamow-Teller strength . . . . . . . . . 15

2.2.4 Beta-delayed nucleon emission . . . . . . . . . . . . 16

2.3 Features of nuclear structure in the $\mathrm{N} \approx \mathrm{Z}$ region $\ldots . . . . . .17$

2.4 Astrophysical implications . . . . . . . . . . . . . . . . . 18

3 Experimental methods $\quad 21$

3.1 Production of exotic nuclei . . . . . . . . . . . . . . . . . 21

3.1.1 Fusion evaporation reactions . . . . . . . . . . . . . 21

3.1.2 In-Flight and Isotope Separation On-line . . . . . . . . . . 22

3.2 Production of exotic refractory isotopes at LISOL . . . . . . . . . . 24

3.2.1 The CYCLONE cyclotron . . . . . . . . . . . . . 25

3.2.2 The laser ion source . . . . . . . . . . . . . . . 25

3.2.3 Mass separation and beam delivery . . . . . . . . . . 27

3.3 Detection setup for $\beta$-delayed $\gamma$-ray measurements . . . . . . . . . 27

3.4 Detection setup for $\beta$-delayed proton emission measurements . . . 30

3.5 Signal processing electronics and data acquisition . . . . . . . . . 31

3.6 Production rates . . . . . . . . . . . . . . . . . . . 32

3.6.1 Predicted production rates . . . . . . . . . . . 32 
3.6.2 Calculated predicted production rates . . . . . . . . . 34

3.6.3 Measured production rates . . . . . . . . . . 35

4 Data reduction and analysis $\quad 37$

4.1 Assignment of $\gamma$ rays . . . . . . . . . . . . . . . . . . 37

4.2 Half-life determination . . . . . . . . . . . . . . . . . . . . . . . . . . . . . . . . . . 38

4.3 Level schemes and branching ratios . . . . . . . . . . . . 38

5 Results 41

5.1 Results of beta decay measurements . . . . . . . . . . . . . . . 41

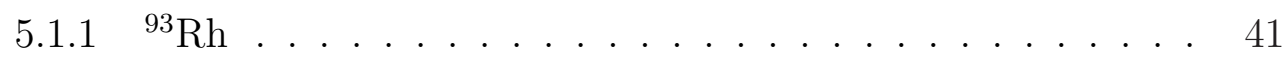

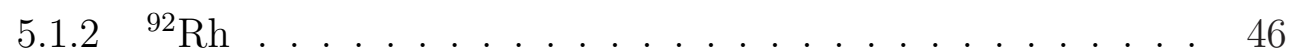

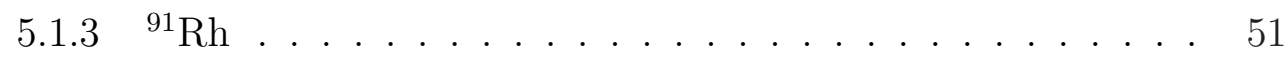

$5.1 .4{ }^{91} \mathrm{Ru} \ldots \ldots \ldots \ldots \ldots \ldots$

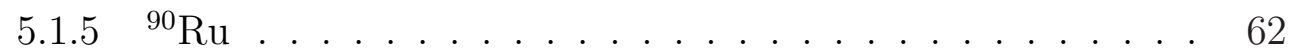

5.2 Results of $\beta$-delayed proton measurements . . . . . . . . . . 65

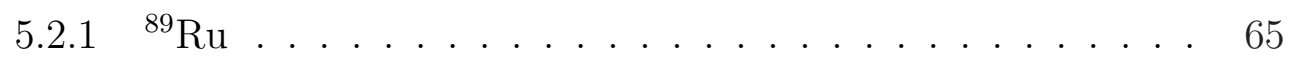

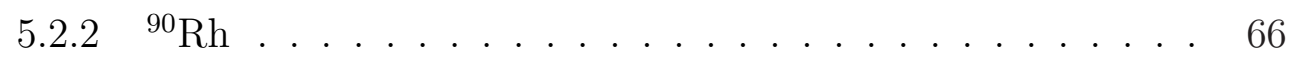

6 Discussion $\quad 67$

6.1 Half-lives . . . . . . . . . . . . . . . . . . . . . . . . . 68

6.2 Large scale shell model calculations . . . . . . . . . . . . . . 69

$6.2 .1{ }^{93} \mathrm{Rh}$ decay $\ldots \ldots \ldots \ldots . \ldots . \ldots 69$

$6.2 .2{ }^{92} \mathrm{Rh}$ decay $\ldots \ldots \ldots \ldots . \ldots 72$

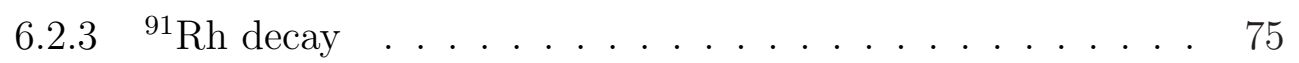

$6.2 .4{ }^{91} \mathrm{Ru}$ decay . . . . . . . . . . . . . . . 80

$6.2 .5{ }^{90} \mathrm{Ru}$ decay . . . . . . . . . . . . . . . . . 82

$6.3 \beta$-delayed proton activity . . . . . . . . . . . . . 84

6.3.1 ${ }^{89} \mathrm{Ru}$ decay . . . . . . . . . . . . . . . . . . . 84

$6.3 .2{ }^{90} \mathrm{Rh}$ decay $\ldots \ldots \ldots \ldots . \ldots . \ldots . \ldots 84$

7 Conclusions and outlook $\quad 85$

$\begin{array}{lr}\text { Samenvatting } & 87\end{array}$

$\begin{array}{lr}\text { References } & 94\end{array}$ 


\section{Chapter 1}

\section{Introduction}

The ultimate goal behind the study of nuclear physics is a complete description of the interactions between nucleons which would explain all the properties of atomic nuclei that we observe in experimental studies. Properties such as excited states, decay properties, ground state masses, spin and parity and reaction cross sections. These properties result from a combination of the electromagnetic, strong and weak forces acting within a finite quantal system and, by exploring different regions of the nuclear chart certain aspects of these interactions can be enhanced or suppressed. The particular conditions offered by the nuclei studied in this work and indicated in figure 1.1 will be discussed.

Physical systems will always seek to reach a point of lowest potential and just as electronic excitations in atoms will de-excite with the emission of photons so nuclei will also try to approach more stable configurations. There are two main ways a nucleus can do this. An excited nucleus can emit photons in the form of $\gamma$ rays and can thus, by electromagnetic de-excitation reach its lowest energy excitation or ground state. Or the nucleus, usually in its ground state but not always, can further de-excite by another radioactive decay process where, by the emission of certain particles, can change into a different, more stable nucleus. It is by the study of these two nuclear de-excitation processes, the energies involved, their lifetimes, intensities and angular emission correlations that information on the structure of nuclei can be derived. The excited states of a nucleus can be probed by adding energy to the system. This can be done in nuclear reactions by producing the nucleus in an excited state and watching it decay, a method known as in-beam spectroscopy. If you already have the nucleus you want to study, produced by whatever means, its excited states can be explored through Coulomb excitation. In this case, an energetic projectile beam is directed at a 


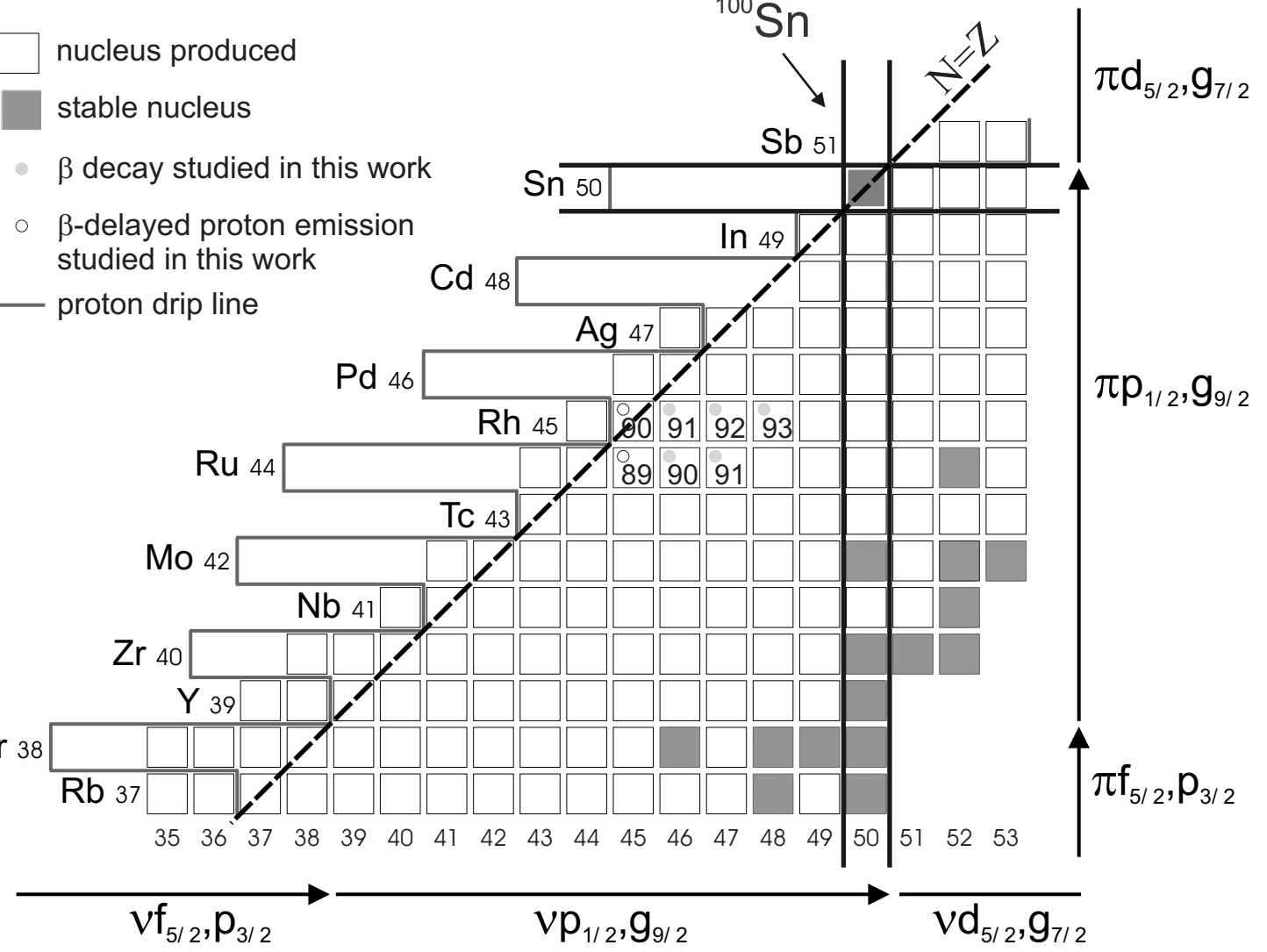

FIG. 1.1: A section of the chart of nuclides in the region around the isotopes presented in this work. The relevant spherical shell model orbitals are indicated. The proton drip line indicated is from mass predictions in ref. [Gor01]. Alternative calculations (e.g. [Mö197]) locate the dripline along different pathways.

target nucleus at an energy which is in most cases chosen to be too low for nuclear reactions to occur. The nuclear excitations are thus purely electromagnetic in nature. The excited states of nuclei studied in this work were populated following radioactive $\beta$ decay of the mother nucleus.

The proceeding chapters will include in chapter 2 , a description of the physics behind the experimental observations relevant to this study as well as the motivation for the work. A description of the experimental method and analysis procedure are presented in chapters 3 and 4 followed by the experimental results and discussion in chapters 5 and 6 . A short summary of the work along with an outlook for future work is given in chapter 7 . 


\section{Chapter 2}

\section{Theory and motivation}

\subsection{Nuclear structure}

Atomic nuclei consist of protons and neutrons bound together within a volume of radius $\sim 10^{-12}-10^{-13} \mathrm{~cm}$. This is about 100,000 times smaller than the radius of the atom but contains more than $99.95 \%$ of its mass. The very fact that nuclei exist, overcoming the repulsive effect of the Coulomb interaction, implies the existence of a strong, attractive interaction between nucleons. This interaction is known as the strong force and is felt only between hadrons which are particles with an underlying quark structure. Although not completely understood, some important properties of the strong force have been identified.

- The nuclear strong force is short range $(\sim 1 \mathrm{fm})$. A plot of binding energies per nucleon shows the strong force saturates at around $A \geq 10$ when all the nearest neighbour positions have been filled.

- It has a very short range repulsive core resulting in relatively similar nuclear densities over large mass ranges.

- The symmetry between the p-p, n-n and n-p interactions is evident in similarities between the spectra of nuclei in the same isobar. As a consequence of this, the proton and neutron can be considered as different states of the same particle, a concept known as isospin that will be discussed later.

The nucleus is an exceedingly complicated quantal system of strongly interacting fermions and the problem of nuclear structure is thus enormous. The main difficulties relate to the fact that atomic nuclei are too large to treat microscopically and too small to be described statistically. 
There are several methods for calculating the properties of an A-nucleon system in terms of an A-body problem. Recent results from such calculations which apply quantum Monte Carlo methods (QMC) [Pie01] to nuclei interacting with realistic potentials are presented in figure 2.1.

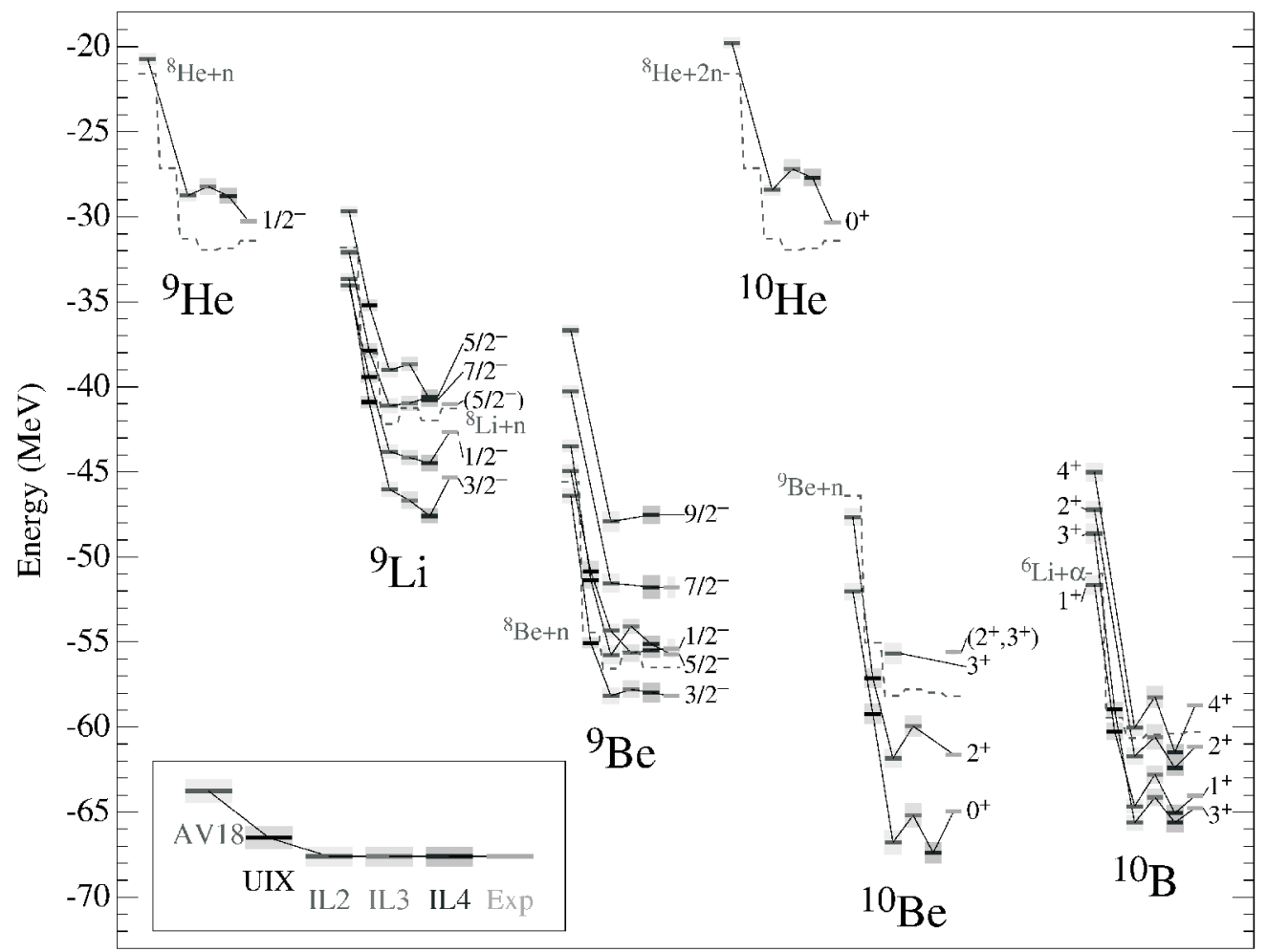

FIG. 2.1: Green's Function Monte Carlo calculations (GFMC) and experimental energies for $A=9,10$ nuclei. The AV18 calculation uses a two-nucleon potential only and all other calculations have a three-nucleon potential in addition (figure taken from ref. [Pie02]).

An alternative approach called the no-core shell model (NCSM) has recently been successfully applied to the excited states in ${ }^{13} \mathrm{C}$ [Nav03]. In this case however the bare nucleon-nucleon interaction is approximated by an effective interaction.

The properties of heavier nuclei, that are as yet outside the scope of the $a b$ initio methods mentioned above, can be interpreted in terms of models. The situation is represented schematically in figure 2.2. The three islands represent starting points upon which phenomenological models can be built without too much recourse to the underlying physical realities of the system. By treating the nucleus as a liquid drop for example, excited states can be explained as rotations and vibrations of this drop. The model thus describes the motion of nucleons in terms of collective coherent behaviour. The shell model in contrast considers 


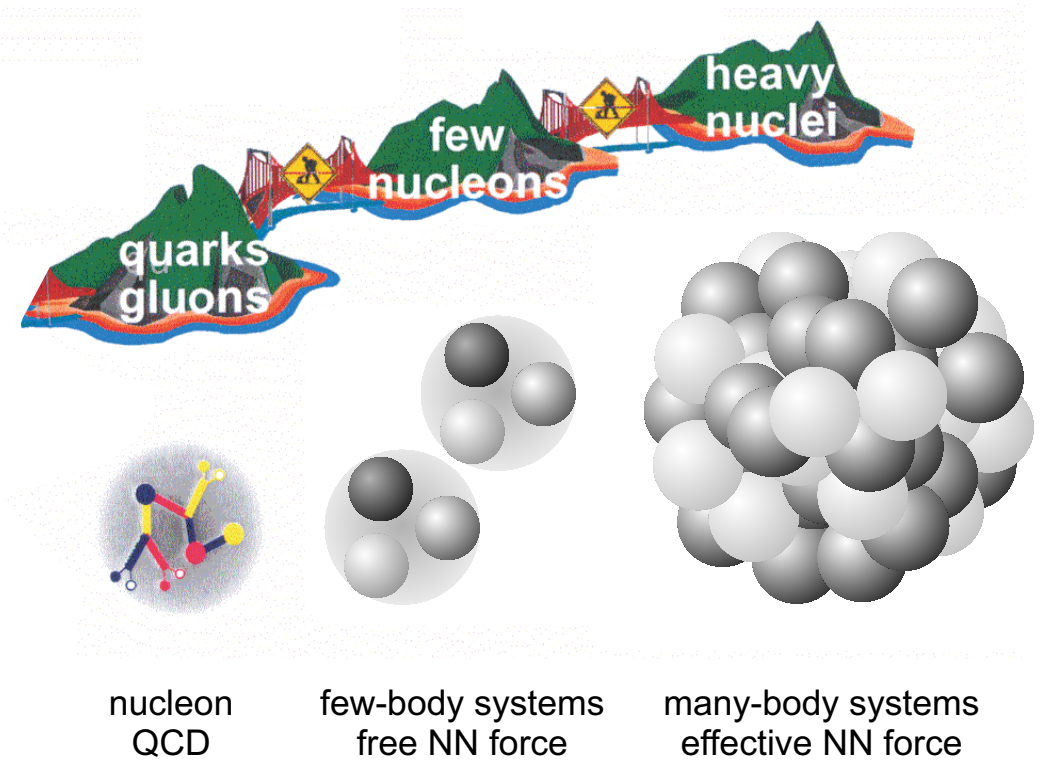

FIG. 2.2: Based on a figure taken from ref. [Naz98]: from hadrons to heavy nuclei.

nuclear properties in terms of the microscopic or single particle behaviour of the last few valence nucleons outside an inert core. These two nuclear models may seem mutually exclusive however, the structure of excited states in nuclei can often be described as a coupling between the excitation modes described by these two models. It can also be the case that particle-hole excitations result in collective behaviour in particular nuclei. This phenomenon is exhibited in ${ }^{186} \mathrm{~Pb}$ [And00] which has two deformed $0^{+}$states above a spherical $0^{+}$ground state.

The description of atomic nuclei can be simplified by making use of the underlying symmetries; see ref. [Gib80] for an introduction to this subject. When certain properties associated with a physical system are conserved there exists an underlying invariance or symmetry principle responsible for its conservation. These symmetries can be expressed in the language of groups and treated mathematically using group theory. The Interacting Boson Approximation (IBA) for example, which reduces the nuclear problem to pairs of nucleons coupled to $I=0$ and $I=2$ allows nuclear properties to be treated in an algebraic manner [Arf85]. 


\subsubsection{The nuclear shell model}

The shell model ${ }^{1}$ describes the nucleus as a sequence of shells which can be occupied by nucleons. It was developed in an attempt to explain certain properties of nuclei that the liquid drop model failed to reproduce. The periodic table of the elements is based upon regularities in the chemical and physical properties of atoms. Quantum mechanics has provided an explanation for this periodicity and introduced the notion of a shell structure in atomic physics. Properties such as ionisation potentials vary across the periodic table with discontinuities corresponding to the filling of electronic shells, the shells being sets of energy levels associated with the quantisation of orbital angular momentum in a central potential.

The ab initio calculations discussed previously were concerned with interactions between individual nucleons which involved the most precise determination of the nucleon-nucleon potential represented in figure 2.3(a). To quantitatively

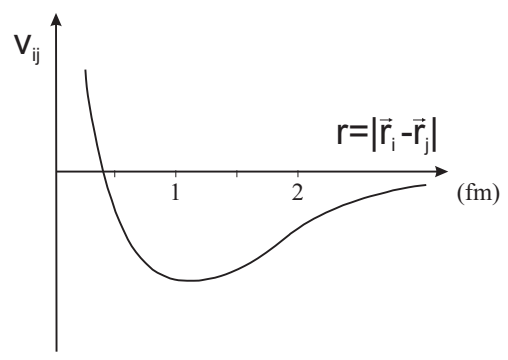

(a)

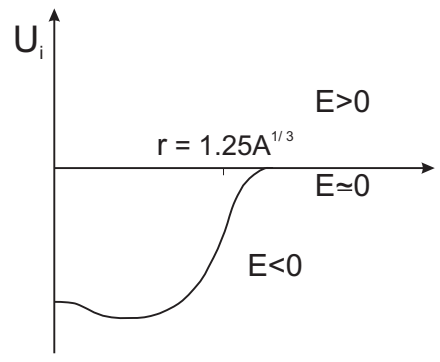

(b)

FIG. 2.3: (a) A simplified representation of the nucleon-nucleon potential and (b) the shape of the typical mean field potential.

describe heavier nuclei, the nucleus can be described in terms of a spherically symmetric mean field potential, such as that shown in figure 2.3(b), that is generated by all nucleons and in which individual nucleons move in unperturbed states almost independently of one another. A nucleus with A nucleons has a Hamiltonian given by:

$$
H=\sum_{i}^{A} T_{i}+\sum_{i j}^{A} v\left(r_{i j}\right)
$$

where $\mathrm{T}$ is the kinetic energy and $v\left(r_{i j}\right)$ is the short-range interaction between two nucleons $i$ and $j$. There is no exact solution to equation (2.1) however, an

\footnotetext{
${ }^{1}$ The reader is directed to refs. [Bru77, Hey90, Sha63] for a fuller discussion of this subject.
} 
approximate solution can be found by introducing a central potential $U(r)$.

$$
H=\sum_{i}^{A}\left[T_{i}+U\left(r_{i}\right)\right]+\lambda\left[\sum_{i j}^{A} v\left(r_{i j}\right)-\sum_{i}^{A} U\left(r_{i}\right)\right]=H_{0}+H_{\text {res }}
$$

The central part $H_{0}$ includes the kinetic energy and potential energy while the non-central part $H_{r e s}$ is the residual interaction which accounts for all other nuclear interactions. The potential should be chosen such that $H_{\text {res }}$ can be treated as a perturbation. Hartree-Fock methods are able to locate an optimum mean field with the smallest residual correction however, the harmonic oscillator potential is mathematically less cumbersome and is a good approximation. The smaller the residual part of the Hamiltonian becomes (as $\lambda \rightarrow 0$ ), the more central the interaction becomes. Moving away from nuclei with magic numbers of protons and neutrons, with the introduction of more valence particles to the system, the residual contribution begins to play a more prominent role in defining nuclear behaviour. The residual interaction can be expanded in different multipoles and the monopole part, which is constant over all space, effects only changes to the particle interaction with the mean field and therefore only the single particle energies. The longer range quadrupole part induces quadrupole deformations in spherical nuclei. This phenomenon has been demonstrated convincingly in the midshell nucleus ${ }^{88} \mathrm{Ru}$ by Hasegawa et al. [Has04] who add explicitly a quadrupole contribution to the Hamiltonian to reproduce experimental results.

\subsubsection{Shell model calculations}

Calculations involving systems with larger numbers of valence particles are only feasible with shell model codes such as OXBASH [Bro88] or the more recent ANTOINE [Cau99] which was used for the calculations presented in this work. Shellmodel calculations can tell us about the composition of nuclear states as well as showing up any anomalous behaviour which may be attributable to either nuclear constructs outside the model space or deficiencies in the interaction used.

The size of matrices that need to be manipulated increases rapidly with the number of valence particles and allowed orbitals however the nucleus can be reduced to the more manageable scheme of an inert core and several valence particles. Nuclear energy levels of the single particle states in a central field are clustered together in groups called shells providing a natural configuration space in which to define the core and restrict the valence particles. The Hamiltonian in equation (2.2) can then be constructed in this basis using a set of single particle 
(or hole) energies and two-body matrix elements of the residual interaction. The single particle energies can be extracted from experiment by subtracting the binding energy of the core nucleus from that of the core plus one valence particle (or hole).

There are several ways to determine the two-body matrix elements for an interaction and the two interactions employed for the calculations in this work were derived using different methods. Gross and Frenkel [Gro76] determined the matrix elements of the effective interaction in the $2 p_{1 / 2}$ and $1 g_{9 / 2}$ proton and neutron subshells using the energies of selected levels in ten $N=48,49,50$ nuclei. These energies which are eigenvalues of the Hamiltonian can be expressed as a linear combination of the two-body matrix elements in order to perform a least squares fit to the experimental energies. For the interaction parameters of Sinatkas and co-workers [Sin92a, Sin92b], the matrix elements of the effective interaction were based on a realistic potential derived from the results of free nucleon-nucleon scattering experiments. Interactions derived in this way encounter the problem of the repulsive hard core that is a feature of the nucleon-nucleon interaction (see figure 2.3(a)). An approximation using Brueckner theory can take this into account producing an effective interaction in terms of a G-matrix. A review of this subject can be found in ref. [Hjo95]. The interaction of Sinatkas uses ${ }^{100} \mathrm{Sn}$ as a core with proton and neutron valence holes allowed to occupy the $g_{9 / 2}, p_{1 / 2} p_{3 / 2}$ and $f_{5 / 2}$ orbitals. Experimental values for the single-particle energies in ${ }^{99} \mathrm{In}$ and ${ }^{99} \mathrm{Sn}$ are not yet known however, these were determined from a least-squares fit to the energies of 68 levels in $N=50,37 \leq Z \leq 44$ nuclei [Sin92a, Sin92b]. Figure 2.4 shows a comparison between the two-body matrix elements of the two interactions and remarkable to note is the similarity between the values extracted from the two very different procedures. The size of the matrix elements reflects the amount of energy that the particular interaction contributes to the unperturbed single particle energies and how much mixing between different configurations contribute to the final states.

The ANTOINE shell model code uses m-scheme, as opposed to j-scheme coupling which, although it creates an energy matrix of much larger dimensions, is much more amenable to diagonalisation using the Lanczos algorithm [Cau99]. For this reason, it was not necessary to include any truncation in the calculations i.e. restrictions on the movement of particles or orbital occupancy. The result of the Hamiltonian diagonalisation is a set of eigenvalues which are the energies of excited states in terms of the binding energy relative to the core and a set of eigenvectors which give the relative contributions to the final state from 


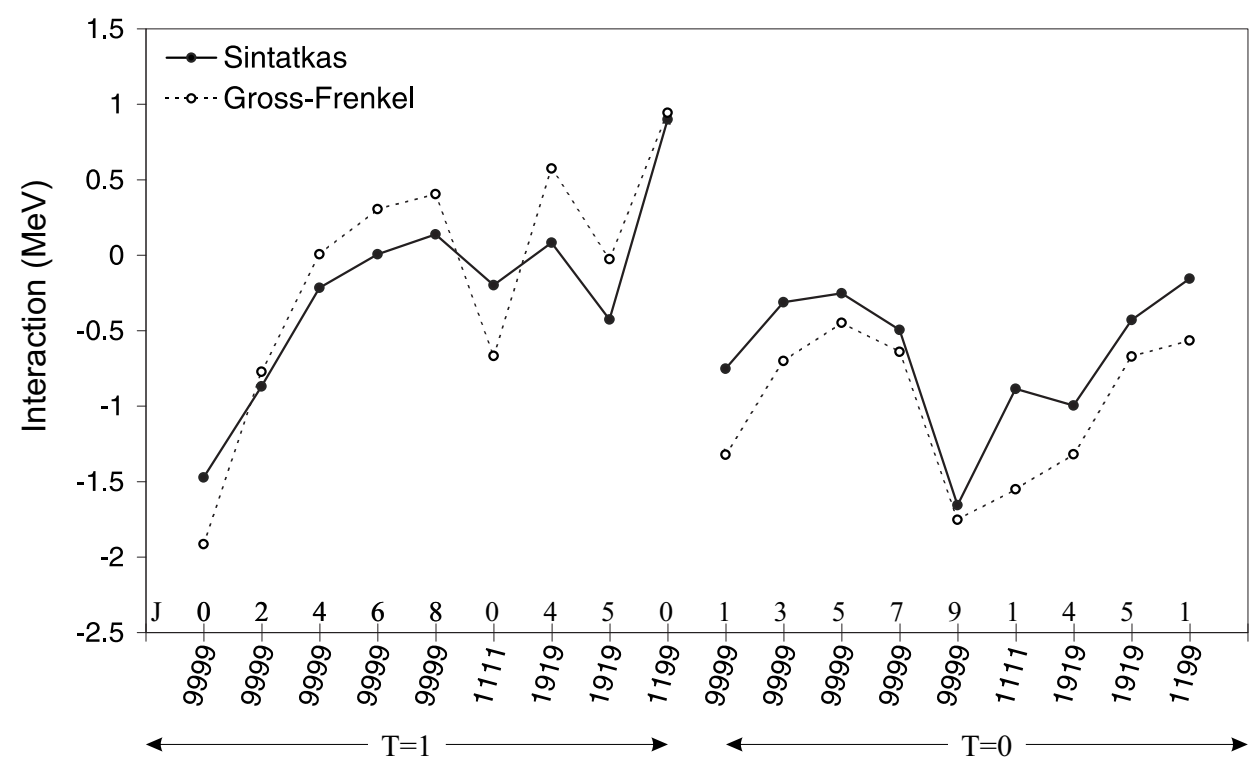

FIG. 2.4: Values for the two-body matrix elements for the Sinatkas and Gross-Frenkel interactions. The orbitals $g_{9 / 2}$ and $p_{1 / 2}$ are denoted by 9 and 1, and e.g. 9191 corresponds to the matrix element $\langle 91|V| 91\rangle$.

individual configurations coupled to the same J.

\subsubsection{Collective excitations}

Moving away from the regions around shell closures, excitations involving coherent motion of nucleons begins to dominate [Boh98]. Some nuclei exhibit properties indicative of a spherical liquid drop that displays collective vibrations when energy is added, others behave as if they have a deformed equilibrium shape with rotational features.

\section{Vibrations}

A rapidly vibrating nucleus with only a few valence nucleons may be described as spherical even if the instantaneous shape is not. Vibrational modes in such nuclei can be characterised by the multipole quantum number $\lambda$, the lowest of which $\lambda=2$, is a quadrupole vibration ${ }^{2}$. The addition of a quadrupole phonon which carries two units of angular momentum, to the $0^{+}$ground state of an eveneven nucleus will produce a $2^{+}$state. The addition of a second phonon produces

\footnotetext{
${ }^{2} \lambda=0$ describes an expansion and contraction of the nuclear surface and is known as the breathing mode. Dipole excitations $(\lambda=1)$ correspond to oscillations of protons against neutrons giving rise to giant dipole resonances (GDR) and the scissors excitation mode.
} 
a $0^{+}, 2^{+}, 4^{+}$triplet at energies around twice that of the first $2^{+}$energy. This $\mathrm{E}_{4^{+}} / E_{2^{+}} \simeq 2$ energy ratio is indicative of a vibrating nucleus. With the addition of more valence particles nuclei become softer against deformation which results in a decreasing vibrational frequency about the spherical equilibrium shape.

\section{Rotations}

For sufficient numbers of valence particles, deformed nuclei which have nonspherical equilibrium shapes can result. The radius of a deformed nucleus can be described by a sum over spherical harmonics $Y_{\lambda}^{\mu}(\theta \phi)$;

$$
R(\theta \phi)=R_{0}\left[1+\sum_{\lambda \mu} \alpha_{\lambda \mu} Y_{\lambda}^{\mu}(\theta \phi)\right]
$$

$R_{0}$ is the radius of a sphere of the same volume and $\alpha_{\lambda \mu}$ are the expansion coefficients. In the case of a $\lambda=2$ quadrupole deformation, this becomes;

$$
R(\theta \phi)=R_{0}\left[1+\alpha_{20} Y_{2}^{0}(\theta \phi)+\alpha_{22}\left(Y_{2}^{2}(\theta \phi)+Y_{2}^{-2}(\theta \phi)\right)\right]^{\text {see footnote } 3}
$$

The deformation amplitudes can be expressed in terms of deformation parameters $\beta$ and $\gamma: \alpha_{20}=\beta \cos \gamma$ and $\alpha_{22}=1 / \sqrt{2} \beta \sin \gamma$. The quantity $\beta$ is a measure of the total deformation of the nucleus in which positive and negative values for $\beta$ correspond to prolate and oblate nuclear shapes. The $\gamma$ value introduces a deformation that breaks the axial symmetry producing an ellipsoid with three unequal axes. Treated quantum mechanically, the rotational energy of a deformed system, in terms of the moment of inertia $\mathcal{J}$ and angular momentum $I$, is given by;

$$
E_{\text {rot }}=\frac{\hbar^{2}}{2 \mathcal{J}} I(I+1)
$$

Only even values of $I$ are allowed thus energies for the first two excitations are $E_{2^{+}}=6 \hbar^{2} / 2 \mathcal{J}$ and $E_{4^{+}}=20 \hbar^{2} / 2 \mathcal{J}$. The ratio $E_{4^{+}} / E_{2^{+}} \simeq 3.33$ is an important signature for this excitation mode.

\section{The deformed shell model}

The single particle model applicable to deformed nuclei was first formulated by S. G. Nilsson and is alternatively referred to as the Nilsson model. A deformed nuclear potential lifts the $(2 J+1)$ degeneracy of the individual single particle

\footnotetext{
${ }^{3} \alpha_{21}=\alpha_{2-1}=0$ are rotations about the symmetry axis and therefore have no quantum mechanical meaning and $\alpha_{22}=\alpha_{2-2}$ due to reflection symmetry.
} 
states because deformation can now define an axis onto which the $(2 J+1)$ magnetic substates $m_{z}$ of the total angular momentum can be projected. These new $\Omega$ states are two-fold degenerate $(+\Omega=-\Omega)$ and their energies can be determined from the appropriate deformed Hamiltonian. Nilsson diagrams ${ }^{4}$ are plots of the energies of the $\Omega$ states as a function of a deformation parameter and are used successfully to predict the spin and parity of deformed band heads as well as the appearance of new magic numbers in regions of deformation in the chart of nuclides.

\subsection{Nuclear beta decay}

Nuclei with an excess of protons or neutrons can acquire a more stable nuclear composition by changing one of their protons into a neutron or vice versa. This process is known as $\beta$ decay and, since it is the process that we have exploited in this work, this section will be devoted to a discussion of the details involved. Beta decay is the result of the weak interaction in the nucleus which acts between pairs of fermions ${ }^{5}$ and brings about a change in flavour in one of the constituent quarks. ${ }^{6}$ There are three types of $\beta$ decay; $\beta^{+}$decay, $\beta^{-}$decay and electron capture. The nuclei discussed in this work have an excess of protons when compared to the composition of stable nuclei and will thus decay by $\beta^{+}$decay or electron capture shown below.

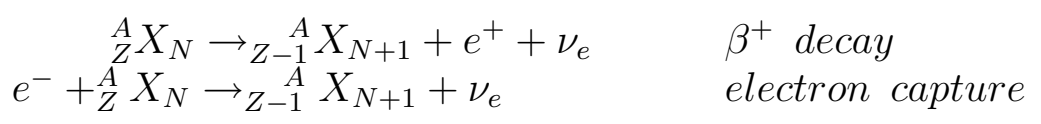

The neutrinos $\nu_{e}$ are needed to conserve lepton number which, in the case of $\beta^{+}$ decay, produces a continuous energy distribution as the available energy is shared between the positron and the neutrino.

As a starting point, time-dependent perturbation theory gives a general expression known as Fermi's golden rule for the transition rate between initial and final states;

$$
\lambda=\frac{2 \pi}{\hbar}\left|V_{f i}\right|^{2} \rho_{f}
$$

The density of final states $\rho_{f}$ which determines the shape of the $\beta$ spectrum has the form; $\rho_{f} \sim p_{e}^{2}\left(Q-E_{e}\right) d p_{e}$, where $\mathrm{Q}$ is the decay energy and $\mathrm{p}_{e}, \mathrm{E}_{e}$ are the

\footnotetext{
${ }^{4}$ see for example ref. [Fir96] pp.14163-73

${ }^{5}$ particles with spin $1 / 2$

${ }^{6}$ see ref. [Gro90] for more on this subject
} 
momentum and kinetic energy of the electron. The matrix element $\mathrm{V}_{f i}$ reflects the strength of the coupling between the initial and final states of the system and in the case of $\beta$ decay is given by;

$$
M_{f i}=g \int\left[\psi_{D}^{*}(\vec{r}) \varphi_{e}^{*}(\vec{r}) \varphi_{\nu}^{*}(\vec{r})\right]_{f} \hat{\mathcal{O}} \psi_{i} d^{3} r
$$

The total final state is in square brackets and includes $\psi_{D}^{*}$, the final state of the daughter nucleus and $\varphi_{e}^{*}$ and $\varphi_{\nu}^{*}$, the wave functions of the electron and the neutrino. The interaction is given by the operator $\hat{\mathcal{O}}$ which changes a proton into a neutron or vice versa, and $g$ is the coupling strength of the interaction. The electron and neutrino are represented by plane-wave functions with momenta $\mathbf{p}$ and $\mathbf{q}$ normalised within the volume $\mathrm{V}$.

$$
\varphi_{e}(\mathbf{r})=\frac{e^{i \mathbf{p} \cdot \mathbf{r} / \hbar}}{\sqrt{V}} \quad \text { and } \quad \varphi_{\nu}(\mathbf{r})=\frac{e^{i \mathbf{q} \cdot \mathbf{r} / \hbar}}{\sqrt{V}}
$$

The exponential $e^{i(\mathbf{p}+\mathbf{q}) \cdot \mathbf{r} / \hbar}$ can be rewritten as an angular momentum expansion. Taking only the first term of the expansion $(l=0)$ and the fact that in the majority of cases $(\mathbf{p}+\mathbf{q}) \cdot \mathbf{r} \ll 1$, the exponential in $(2.8)$ is $\simeq 1$. This is called the allowed approximation and is only applicable when the change in orbital angular momentum between the initial and final states $\Delta I=0$ or 1 . These transitions are referred to as allowed transitions of Fermi $(\Delta I=0)$ and GamowTeller $(\Delta I=0,1)$ type and are the subject of section 2.2.1.

In cases where the initial and final states are such that decay is only possible with the transfer of angular momentum, higher order terms of the lepton wavefunction expansion are required. These decays are known as forbidden due to their low probability.

The plane wave function of the emitted $\beta$ particle is distorted by the Coulomb field of the nucleus. The Fermi function $\mathrm{F}\left(\mathrm{Z}_{D}, \mathrm{E}_{e}\right)$ is introduced to account for this where $\mathrm{Z}_{D}$ is the atomic number of the daughter nucleus and $\mathrm{E}_{e}$ is the kinetic energy of the $\beta$ particle. The final decay rate is given by;

$$
\lambda=\frac{g^{2}\left|M_{f i}\right|^{2}}{2 \pi^{3} \hbar^{7} c^{3}} \int F\left(Z_{D}, E_{e}\right) p_{e}^{2}\left(Q-E_{e}\right)^{2} d p_{e}
$$

which can be expressed as;

$$
\lambda=\frac{g^{2}\left|M_{f i}\right|^{2}}{2 \pi^{3} \hbar^{7} c^{3}} m_{e}^{5} c^{7} f\left(Z_{D}, E_{e}\right)
$$


using the Fermi integral $f\left(Z_{D}, E_{e}\right)$ which has been evaluated for different values of $\mathrm{Z}_{D}$ and $\mathrm{E}_{e}$ see footnote 7

Rearranging equation (2.10) with $\lambda=\frac{\ln 2}{t_{1 / 2}} \quad$ gives;

$$
f\left(Z_{D}, E_{e}\right) t_{1 / 2}=\frac{K}{g^{2}\left|M_{f i}\right|^{2}}
$$

with

$$
K=\ln 2 \frac{2 \pi^{3} \hbar^{7}}{m_{e}^{5} c^{4}}
$$

Expression (2.11) is known as the comparative half-life or $f t$ value. If $t_{1 / 2}$ is the partial half-life (i.e. half-life divided by the $\beta$ branching ratio $b_{\beta}$ ) then the $f t$ value for each $\beta$ transition can be determined ${ }^{8}$ thus providing a simple way to access the matrix element and thus the interaction of the decay.

\subsubsection{Fermi and Gamow-Teller decay}

There are two distinct possibilities for allowed $\beta$ decay. The spins of the emitted electron and neutrino can be parallel or antiparallel, classified as Fermi (F) and Gamow-Teller (GT) respectively. Returning to equation (2.7), matrix elements for the F and GT cases may be written separately.

$$
\begin{array}{ll}
\text { Fermi case } & M_{f i}=M_{F}=g_{V} \int\left[\psi_{D}^{*}(\vec{r}) \varphi_{e}^{*}(\vec{r}) \varphi_{\nu}^{*}(\vec{r})\right]_{f} \hat{\mathcal{O}}_{F} \psi_{i} d^{3} r \\
\text { Gamow-Teller case } & M_{f i}=M_{G T}=g_{A} \int\left[\psi_{D}^{*}(\vec{r}) \varphi_{e}^{*}(\vec{r}) \varphi_{\nu}^{*}(\vec{r})\right]_{f} \hat{\mathcal{O}}_{G T} \psi_{i} d^{3} r
\end{array}
$$

The Fermi operator can be expressed as $\hat{\mathcal{O}}_{F}\left(\beta^{ \pm}\right)=\sum_{j=1}^{A} \tau_{ \pm}(j)$ where $\tau_{+}\left(\tau_{-}\right)$ is the isospin ladder operator which operates on the total nuclear wavefunction converting a proton(neutron) into a neutron(proton) without altering the state of the motion. In the case of $\beta^{+}$decay, the projection of the isospin $\mathrm{T}_{Z}$ changes by +1 while the isospin $T$ remains the same. Fermi decay is therefore only possible between isobaric analogue states (IAS). For Gamow-Teller decay, $\hat{\mathcal{O}}_{G T}\left(\beta^{ \pm}\right)=$ $\sum_{j=1}^{A} \vec{\sigma}(j) \tau_{\mp}(j)$. Here, in addition to $\tau_{ \pm}$, the Pauli matrices $\sigma$ also act on the $\mathrm{j}^{\text {th }}$ nucleon. The Fermi operator $\hat{\mathcal{O}}_{F}$ transforms as a vector and the Gamow-Teller operator $\hat{\mathcal{O}}_{G T}$ as an axial vector, the coupling constants for the two interactions $g_{A}$ and $g_{V}$ cannot therefore be assumed to be identical. Indeed the ratio $g_{A} / g_{V}$ has been determined from the decay of the free neutron as -1.2670(30) [Hag02].

\footnotetext{
${ }^{7}$ in ref. [Fir96] pp 14190-14192 for example

${ }^{8}$ using for example the code provided on the website ref. [nndc]
} 
The nature of the operators $\hat{\mathcal{O}}_{F}$ and $\hat{\mathcal{O}}_{G T}$ impose selection rules for properties of the nuclear states involved in allowed transitions. These are summarised in table 2.1 .

\begin{tabular}{cccccccc}
\hline \hline $\begin{array}{c}\text { decay } \\
\text { mode }\end{array}$ & operator & spin & orbital angular & parity & isospin & coupling & typical \\
momentum $l$ & $\pi$ & T & constant & $\log f t$ \\
\hline $\mathrm{F}$ & $\tau$ & $\Delta I=0$ & $\Delta l=0$ & $\Delta \pi=0$ & $\Delta T=0$ & $\mathrm{~g}_{F}$ & $3.3-3.7$ \\
$\mathrm{GT}$ & $\sigma \tau$ & $\begin{array}{c}|\Delta I|=0,1 \\
\left(\text { no } 0^{+} \rightarrow 0^{+}\right)\end{array}$ & $\Delta l=0$ & $\Delta \pi=0$ & $\Delta T \mid=0,1$ & $\mathrm{~g}_{G T}$ & $4.6-6.8$ \\
& & & & & & \\
\hline \hline
\end{tabular}

TABLE 2.1: Selection rules for allowed transitions.

\subsubsection{Fermi and Gamow-Teller strength}

Excepting the $0^{+} \rightarrow 0^{+}$case, all $\beta$ decays can contain a GT component. The expression for $f t$ in equation $(2.11)$ can be rewritten as,

$$
f\left(Z_{D}, E_{e}\right) t_{1 / 2}=\frac{K}{g_{V}^{2}\left|M_{F}\right|^{2}+g_{A}^{2}\left|M_{G T}\right|^{2}}
$$

The Fermi strength $\mathrm{B}(\mathrm{F})$ and the Gamow-Teller strength $\mathrm{B}(\mathrm{GT})$ are given by;

$$
\begin{gathered}
B(F)=\left|M_{F}\right|^{2} \\
B(G T)=\left|M_{G T}\right|^{2}\left(\frac{g_{A}}{g_{V}}\right)^{2}
\end{gathered}
$$

Expressed in this way $\mathrm{B}(\mathrm{F})$ and $\mathrm{B}(\mathrm{GT})$ are dimensionless. Using the quantum mechanical relation for raising and lowering operators, for a pure Fermi decay;

$$
\tau_{ \pm}\left|T, T_{z}\right\rangle=\sqrt{T(T+1)-T_{z}\left(T_{z} \pm 1\right)}\left|T, T_{z} \pm 1\right\rangle
$$

the Fermi matrix element $\left|M_{F}\right|^{2}=2$ for $\mathrm{T}=1$. Using this result, $\mathrm{K} / g_{V}^{2}$ in (2.13) has been determined experimentally from nine $0^{+} \rightarrow 0^{+}$transitions to be $6145(4) \mathrm{s}$ [Har98].

In Fermi decay, the Hamiltonian commutes with $\hat{T}$ and $\hat{T}_{z}$. Isospin is therefore considered to be a good quantum number and the full Fermi strength is expected to go to the isobaric analog state (IAS) in the daughter. The perturbing effect of the Coulomb interaction which is different in the two nuclei however means that a small fraction can mix this strength into other states in the daughter. Calculations of isospin mixing in $N \simeq Z$ nuclei [Dob95, Col95] predict mixing of $\lesssim 5 \%$ in nuclei around $A=90$. 
The additional spin operator in the GT matrix element places less restrictions on $\beta$ decay and the GT strength can be distributed widely over a large number of daughter states. Gamow-Teller decay does however show a preference for decay to particle-hole excited states in the daughter nucleus that are analogous to the $\beta$-decaying state in the mother. This group of states is referred to as the Gamow-Teller Giant Resonance (GTGR) and is normally at energies that are inaccessible from $\beta$ decay. Decreasing the number of neutrons in a particular isotope increases the proton single particle energies. Calculations by Hamamoto and Sagawa [Ham93] show that for $N=Z$ nuclei above $A>65$, the ground state of the mother nucleus lies above the GTGR in the daughter and can therefore be populated in $\beta$ decay. Recent experiments using total gamma absorption devices (e.g. [Gie03, Jan00]) have verified these predictions.

Gamow-Teller strength B(GT) affords a direct measure of the difference between the initial and final state wavefunctions and as such, the mapping of $B(G T)$ in a nucleus provides an important test of structure calculations for that nucleus. The particular interest in $\mathrm{B}(\mathrm{GT})$ values stems from the fact that studies have shown that experimental values are significantly lower than those expected from free neutron $\beta$ decay $(3(N-Z))$ [Ike63] or from shell model calculations; a phenomenon known as quenching.

\subsubsection{Quenching of the Gamow-Teller strength}

Gamow-Teller strength quenching is defined as;

$$
q=\sqrt{\frac{B(G T)_{\text {exp }}}{B(G T)_{\text {calculated }}}}
$$

and has been calculated in the $0 p$ shell [Cho93] to be $0.82(2)$ in the 1 s0d shell as $0.77(2)$ [Wil83] and $0.74(2)$ in the 1p0f shell [Mar96]. Recent measurements of nuclei around ${ }^{100} \mathrm{Sn}$ [Jan00] involving $\pi g_{9 / 2} \rightarrow \nu g_{7 / 2}$ have placed $\mathrm{q}$ at around 0.42. The origin of this quenching has been variously attributed to a significant altering of $\mathrm{g}_{G T}$ in the presence of nuclear matter and to nuclear structure effects.

The conserved vector current (CVC) hypothesis [Fey58] predicts the vector current, which governs Fermi decay, to be unaffected by the strong interaction. Thus ft values from all Fermi decays are expected to be equal and, B(F) in a bound nucleus is expected to be identical to that of the free neutron. This is in contrast to the axial vector current associated with Gamow-Teller decay which is not conserved. In the case of neutron decay, since there are three ways for the leptons 
to couple to $\mathrm{S}=1$ and only one possibility for $\mathrm{S}=0$ it is expected that GamowTeller transitions should occur three times as frequently as the Fermi transitions. Experimentally however it is found that the strong interaction renormalises $g_{G T}$ such that the ratio of GT to Fermi decay is $82: 18$ which results in the ratio $g_{G T} / g_{F}=-1.267$ quoted in section 2.2.1.

A study of nuclei in the region $A=11-21$ [Wil73] yielded an amended value $g_{\text {Aeff }} / g_{A}=0.92(5)$. The extent to which nuclear-structure considerations, such as pairing, core polarisation and higher order configuration mixing of states outside the model space, play a part in strength quenching is discussed in [Tow85]. In particular higher order effects and core polarisation, whereby nucleons excited out of a closed shell couple to the residual core, have been shown to account for a significant amount the missing strength [Hu99]. The existence of subnucleonic degrees of freedom may also play a part in reducing the predicted $\mathrm{B}(\mathrm{GT})$, an example of the treatment of $\Delta$-hole excitations is given in [Ari98]

\subsubsection{Beta-delayed nucleon emission}

Further from stability, as the proton drip line indicated in figure 1.1 is approached, the energy available for $\beta$ decay increases. The addition of more protons to the nucleus without the stabilising effect of additional neutrons will lower the proton separation energy $\left(S_{p}\right)$. The combination of these two factors leads to an increased probability for proton emission [Kra88]. Nuclei on the drip line are unstable against ground state particle emission however while $S_{p}$ is still greater than 0 , proton emitting states in the daughter can be accessed through $\beta$ decay if $\mathrm{Q}_{E C}>\mathrm{S}_{p}$. A schematic representation of $\beta$-delayed proton emission is depicted in figure 2.5. Compared with $\beta$ decay, proton emission is prompt and the $\beta$-delayed

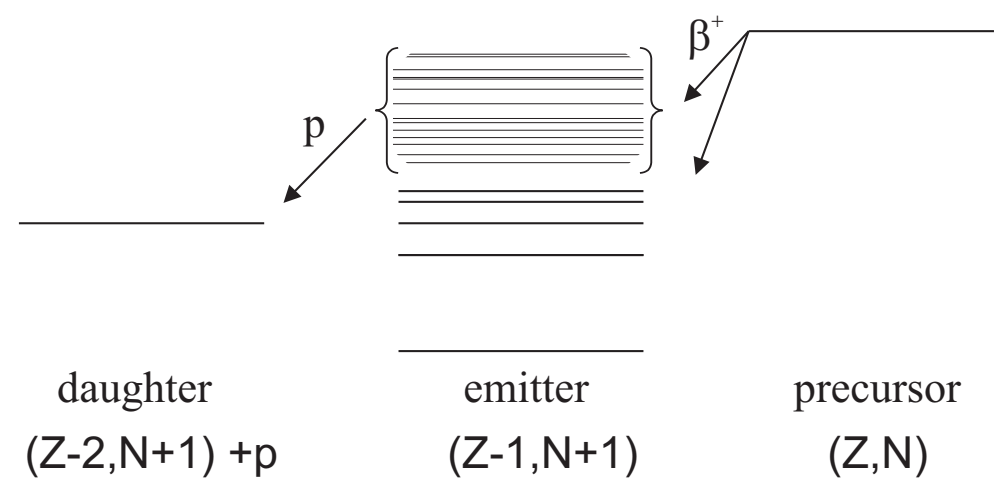

FIG. 2.5: Schematic of $\beta$-delayed proton emission. 
protons show the same half life as $\beta$ decay and can provide information on decay strengths in the upper part of the $\mathrm{Q}_{E C}$ window. The energy of the protons can tell us more about excited states in the emitter however the large density of final states characteristic of nuclei in this region mean that a broad spectrum of proton energies will often be seen.

\subsection{Features of nuclear structure in the $\mathrm{N} \approx \mathrm{Z}$ region}

The investigation of neutron deficient nuclei close to the $\mathrm{N}=\mathrm{Z}$ line offer a number of possibilities for a greater understanding of nuclear structure. Studies of nuclei close to doubly-closed shells are important testing grounds for nuclear models such as the shell model as the properties of such nuclei can often be described in terms of the coupling of a small number of valence particles to an inert doublymagic core. The closest doubly-magic nucleus to the nuclei studied here is ${ }^{100} \mathrm{Sn}$ with $N=Z=50$ which is the heaviest measured doubly-magic $N=Z$ nucleus. The next heaviest contender ${ }^{164} \mathrm{~Pb}$ is expected to be unbound. The close proximity of ${ }^{100} \mathrm{Sn}$ makes large scale shell model calculations possible [Her97] allowing a more complete comparison of not only level schemes but also of electromagnetic transition rates and Gamow-Teller strengths.

$\beta$ decay in this region is characterised by fast $\pi \mathrm{g}_{9 / 2} \rightarrow \nu \mathrm{g}_{9 / 2}$ Gamow-Teller and Fermi transitions which involve spin and/or isospin transfer. The strength of Gamow-teller transitions B(GT) has been shown to be significantly smaller than expected, a topic that has generated a great deal of interest [Bro85]. Although $\beta$ decay provides the most direct information on Gamow-Teller transition strength, only transitions to states lying within the $\mathrm{Q}_{E C}$ window can be investigated. States at higher energies can be explored through charge exchange $(p, n)$ and $(n, p)$ reactions which have no such constraints. See e.g. ref. [Rap94] for a review of the method. Exchange reactions introduce the added complication of having to convert reaction cross sections into Gamow-Teller strengths. This is a result of variations in Fermi and Gamow-Teller cross sections between different nuclei in a way that cannot be reproduced by reaction theory calculations [Tad87]. Charge exchange spectra can be normalised by comparison with results from $\beta$ decay [Goo80] or, if this is not well known, by comparison with the Fermi strength [Goo01] which is assumed to be concentrated in the isobaric analogue state. The phenomenon of missing strength however persists. 
In most nuclei, valence protons and neutrons, i.e. particles outside the nearest closed shell, occupy different shells thus pairing interactions between the protons and neutrons are suppressed. In the region around $N=Z$ where nuclei have almost equal numbers of protons and neutrons, the valence particles occupy the same orbitals. Enhanced particle interactions are expected as consequence of this large spatial overlap between their single particle wave functions [Goo99, Kan99]. The most important of these is the pairing interaction of which most of our knowledge comes from nuclei with a sizeable neutron excess where n-n and p-p pairings coupled to total isopin $T=1$ (spins antiparallel) dominate. The Fermionic nature of nucleons means that, in order to obey the Pauli exclusion principle, two identical particles cannot have the same set of quantum numbers thus nucleons identified by the same angular momentum must have opposite spins. No such constraints exists for nonidentical nucleons thus for nuclei close to the $N=Z$ line, there is expected to be competition between valence particles coupled to isospin $T=0$ (spins parallel) as well as the customary $T=1$ like-nucleon pairing. Studies have shown [Van97(b)] that if one mode is greatly favoured over the other, a pure state results. However, if the pairs have comparable energies, the result is an admixture of $T=0$ and $T=1$ (see ref. [Sch00(b)] for a recent result). The effects of an enhanced $T=0$ pairing manifest themselves in a number of ways. The greater interaction strength of a $T=0$ pair as compared to that of a $T=1$ pair may mean that $T=0$ states may form the ground state of odd-odd $N=Z$ nuclei in the region of ${ }^{100} \mathrm{Sn}$ [Goo99].

At higher spins in even-even nuclei, where the last pair of nucleons couple to $J=0^{+}$, the Coriolis force exerts a different pressure on each of the two particles by trying to align both nucleon spins along the axis of rotation which acts to break up the pair. The parallel spin orientations of the members of a $T=0$ pair mean that this configuration can survive up to higher values of angular momentum thus delaying backbending to higher spins [Fra99, Wys01]. With more information on these p-n interactions as well as like-nucleon pairing we can gain a better insight into the residual interaction inside the nucleus.

\subsection{Astrophysical implications}

The study of neutron deficient nuclei in this region also has important implications for astrophysics. The rapid proton capture (rp) process [Sch98] which follows a path in nuclei near $N=Z$ for $A=60-100$ plays a critical rôle 
during hydrogen burning at high temperatures and densities on the surface of neutron stars, in X-ray bursters and X-ray pulsars. As the proton drip line is approached, further proton capture has to compete with the inverse process of photo-disintegration $(\gamma, \mathrm{p})$; having eventually to defer to $\beta$ decay before nucleosynthesis can proceed. The life-times of these 'waiting point' nuclei are thus the critical factors in determining the time scale of the process, energy generation and the resulting nuclear abundances. The half-lives determined in this study are compared to the theoretical calculations of Herndl and Brown [Her97] where half-lives are extracted from calculated Gamow-Teller strengths. 


\section{Chapter 3}

\section{Experimental methods}

Before considering a study of exotic nuclear species, the nuclei first have to be produced. As we explore regions of the table of isotopes increasingly further from stability so the demands made on production and detection techniques and technologies increase. This chapter gives a general account of the machinery and mechanisms involved in the production, transport and final detection of nuclei as well as details specific to the production of the exotic nuclei presented in this work.

\subsection{Production of exotic nuclei}

\subsubsection{Fusion evaporation reactions}

The nuclei studied in this work were produced in fusion evaporation reactions. In such reactions, a projectile having an energy above the Coulomb barrier can fuse with a target nucleus to form a compound nucleus. The entire projectile energy is absorbed by the compound nucleus in the form of momentum and excitation energy. Figure 3.1 shows the sequence of events and their timescales from the moment of impact until the final nucleus reaches its ground state. The initial fusion stage takes place $\sim 10^{-22}$ s after impact and at this stage the highly excited compound nucleus loses any recollection of its previous incarnation thus, of the variety of options open to it, decay channels are chosen on the basis of the total energy of the system. In the next $\sim 10^{-19} \mathrm{~s}$, the compound nucleus loses energy by particle emission. The evaporation of particles can carry away large amounts of excitation energy $(8-10 \mathrm{MeV})$ and continues till this process is no longer energetically possible. Thus, the more energy absorbed by the compound 


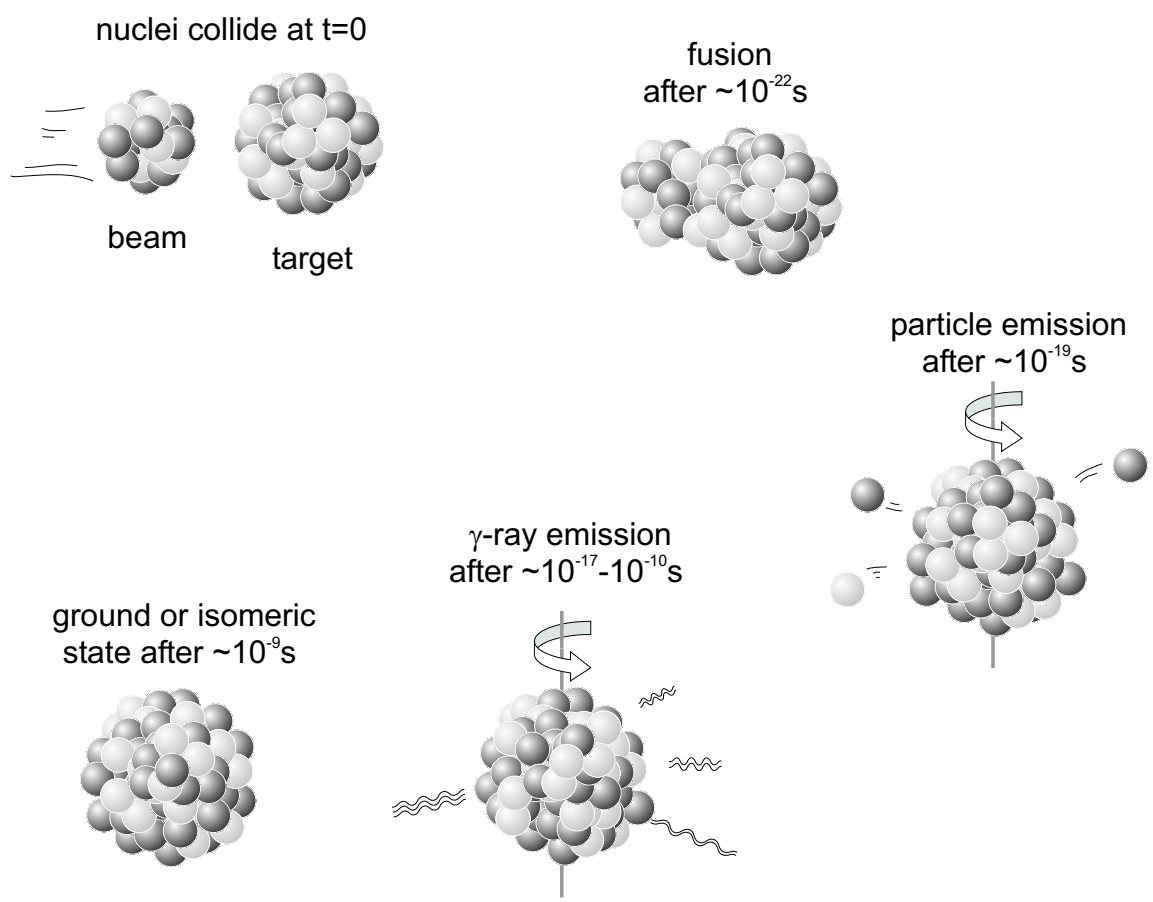

FiG. 3.1: Schematic of fusion-evaporation reaction process

nucleus, the more particles are likely to be evaporated. The final de-excitation stage involves the emission of sequences of $\gamma$-rays until after $\sim 1$ ns the resulting nucleus reaches either its ground state or a metastable isomeric state. As is usually the case, the target and projectile are isotopes of stable nuclei, the resulting compound nucleus will therefore have a relatively low $\mathrm{N} / \mathrm{Z}$ ratio in comparison to stable nuclei. This, coupled to the fact that neutrons are preferentially evaporated because they do not feel the Coulomb barrier means that this reaction is ideal for producing neutron deficient nuclei.

\subsubsection{In-Flight and Isotope Separation On-line}

Of the variety of techniques available for the production of exotic nuclei two main classifications can be made. Isotope Separation on-line (ISOL) and the In-Flight (IF) method. The nuclei detailed in this work were produced using the ISOL technique however as much of the literature referenced in this work relates to IF experiments, details of both processes will be discussed in the following sections. The main features of IF and ISOL techniques are represented schematically in figure 3.2. The essential difference between the two methods is the presence of an ion source in the scheme of the ISOL method. A typical IF experiment uses 
Isotope Separator On Line

(ISOL)

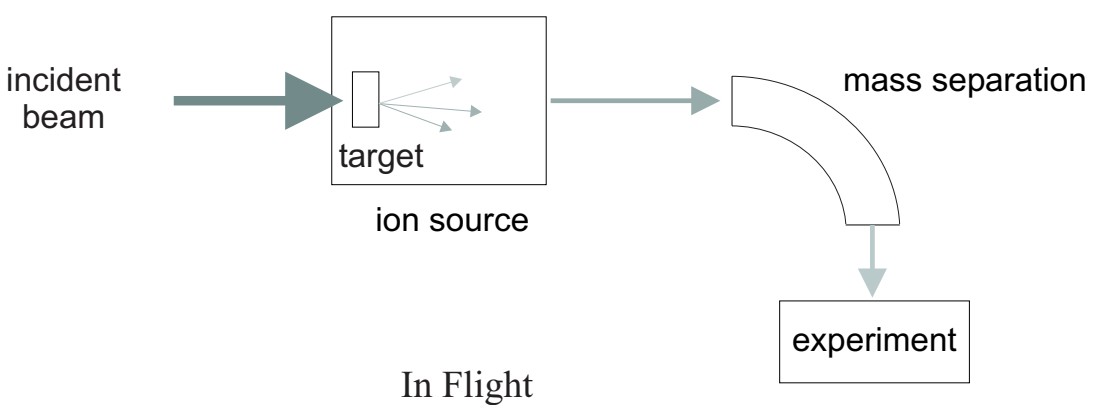

(IF)

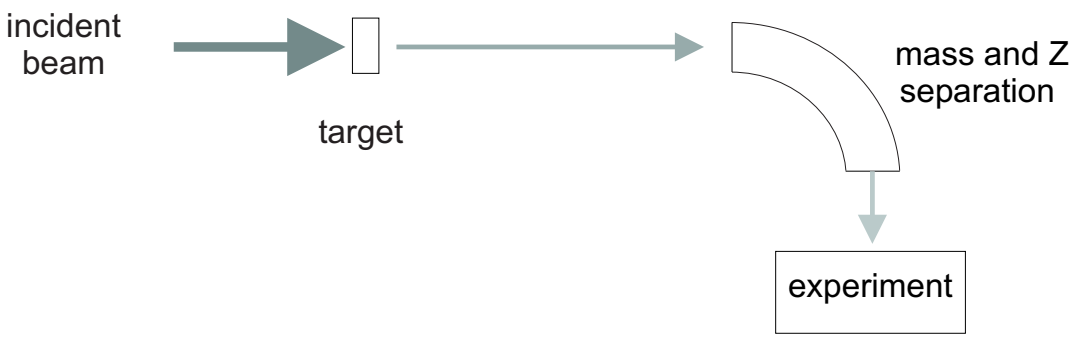

FIG. 3.2: Schematic of LISOL and IF techniques

a high energy beam which hits a target producing, via fusion, fragmentation or fission reactions, a large variety of nuclei. After leaving the target, the resulting beam can be purified by for example, electric and magnetic fields combined in such a way as to produce a velocity filter. A focussing/defocussing combination of magnets can be used for $m / q$ separation and wedge degraders can further separate according to $\mathrm{Z}$.

The same reaction mechanisms are exploited in the ISOL method however, reaction products are thermalised after production inside a target-ion source system. The resulting atoms can then be ionised and passed on to mass separation before collection for study. Alternatively, the resultant beam can be reaccelerated and used as a projectile on a second target further downstream.

The obvious advantage of the IF method is that, without the intervening thermalising step, beam delivery is effectively instantaneous (within micro seconds) whereas for ISOL this can take upwards of tens of milliseconds. The main drawbacks of IF techniques relate to beam quality. Mass and elemental selection as well as energy precision are generally poorer than that achievable using ISOL. 


\subsection{Production of exotic refractory isotopes at LISOL}

The neutron deficient rhodium and ruthenium nuclei were produced in fusion evaporation reactions at the Louvain-la-Neuve cyclotron facility in Belgium and mass separated using the LISOL facility [Van97(a)]. A schematic representation of the setup is shown in figure 3.3.

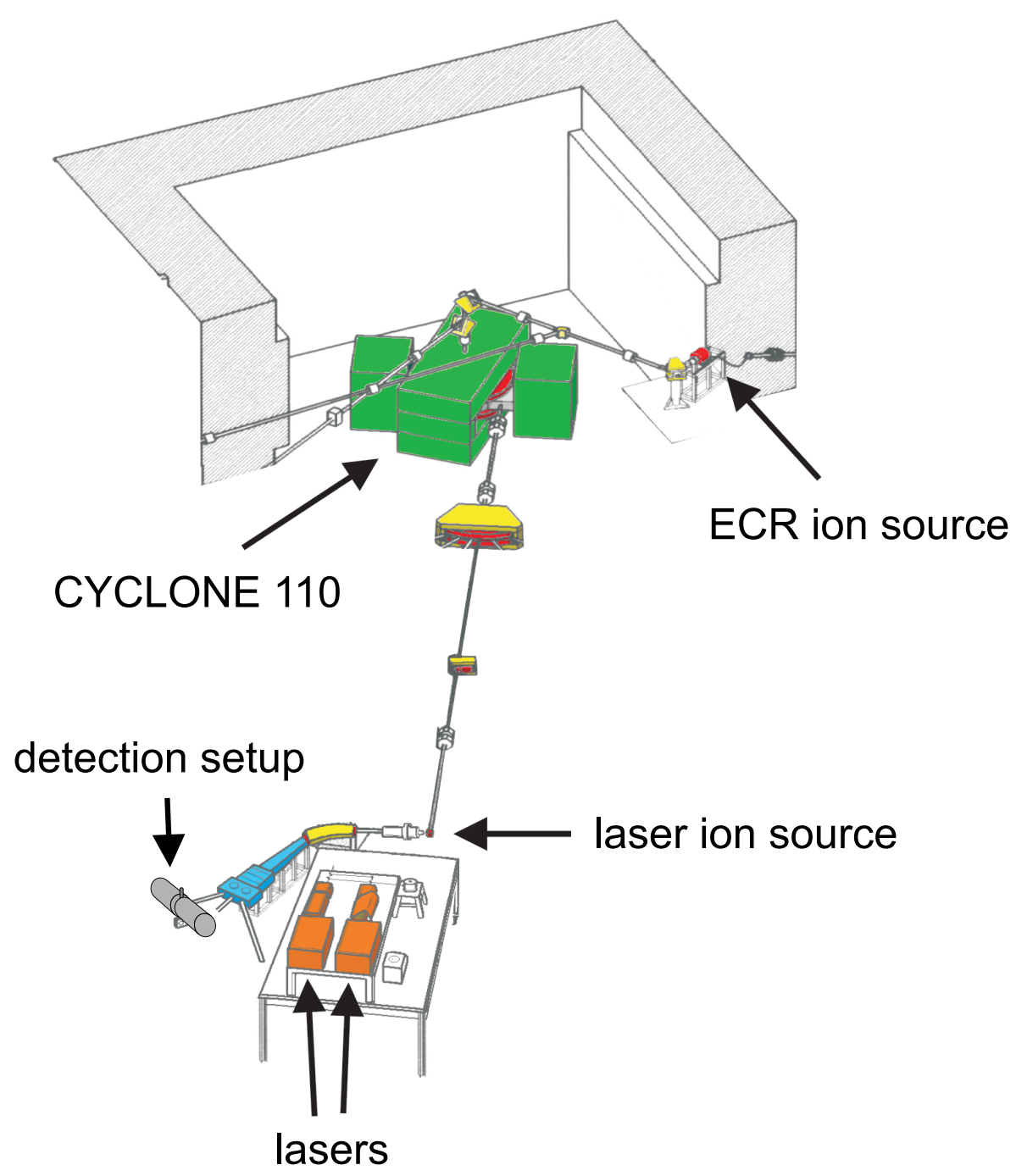

FIG. 3.3: The CYCLONE 110 cyclotron and the LISOL beamline at Louvain-la-Nueve 


\subsubsection{The CYCLONE cyclotron}

Radioactive nuclei were produced using a stable beam of ${ }^{36,40} \mathrm{Ar}$ from the CYCLONE cyclotron. This device which was built in the early seventies is a multiparticle, variable energy, isochronous cyclotron capable of accelerating heavier ions up to an energy of $110 \mathrm{q}^{2} / \mathrm{A} \mathrm{MeV}$ (where $\mathrm{q}$ is the charge and A the mass of the ion).

Atoms of argon gas were ionised inside an electron cyclotron resonance (ECR) ion source. The gas is released into a plasma chamber and any free electrons are confined by magnetic fields. Microwaves are radiated into the chamber to resonantly accelerate the electrons. Ions are not accelerated due to their heavy mass and are confined electrostatically by the space charge of the plasma electrons. The hot electrons collide with the atoms knocking out their electrons thus creating a plasma inside the chamber. Higher charge states are produced by successive collisions and the resulting highly-charged ions can be extracted from the source and injected into the cyclotron for acceleration.

Inside the cyclotron, ions are confined in a circular trajectory by strong magnetic fields and accelerated in the alternating high-tension gap between electrodes. This gap is crossed many thousands of times, successively increasing the energy of the particles and causing them to spiral outwards. As the energy of the ion increases so does its mass and the angular velocity of the ion no longer matches the cyclotron frequency and is slowed down. An isochronous cyclotron with its combination of a radially increasing magnetic field and an azimuthally varying magnetic field compensates for the relativistic mass increase of the accelerated particles. Beams of ${ }^{36(40)} \mathrm{Ar}^{10+(11+)}$ typically of $1-2 \mu \mathrm{A}$ (actual values are included in table 3.2) were released from the cyclotron at energies between 235 and $270 \mathrm{MeV}$. A set of tantalum degraders of varying thicknesses were placed in the beam line to fine tune the beam energy.

\subsubsection{The laser ion source}

The cyclotron beam was focussed on a target of ${ }^{58} \mathrm{Ni}$ foil enriched to $99.93 \%$ and with a thickness of $4.4 \mathrm{mg} / \mathrm{cm}^{2}$. The target was positioned inside a laser ion source [Kud96, Kud01] which is essentially a gas cell filled with purified Ar gas at $~ 500$ mbar. A schematic layout of the ion source is shown in figure 3.4(a) with a photograph of the ion source and its surroundings in figure 3.4(b).

Nuclei recoiling out of the target were stopped and neutralised in a buffer gas before being selectively laser ionised by two dye lasers tuned to the resonant 


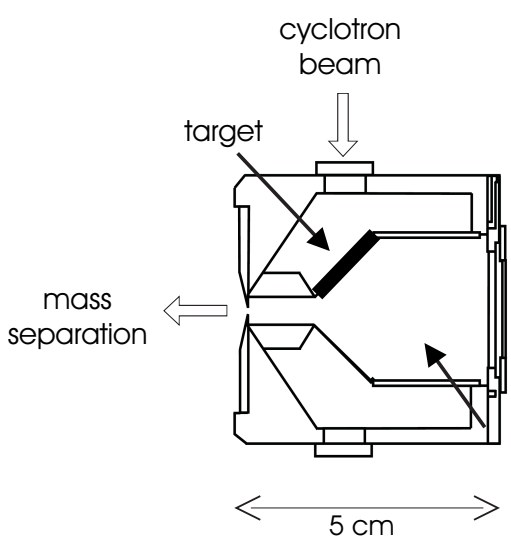

(a)

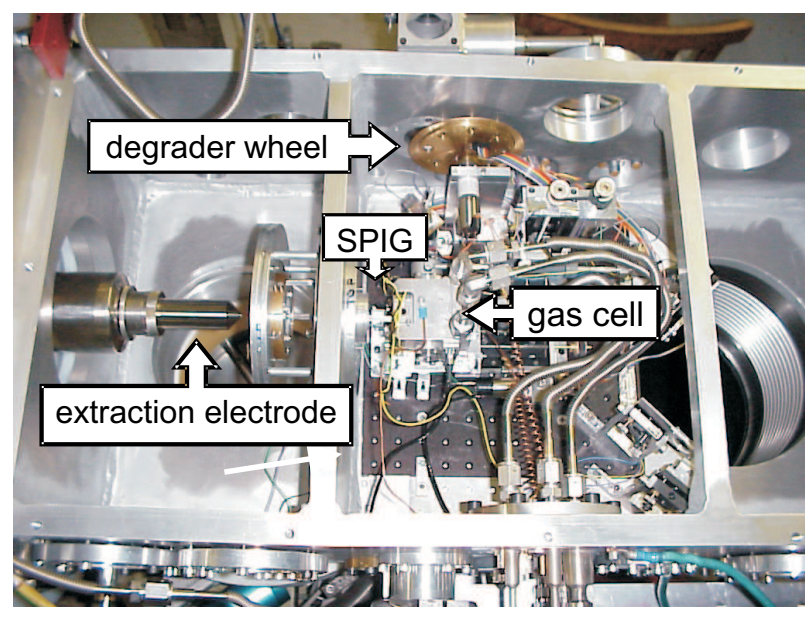

(b)

FIG. 3.4: Schematic of the laser ion source (a) and a photograph of the laser ion source in situ (b).

atomic transitions of the particular element. The laser system involved two excimer (XeCl) lasers (Lambda Physik LPX240i) of wavelength $308 \mathrm{~nm}$ that pump two dye lasers (Lambda Physik Scanmate 2). With a pulse width of 15 ns and a repetition rate of $200 \mathrm{~Hz}$ the lasers ionise atoms by way of a two-step process illustrated in figure 3.5. Atomic electrons are first excited by laser photons to an excited, but still bound, intermediate level. A second laser frequency then excites to states lying above the ionisation limit. Excitation to autoionising states is used, as opposed to any route via the continuum, to exploit their more effective ionisation properties. The laser wavelengths used in this series of measurements

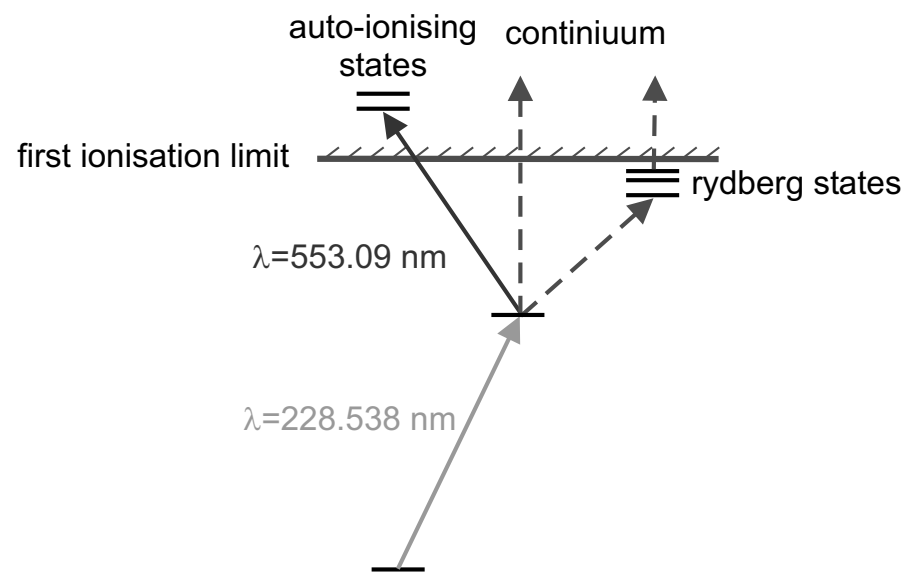

FiG. 3.5: Laser ionisation scheme for ruthenium. 
are included in table 3.1; the particular atomic transitions associated with these energies are however not known.

\begin{tabular}{ccc}
\hline \hline & $\begin{array}{c}\lambda_{\text {first step }} \\
(\mathrm{nm})\end{array}$ & $\begin{array}{c}\lambda_{\text {second step }} \\
(\mathrm{nm})\end{array}$ \\
\hline $\mathrm{Rh}$ & 232.258 & 572.55 \\
$\mathrm{Ru}$ & 228.538 & 553.09 \\
\hline \hline
\end{tabular}

TABLE 3.1: Laser wavelengths used for ionisation of rhodium and ruthenium atoms

\subsubsection{Mass separation and beam delivery}

On exiting the cell, laser ionised nuclei and other surviving ions, are guided towards the LISOL mass separator by a sextupole ion guide (SPIG) [Van97(a)] indicated in figure 3.4(b). The SPIG consists of six stainless steel rods each with a diameter of $1.5 \mathrm{~mm}$ and a length of $124 \mathrm{~mm}$ positioned at the vertices of a hexagon (inner $\varnothing=3 \mathrm{~mm}$ ). An oscillating 4.7 MHz RF voltage applied to the rods, with each rod in antiphase with its neighbour, confines the ion beam within the hexagonal structure. The cyclotron and separator were pulsed in antiphase to counteract the detrimental effects of a high electron density present inside the gas cell when the beam is on [Van00]. From the SPIG, surviving ions are accelerated to mass separation using the extraction electrode at a potential difference of $50 \mathrm{kV}$ and placed as indicated in figure 3.4(b). A conventional mass separation system involving an evacuated beam tube, focussing, steering, and bending magnets and electrostatic lenses is used to isolate a particular beam mass and transport it. The final destination for surviving nuclei was a tape, at the centre of a detection set-up, which was moved periodically to remove the buildup of radioactivity from long-living daughter nuclei.

\subsection{Detection setup for $\beta$-delayed $\gamma$-ray mea- surements}

The detection apparatus [Wei99] as represented in figure 3.6 typically included two high-purity germanium detectors of 90 and $75 \%$ relative efficiency for $\gamma$ ray detection arranged in a compact configuration around $\beta$-sensitive plastic $\Delta \mathrm{E}$ detectors of about $1.3 \mathrm{~mm}$ thickness that enclosed a tape station. Data were 
collected in singles and coincidence modes and are the accumulation of several experimental runs.

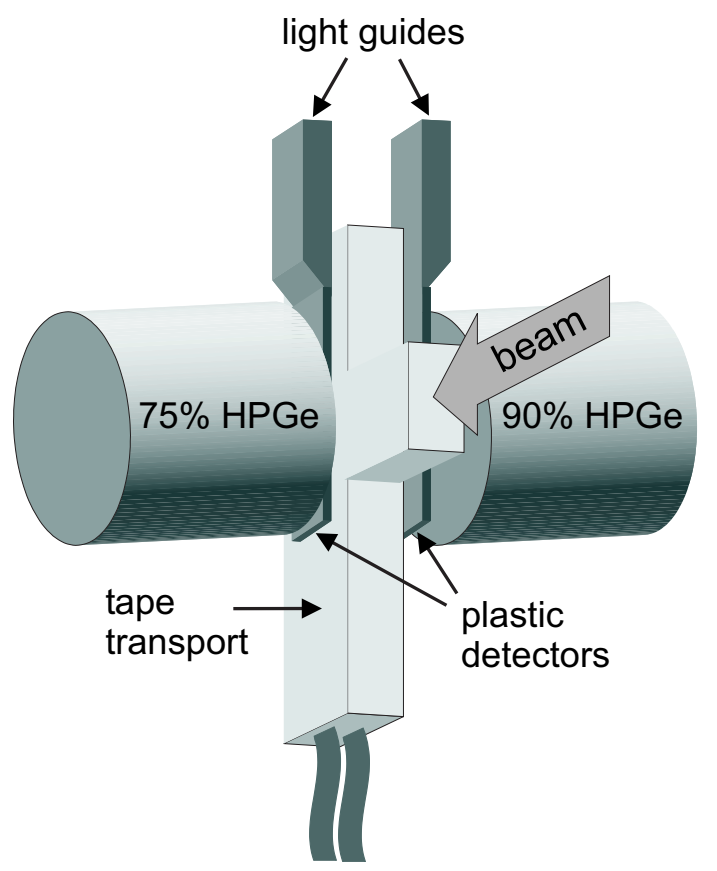

FIG. 3.6: Simplified schematic of the $\beta \gamma \gamma$ detection setup

As mentioned in section 3.2.3, the separator beam was pulsed in microcycles, typically $50 \mathrm{~ms}$ on and $50 \mathrm{~ms}$ off. In addition to this a macrocycle, a beam-on followed by a beam-off, period was used. The situation is represented schematically in figure 3.7. The purpose of this was to follow the growing-in and decay

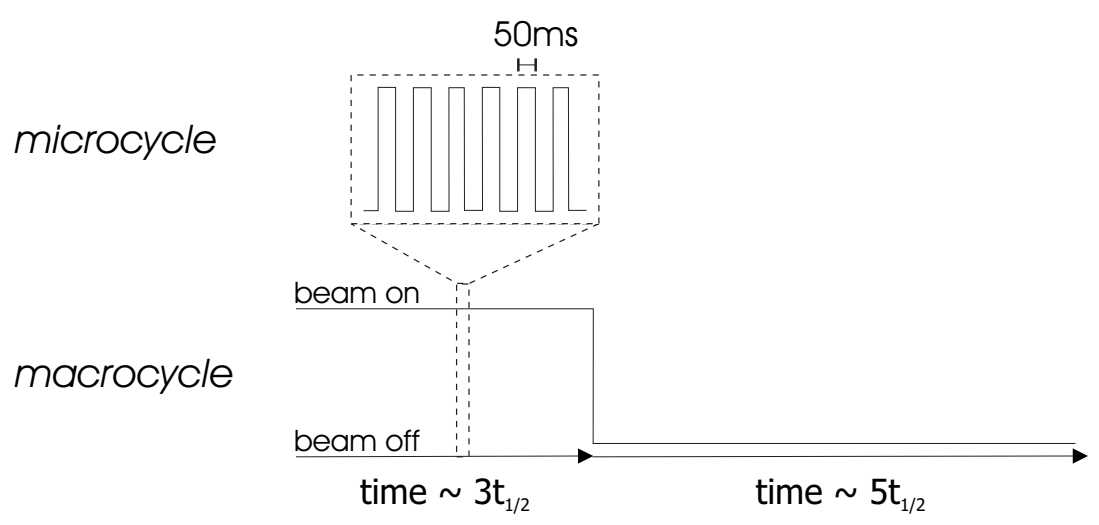

FIG. 3.7: Time structure of implantation of the mass separated beam

of the particular nucleus to determine as accurately as possible the half-life. The on/off times included in table 3.2 were altered to suit the expected half-life of a 
particular isotope. A time-to-digital converter (TDC) was started at the beginning of each macrocycle and recorded the time of each triggered event relative to the start. At the end of each macrocycle, the TDC was reset and this process repeated over the whole measurement period.

Data were collected with the lasers on and, in order to facilitate the identification of resonantly produced $\gamma$ lines, data were also collected without lasers. The acquisition times for the various measurements are included in table 3.2.

Efficiencies for the detection setup were measured using standard $\gamma$ sources. The particle tracking and detector simulation code GEANT [Gea] was also used to calculate efficiencies. The $\beta$-detection efficiency was typically $45 \%$ and for the $1.33 \mathrm{MeV}{ }^{60} \mathrm{Co}$ line the photo-peak efficiency for the Ge-detector system was 4.6\%. Efficiencies for the $511 \mathrm{keV}$ annihilation line as simulated by GEANT are also included in table 3.2. The differences between the efficiencies for the $511 \mathrm{keV}$ line are due to the different $\mathrm{Q}_{E C}$ values and decay schemes of each nucleus. The larger the $\mathrm{Q}_{E C}$ value of a $\beta$-decaying nucleus, the more kinetic energy there is available to the $\beta$ particle and the further it will travel from the implantation point - the optimised detection position - before annihilation. The $511 \mathrm{keV}$

\begin{tabular}{ccccccc}
\hline \hline & $\begin{array}{c}\text { Macro Cycle } \\
\text { on/off(s) }\end{array}$ & \multicolumn{2}{c}{ Lasers On } & \multicolumn{2}{c}{ Lasers Off } & \multirow{2}{*}{$\eta_{511 \text { within decay }}(\mathrm{hrs})$} \\
$\mathrm{I}_{\text {cyc }}(\mu \mathrm{A})$ & $\mathrm{t}_{a c q}(\mathrm{hrs})$ & $\mathrm{I}_{c y c}(\mu \mathrm{A})$ & scheme $(\%)$ \\
\hline${ }^{93} \mathrm{Rh}$ & $30 / 50$ & 20.37 & 1.0 & 2.66 & 0.9 & $6.0(3)$ \\
${ }^{92} \mathrm{Rh}$ & $12 / 20$ & 8.26 & 2.2 & 11.0 & 1.6 & $3.2(2)$ \\
${ }^{91} \mathrm{Rh}$ & $12 / 20$ & 20.9 & 2.0 & 2.87 & 1.6 & $4.6(2)$ \\
${ }^{91} \mathrm{Ru}$ & $12 / 20$ & 3.08 & 2.1 & 2.87 & 1.6 & $5.6(3)$ \\
${ }^{90} \mathrm{Ru}$ & $32 / 32$ & 2.13 & 1.0 & 1.07 & 1.0 & $6.4(3)$ \\
\hline \hline
\end{tabular}

TABLE 3.2: A summary of the experimental parameters and calculated $511 \mathrm{keV}$ annihilation radiation efficiencies $\left(\eta_{511}\right)$ for each of the measured rhodium and ruthenium isotopes. The beam currents $\left(\mathrm{I}_{c y c}\right)$ are those measured in a Faraday cup just outside the cyclotron for a ${ }^{40} \mathrm{Ar}^{11+}$ beam in the case of ${ }^{93} \mathrm{Rh}$ and ${ }^{36} \mathrm{Ar}^{10+}$ for all other nuclei. The number of incident beam ions per second can be calculated from $\frac{I_{c y c}}{e q}$, where $e$ is the electronic charge and $q$ is the charge state of the beam.

efficiency of all nuclei that appeared in $\beta$-gated spectra was calculated within their respective level schemes. The reason for this, as elaborated in section 4.3, is to determine the number of $511 \mathrm{keV}$ events that can eventually be attributed to ground state feeding in the studied nucleus. 


\subsection{Detection setup for $\beta$-delayed proton emis- sion measurements}

Measurements of $\beta$-delayed proton activity in the two lighter ${ }^{89} \mathrm{Ru}$ and ${ }^{90} \mathrm{Rh}$ nuclei were also undertaken. For this set of measurements, the mass separated beam was implanted into thin carbon foils in front of a $\Delta \mathrm{E}-\mathrm{E}$ Si telescope system [Maz02] which was borrowed from GSI and appears in figures 3.8(a) and 3.8(b). The

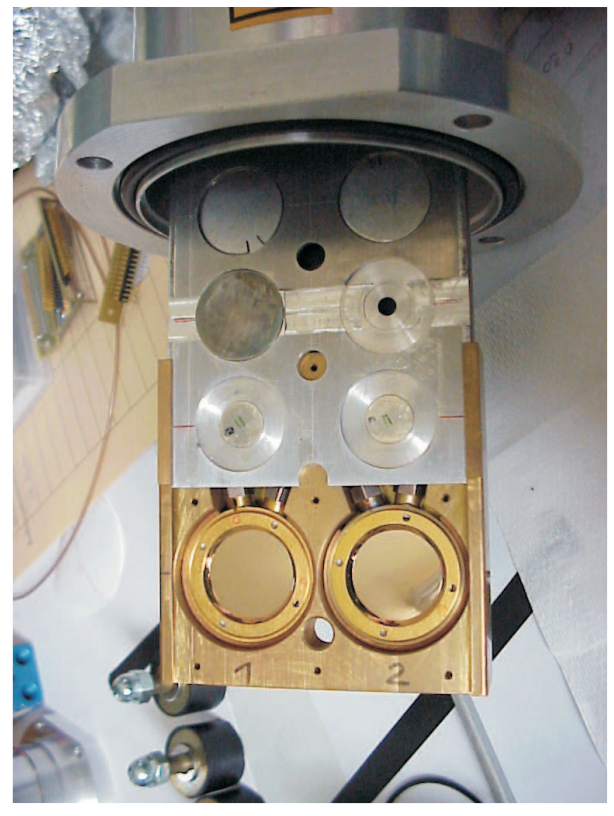

(a)

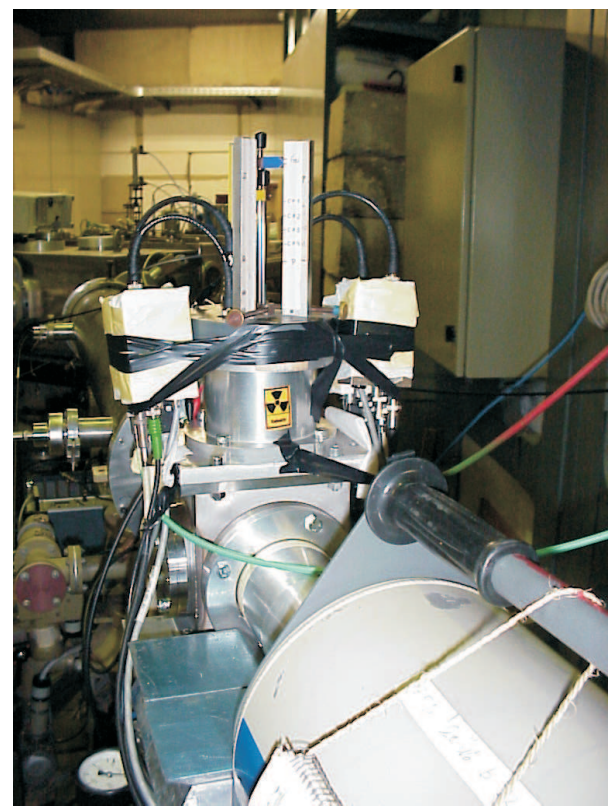

(b)

Fig. 3.8: (a) A photograph of the telescope system used for $\beta$-delayed proton emission measurements and (b) the chamber housing the telescopes attached to the beamline.

thicknesses of the $\Delta \mathrm{E}$ layers were 25 and $30 \mu \mathrm{m}$ and $\mathrm{E}$ layers were $700 \mu \mathrm{m}$. Protons can be readily identified in a plot of energy loss in the $\Delta \mathrm{E}$ section versus the remaining energy deposited in the E detector. The system had a resolution of $\sim 100 \mathrm{keV}$ for the $5486 \mathrm{keV} \alpha$ line in ${ }^{241} \mathrm{Am}$ and an absolute efficiency of $34 \%$. The high efficiency of this detection system as compared with $\gamma$-ray detection together with the increasing probability of such decays as the drip line is approached make this method a powerful tool for extracting nuclear structure information where present production rates preclude $\gamma$-ray spectroscopy. The telescope system was housed inside a vacuum chamber attached to the beamline as shown in figure 3.8(b) with a $75 \%$ relative efficiency HPGe detector placed directly behind. 


\subsection{Signal processing electronics and data ac- quisition}

The experimental data presented in this work is the accumulation of a number of experimental runs. Small changes were made to the electronics scheme between successive measurements however, the general layout remained the same. A typical electronics scheme for the detection setup that appears in figure 3.6 is shown in figure 3.9. The preamplifier signal from the germanium detectors

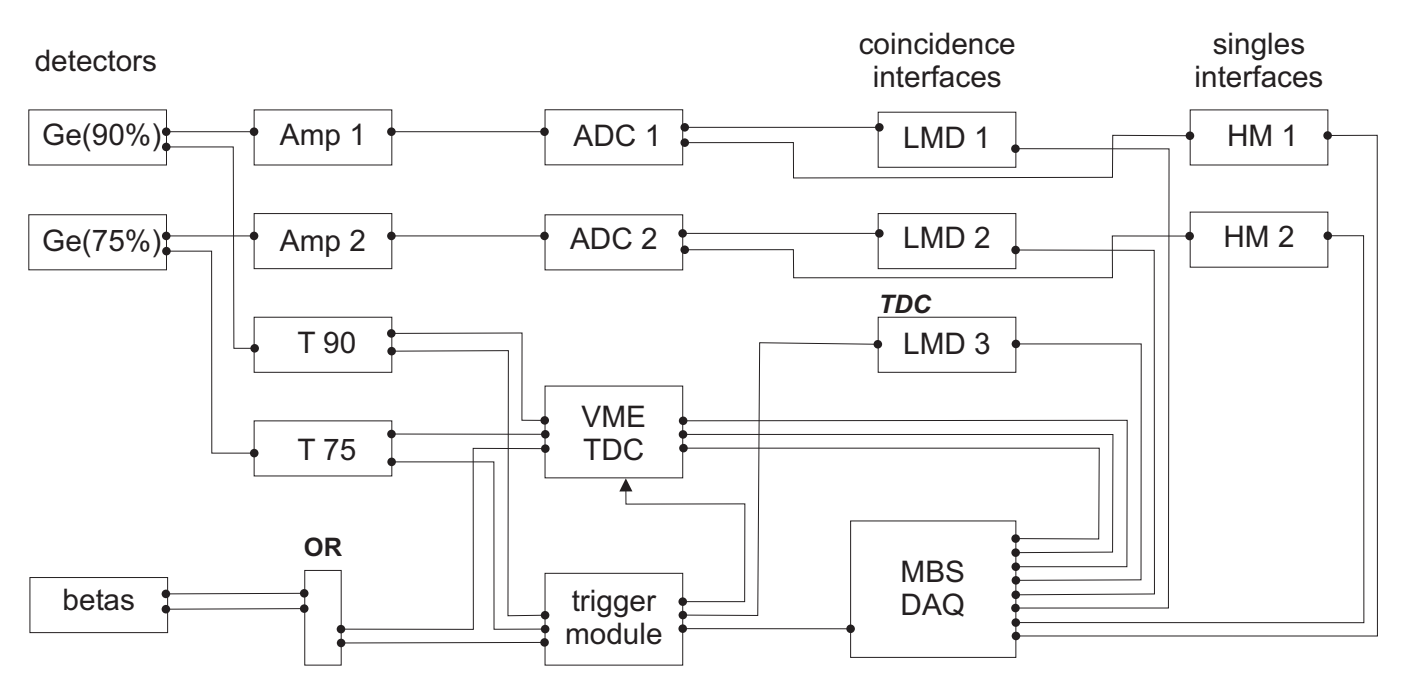

FIG. 3.9: A simplified electronic scheme for $\beta$-delayed $\gamma$ spectroscopy measurements

reflects the timing of charge collection in the detectors and is characterised by a short rise time and a long decay time. Two identical outputs from the preamplifier are needed. The first output goes to a spectroscopy amplifier where the signal is amplified and its shape converted to a more manageable gaussian shape, the energy of the $\gamma$ ray can then be determined from the height of the pulse. The amplified signal is then send to an analogue-to-digital converter (ADC) where it is connected to the interfaces of the data acquisition system. The second preamplifier output is used for timing purposes where the signal is processed as before except that a faster Timing Filter Amplifier (TFA) is used. From the TFA, the signal is then sent to a Constant Fraction Discriminator (CFD) which produces a negative logic signal from the input. The TFA and CFD stages are combined in 'T90' and 'T75' in figure 3.9.

The plastic $\beta$ detectors are used only for counting and timing purposes not energy measurement. The output from these detectors which includes a preamplification stage, can be used as the input for logic modules. The timing signals 
from the two germanium detectors and the logical OR of all $\beta$ detector signals are sent to a trigger module which produces an output when it receives a signal from any two channels that arrive within $1 \mu$ s of each other. One of the outputs from the trigger module was sent to a TDC which as discussed earlier in section 3.3, collects counts as a function of time. Another output was sent to the data acquisition system as a trigger for coincidence or listmode data readout. Data were thus only read out in the event of a $\gamma-\gamma$ or $\beta-\gamma$ coincidence. A second timing signal from each detector was sent to a VME TDC. This module records the arrival time of each event relative to the start signal from the trigger module and is used to create plots of coincidence events as a function of the time difference between them for any combination of two inputs.

As figure 3.9 shows, there are two outputs from the Ge $\gamma$-ray energy ADCs, the second output was used to collect data in singles mode where recorded events were uncorrelated with events in any other detector. Time information is absent in singles data however, time behaviour can still be observed with multiscaling which is done using the histogramming memory modules (indicated 'HM' in figure 3.9). With multiscaling, the total macrocycle is chopped into 16 time slices with each slice filling a different spectrum.

For the electronics setup used for the $\beta$-delayed proton emission measurements all Si detectors were readout in singles and coincidence modes while the Ge $\gamma$ detector was readout only in singles.

\subsection{Production rates}

The measurement of isotopic production rates allows for comparisons between different experimental methods to be made. The performance of the laser ion source can also be tested as well as the reliability of cross section calculation codes.

\subsubsection{Predicted production rates}

Isotope production $(\mathrm{P})$ expressed in units of nuclei produced per electrical micro Coulomb of beam is calculated according to;

$$
P=\frac{n \sigma}{q e} 10^{-6}
$$

where $\mathrm{q}$ is the charge state of the beam, e is the electronic charge and $\sigma$ is the interaction cross section. $\mathrm{n}$ is the number of particles in the target per unit area 
seen by the beam and is given by;

$$
n=\frac{N_{A}}{A} \rho x
$$

$\mathrm{N}_{A}$ is Avogadro's number and $\rho, \mathrm{A}$ and $\mathrm{x}$ are the density, mass number and thickness of the target. The cross section which gives reaction probability in terms of area is the critical parameter in the production rate calculation since all other parameters are easily measured. Cross sections were calculated using the statistical fusion-evaporation code HIVAP [Rei81] and are shown in figure 3.10.

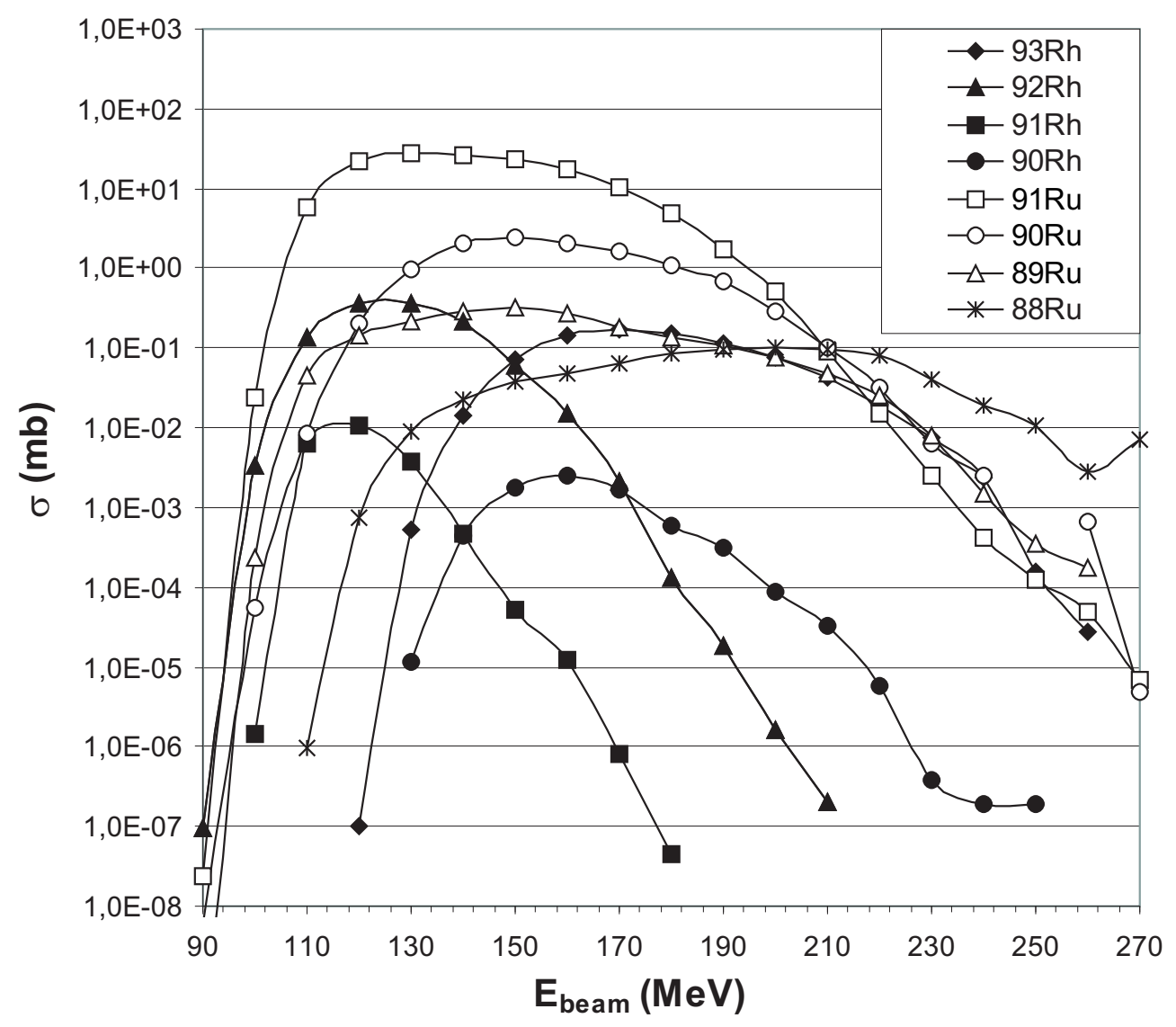

FIG. 3.10: Cross section calculation for the measured isotopes using the fusionevaporation code HIVAP [Rei81]. Values were calculated for the ${ }^{40} \mathrm{Ar}+{ }^{58} \mathrm{Ni}$ reaction for production of ${ }^{93} \mathrm{Rh}$ and ${ }^{36} \mathrm{Ar}+{ }^{58} \mathrm{Ni}$ for all other nuclei.

Only the energy of the beam as it leaves the cyclotron is known, the final beam energy in front of the target has to be calculated and this was done using the ion transport code SRIM [Sri]. Successful attempts were later made to measure the beam energy close to the target [Fac04a] using a silicon PIPs detector. This had not however been fully implemented when the data for the present work were taken. 


\section{SRIM calculations}

Figure 3.4 shows some of the obstacles lying in the path of the beam as it travels towards the target. The ion source is housed inside a box which the beam enters via a Havar window. A set of Ta degraders of varying thickness are placed just inside the box and mounted on a wheel which can be turned to fine tune the beam energy. The ion source itself also has a thin Mo window and several millimeters of buffer gas which need to be negotiated before the beam reaches the target. The code SRIM [Sri] was used to calculate the energy lost in each of these obstacles to get the final beam energy on the target. Table 3.3 includes the results.

\subsubsection{Calculated predicted production rates}

The ${ }^{58} \mathrm{Ni}$ target of $4.4 \mathrm{mg} / \mathrm{cm}^{2}$ was oriented at $45^{0}$ to the beam direction resulting in an effective target thickness of $4.95 \mu \mathrm{m}$. At the energies given in table 3.3, the argon beam loses around $10 \mathrm{MeV} / \mu \mathrm{m}$ in the target and can thus decrease by $50 \mathrm{MeV}$ as it travels the full thickness of the target. The cross sections are very sensitive to the incident beam energy. Figure 3.10 shows that these can easily vary by two orders of magnitude within a $50 \mathrm{MeV}$ range around the maximum cross section. To account for the variation in cross section, the target was divided into 30 sections each with a thickness of $0.165 \mu \mathrm{m}$ and the yield in each section was calculated using the cross section value in the centre of the section extrapolated from a straight line fit to the two nearest data points. The final calculated productions are included in table 3.3.

\begin{tabular}{ccccc}
\hline \hline Reaction & $\begin{array}{c}\text { Predicted production } \\
(\mathrm{at} / \mu \mathrm{C})\end{array}$ & $\begin{array}{c}\mathrm{E}_{c y c} \\
(\mathrm{MeV})\end{array}$ & $\begin{array}{c}\mathrm{E}_{\text {tar }} \\
(\mathrm{MeV})\end{array}$ \\
\hline${ }^{93} \mathrm{Rh}$ & ${ }^{58} \mathrm{Ni}\left({ }^{40} \mathrm{Ar}^{11+}, 1 \mathrm{p} 4 \mathrm{n}\right)$ & $1.58 \times 10^{3}$ & 250 & 171 \\
${ }^{92} \mathrm{Rh}$ & ${ }^{58} \mathrm{Ni}\left({ }^{36} \mathrm{Ar}^{10+}, 1 \mathrm{p} 1 \mathrm{n}\right)$ & $5.38 \times 10^{3}$ & 235 & 135 \\
${ }^{91} \mathrm{Rh}$ & ${ }^{58} \mathrm{Ni}\left({ }^{36} \mathrm{Ar}^{10+}, 1 \mathrm{p} 2 \mathrm{n}\right)$ & $1.08 \times 10^{2}$ & 235 & 158 \\
${ }^{90} \mathrm{Rh}$ & ${ }^{58} \mathrm{Ni}\left({ }^{36} \mathrm{Ar}^{10+}, 1 \mathrm{p} 3 \mathrm{n}\right)$ & $3.72 \times 10^{1}$ & 270 & 188 \\
${ }^{91} \mathrm{Ru}$ & ${ }^{58} \mathrm{Ni}\left({ }^{36} \mathrm{Ar}^{10+}, 2 \mathrm{p} 1 \mathrm{n}\right)$ & $5.70 \times 10^{5}$ & 235 & 158 \\
${ }^{90} \mathrm{Ru}$ & ${ }^{58} \mathrm{Ni}\left({ }^{36} \mathrm{Ar}^{10+}, 2 \mathrm{p} 2 \mathrm{n}\right)$ & $5.18 \times 10^{4}$ & 255 & 180 \\
${ }^{89} \mathrm{Ru}$ & ${ }^{58} \mathrm{Ni}\left({ }^{36} \mathrm{Ar}^{10+}, 2 \mathrm{p} 3 \mathrm{n}\right)$ & $7.07 \times 10^{3}$ & 270 & 188 \\
\hline \hline
\end{tabular}

TABLE 3.3: Expected production values for each of the measured isotopes using cross sections from HIVAP for the exit channels given. $\mathrm{E}_{c y c}$ and $\mathrm{E}_{t a r}$ are the initial energy of the cyclotron beam and the final optimised beam energy in front of the target for each of the measured nuclei calculated using SRIM. 


\subsubsection{Measured production rates}

Production rates of individual nuclei using resonant laser ionisation are determined according to;

$$
P=\frac{c_{d} c_{c} A}{t_{c y c} \eta_{\beta} \eta_{\gamma} I_{c y c} t_{a c q}} \quad \text { where } \mathrm{A} \text { is the number of counts in the photopeak }
$$

\begin{tabular}{c|c|c}
\hline \hline & $\begin{array}{c}\text { Yield from mass sep. } \\
(\text { at } / \mu \mathrm{C})\end{array}$ & Selectivity \\
\hline${ }^{93} \mathrm{Rh}$ & $31(7)$ & $>70$ \\
${ }^{92} \mathrm{Rh}$ & $21(4)$ & $>310$ \\
${ }^{91} \mathrm{Rh}$ & $24(4)$ & $>26$ \\
${ }^{91} \mathrm{Ru}$ & $441(59)$ & $15(3)$ \\
${ }^{90} \mathrm{Ru}$ & $16(4)$ & $2.6(8)$ \\
\hline \hline
\end{tabular}

TABle 3.4: Performance of the ion source and selectivity values for each of the measured nuclei. Production rates can be expressed alternatively in particles per second by multiplying the yield by the cyclotron current $\left(\mathrm{I}_{c y c}\right)$ which are given in table 3.2 .

The production values included in table 3.4 are in units of at $/ \mu \mathrm{C}$ which is the number of nuclei implanted on the tape per electrical micro Coulomb of cyclotron beam. Account is taken of beam transport losses in the primary cyclotron beam $\left(\mathrm{t}_{c y c}\right)$. Corrections to the beam dose are made so as to include only the time when the beam was actually on $\left(c_{d}\right)$; i.e. half of the growing-in period (see figure 3.7). Not all nuclei implanted on the tape will necessarily decay within the measurement time but are included in the production rate nevertheless. This cycle correction $\left(\mathrm{c}_{c}\right)$ is defined as the ratio of the number of nuclei that are implanted on the tape to the number that decay in front of the detectors. The half-life of the nucleus must be determined before this correction can be calculated. Values for the cyclotron current $\left(\mathrm{I}_{c y c}\right)$ which is the dc current reading in a faraday cup outside the cyclotron and acquisition times $\left(\mathrm{t}_{a c q}\right)$ are listed in table 3.2. The final corrections $\left(\eta_{\beta}\right.$ and $\left.\eta_{\gamma}\right)$ are for $\beta$ and $\gamma$-detection efficiencies which were calculated within the decay scheme.

The efficiency of the ion-source was measured to be around $2 \%$ and $0.2 \%$ for ${ }^{95} \mathrm{Rh}$ and ${ }^{94} \mathrm{Ru}$ respectively [Fac04a, Fac04b] at the rather high cyclotron beam currents that were used for this set of measurements. This was done by placing a target, with a stopper foil directly behind it, in front of the argon beam. After a set period of implantation, the target and stopper were removed 
and placed separately in front of efficiency calibrated HPGe detectors. In this way, absolute isotope productions inside the ion source were determined. The nature of the technique however, meant that ion source efficiencies for the shorter living isotopes such as those studied in this work could not be determined. The discrepancy between the ion source efficiencies for rhodium and ruthenium may be attributable to the quality of the ionisation procedure for each element. Only for rhodium was a filament available inside the gas cell beforehand to produce stable rhodium atoms allowing for fine tuning the ionisation procedure. Certainly this explanation is borne out by values for selectivity which is the ratio of isotope production with and without lasers and which are given in table 3.4.

The values for the efficiency of the ion source, given in the preceding paragraph, were used to derive cross sections for each isotope to compare directly with HIVAP calculations. This is shown in figure 3.11. Because production cross

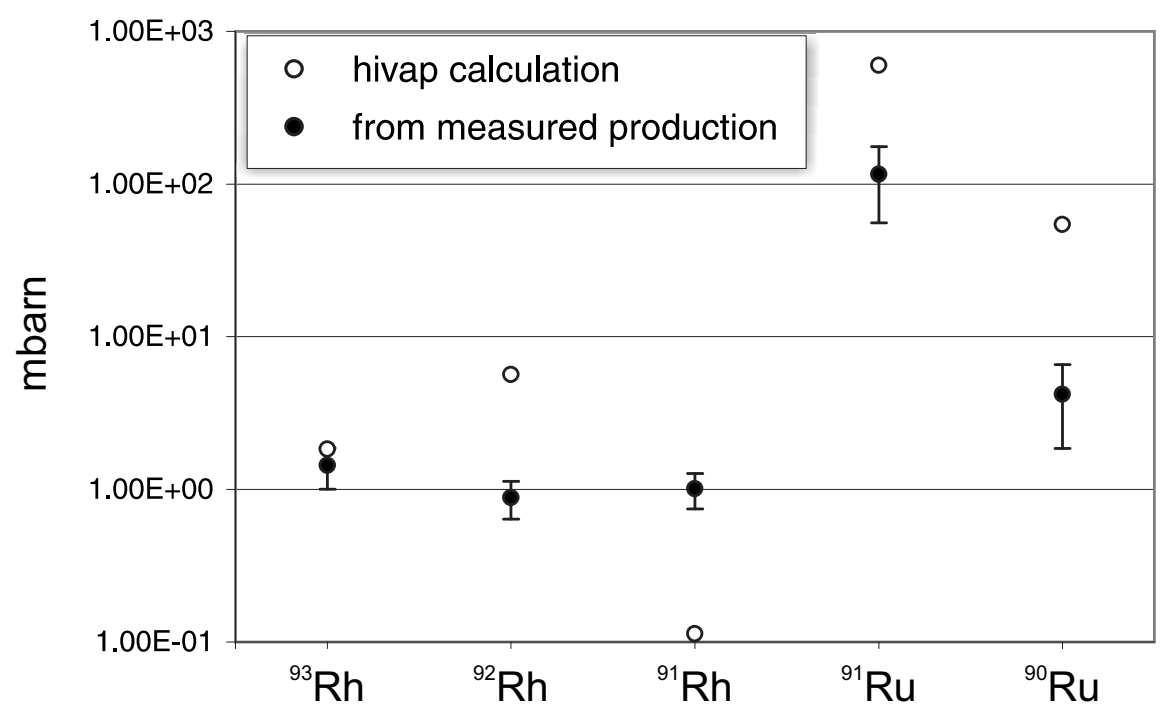

FIG. 3.11: A comparison between the experimental total effective cross section, as extracted from the measured production rate, and the predicted value from HIVAP for each of the measured nuclei. See text for details.

sections vary with energy (recall figure 3.10) isotope production will vary through the target as the incident beam loses energy. The cross sections which are derived using equation (3.1) and the measured production rates will therefore represent a total effective cross section. Predicted cross sections from HIVAP were summed across the beam energy ranges through the target, given in table 3.3, in order to compare with the measured values. The results which are plotted in figure 3.11 show that although general trends in production are reproduced, actual values differ significantly. 


\section{Chapter 4}

\section{Data reduction and analysis}

In this chapter, the procedures involved in extracting nuclear physics information from the accumulated spectroscopy data is described.

\subsection{Assignment of $\gamma$ rays}

Data were collected in macrocycles, as was mentioned in sec. 3.3, and also with and without lasers. A comparison of data taken with and without lasers was used in the first instance to identify $\gamma$ lines which may be attributable to the decay of resonantly produced nuclei or their subsequent daughter decay. Gamma lines only present when lasers are used are expected to result from elemental selective photoionisation in the gas cell. Gamma events promptly following $\beta$ decay were identified in $\beta$-gated spectra. The low production cross sections of the exotic isotopes studied in this work mean that some $\gamma$ decays observed in $\beta$-gated spectra, particularly those from weakly fed $\beta$ branches, can be obscured in singles spectra by the large amount of room background. This was the case for several of the $\gamma$ lines resulting from the decay of ${ }^{93} \mathrm{Rh}$. The experimental setup is therefore less sensitive to the detection of isomeric decay than to correlated decays of a similar intensity. Having identified the activities that appear to be resonantly produced, individual $\gamma$ lines were then firmly associated with the decay of a particular isotope by virtue of their half-life behaviour and, wherever possible $\gamma-\gamma$ coincidences. 


\subsection{Half-life determination}

Every event recorded in coincidence data has a time value associated with it which corresponds to the length of time between the start of the macrocycle and the arrival of the event. The TDC, which measures this time interval, allows plots of counts as a function of their arrival time to be made. To measure the half-life of a particular $\gamma$ line, the time behaviour of the area of the line should be traced. The most reliable way to do this is by slicing up the TDC spectrum into smaller time intervals, projecting these time bins onto the Ge $\gamma$ energy spectra and recording the peak areas as they passed through the growing-in and decay stages of each macrocycle. For smaller peaks it is often not possible to use this method. In these cases, gates can be put around the lines in the Ge $\gamma$-ray energy spectra and projected back onto the TDC spectrum.

The time behaviour of the $\gamma$ lines was then fitted using the function minimisation and error analysis program MINUIT [Min]. The function to be fitted included the underlying microcycle structure and was fitted over the whole macrocycle. For most of the $\gamma$ lines, a one half-life function sufficed however for the $511 \mathrm{keV}$ annihilation line, which included contributions from all $\beta$-decaying isobars, it was often necessary to use up to six half-life components.

\subsection{Level schemes and branching ratios}

Having identified the $\gamma$ lines associated with the nucleus of interest, a decay scheme may then be constructed. Depending on the intensities of particular $\gamma$ lines, an examination of $\gamma-\gamma$ matrices, such as that shown in figure 4.1 , can reveal coincidences between the $\gamma$ events in different detectors. In this way and, in conjunction with in-beam and decay data where available, the decay schemes for each nucleus were assembled. As was mentioned in section 3.3, GEANT was used to calculate $\gamma$ and $\beta$ efficiencies. It was also used to distinguish between sum peaks and cross-over transitions ${ }^{1}$. In order to do this it was first necessary to establish the decay scheme then, every combination of prompt gamma rays that this scheme allowed was inserted, together with the relevant $\mathrm{Q}_{E C}$ value, into GEANT to determine absolute efficiencies for particular gamma-ray energies. Uncorrelated $\gamma$ events were placed as levels fed directly from $\beta$ decay of the mother.

\footnotetext{
${ }^{1} c f$ treatment in ref. [Van02]
} 


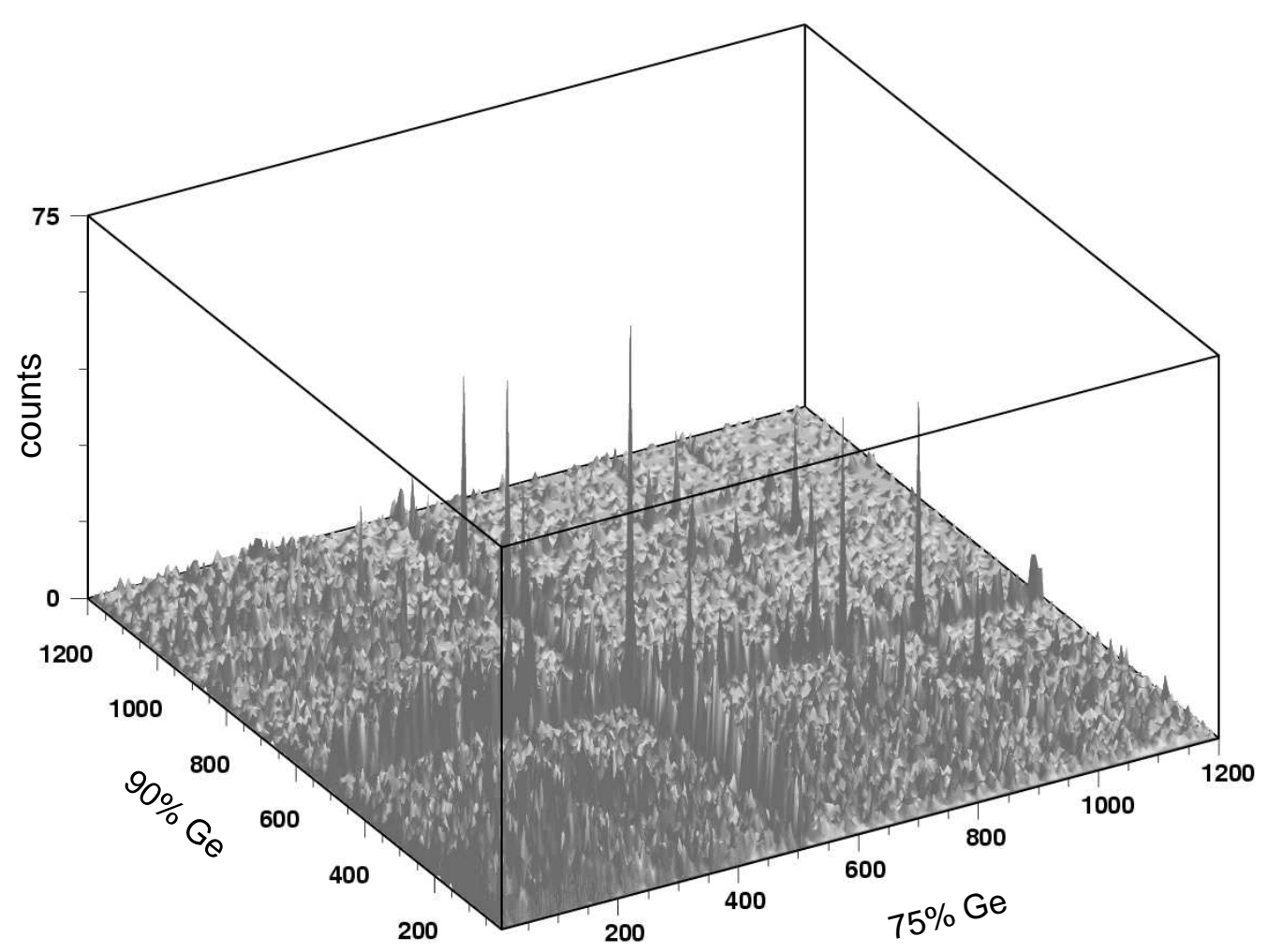

FIG. 4.1: A 2-dimensional $\gamma-\gamma$ matrix from the data of ${ }^{92} \mathrm{Rh}$. Note the relative strength of the 511-511 coincidence peak.

Beta decay feeding the ground state of the daughter nucleus was calculated using the $511 \mathrm{keV}$ line. Counts in this line are due to the annihilation of a $\beta^{+}$ particle with an electron to produce two back-to-back $511 \mathrm{keV}$ photons. The number of counts in the $511 \mathrm{keV}$ line due to daughter and/or granddaughter decay was first subtracted. This contribution was calculated from the peak areas in the $\gamma$ spectra and the $\gamma$-ray efficiencies determined by GEANT calculations which included the complete level schemes. Similarly, the counts in the $511 \mathrm{keV}$ due to $\beta$ decay of the mother nucleus via excited states in the daughter were also calculated and subtracted. The remaining $511 \mathrm{keV}$ counts were attributed to $\beta$-decay feeding to the ground state of the daughter.

This 'tried and tested' technique is not without its hazards; the large amount of energy available to $\beta$ decay for nuclei in this region suggests a significant possibility of feeding to highly excited states which subsequently decay to the observed lower lying levels. Values for $\beta$ branching to the ground state of the daughter are particularly vulnerable to this problem. Beta decay in this region to excited states in the daughter is often highly fragmented which can lead to weakly populated states and branching to states producing $\gamma$ rays outside the 
$\sim 4 \mathrm{MeV}$ energy range of the $\gamma$-detection setup. The $511 \mathrm{keV}$ counts resulting from these undetected $\gamma$ events can then be wrongly attributed to ground state decay. A further consequence may be that apparently forbidden $\beta$ decays, e.g. the $13 / 2^{+}$state populated in ${ }^{91,93} \mathrm{Rh}$ decay, may result from $\gamma$ transitions from higher lying levels fed by allowed $\beta$ transitions. Log $f t$ values were calculated using $\mathrm{Q}_{E C}$ values from mass excesses taken from ref. [Aud95] and in view of the comments above, it ought to be pointed out that these values should be regarded as lower limits. 


\section{Chapter 5}

\section{Results}

The final conclusions of the data reduction and analysis techniques detailed in the previous chapter are presented in this chapter. A summary of the available experimental information on each of the measured isotopes prior to this work is also presented.

\subsection{Results of beta decay measurements}

\subsection{1 ${ }^{93} \mathrm{Rh}$}

Excited states in ${ }^{93} \mathrm{Rh}$ were first observed in an in-beam measurement [Rot95] and later in the $\beta$ decay of ${ }^{93} \mathrm{Pd}[\mathrm{Sch} 00(\mathrm{a})]$. In-beam measurements were also used to explore excited states in the daughter nucleus ${ }^{93} \mathrm{Ru}$ described for the first time in ref. [Nil73] using the ${ }^{92} \mathrm{Mo}(\alpha, 3 \mathrm{n}){ }^{93} \mathrm{Ru}$ reaction and later with a ${ }^{58} \mathrm{Ni}\left({ }^{40} \mathrm{Ca}, 4 \mathrm{pn}\right){ }^{93} \mathrm{Ru}$ reaction [Arn94]. In common with most of its odd-A neighbours in the region, the ground state of ${ }^{93} \mathrm{Ru}$ is expected to be $9 / 2^{+}$with a low lying isomeric $1 / 2^{-}$state.

The ${ }^{58} \mathrm{Ni}\left({ }^{40} \mathrm{Ar}, \mathrm{p} 4 \mathrm{n}\right)$ reaction was used in this study to produce ${ }^{93} \mathrm{Rh}$ nuclei and explore for the first time the lower spin states in ${ }^{93} \mathrm{Ru}$ accessed through $\beta$ decay. A beam energy of $171 \mathrm{MeV}$ in front of the target coincided with the maximum calculated cross section from HIVAP of $169 \mu \mathrm{b}$ for this particular reaction channel. Macrocycle times for ${ }^{93} \mathrm{Rh}$ were $30 / 50 \mathrm{~s}$ beam ON/OFF. Figure 5.1 shows the $\beta$-gated spectra at mass 93 accumulated during three separate measurements.

A line corresponding to the one seen in figure 5.1 at $1393 \mathrm{keV}$ was identified in ref. [Nil73] as belonging to a $\left(13 / 2^{+}\right)$to ground state transition. This result is compatible with the most recent in-beam measurement [Arn94] using 

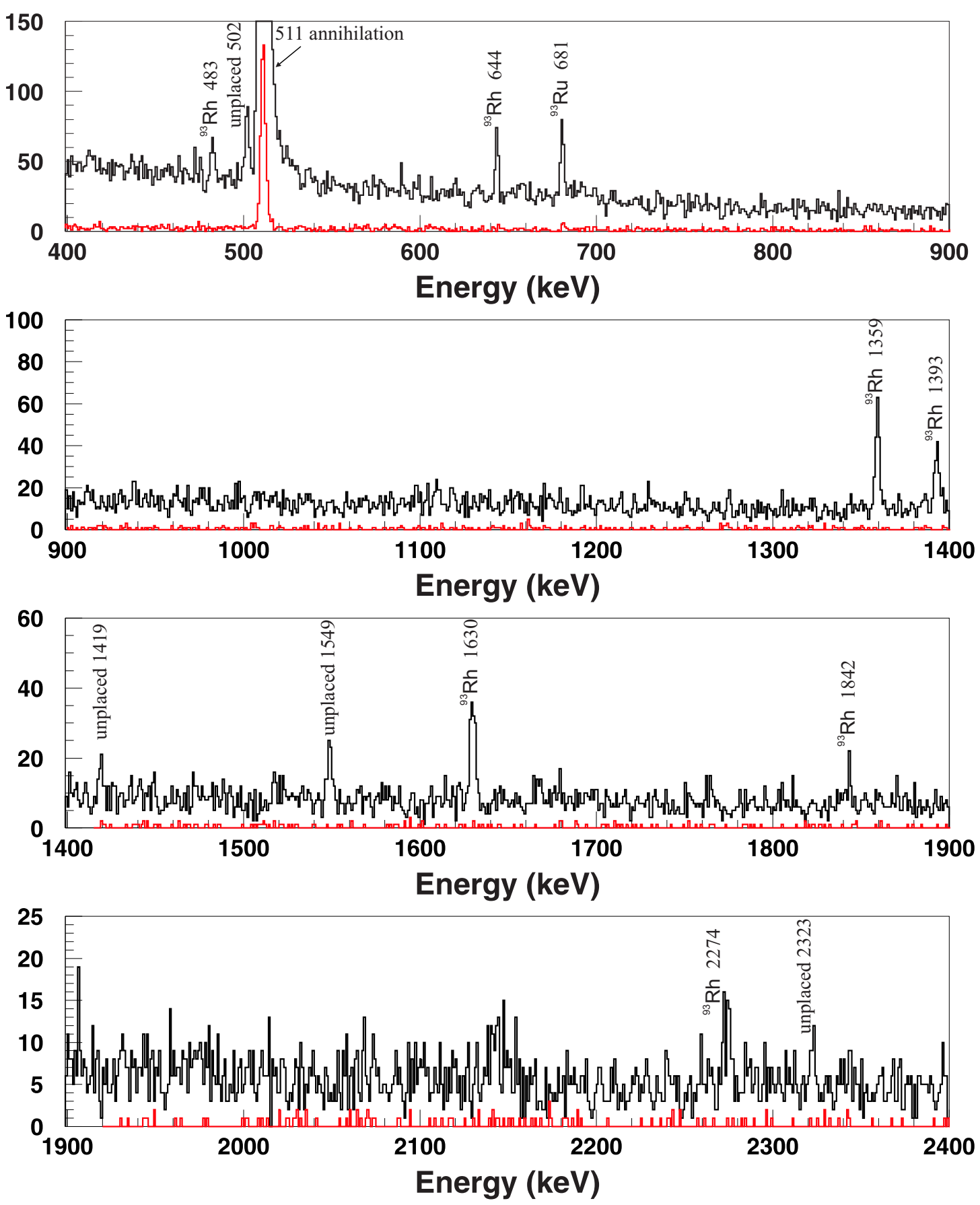

FiG. 5.1: Mass $93 \beta$ gated spectra with the lasers tuned to rhodium (black lines) and without lasers (gray lines). $\gamma$ lines labelled 'unplaced' are not included in the decay scheme in figure 5.3 and are indicated here for reference purposes (see text for details). Energies labels are given in keV. 
the ${ }^{58} \mathrm{Ni}\left({ }^{40} \mathrm{Ca}, 4 \mathrm{pn}\right){ }^{93} \mathrm{Ru}$ reaction.

In addition to the $1393 \mathrm{keV}$ line observed in in-beam studies, six additional $\gamma$ lines could be unambiguously assigned to ${ }^{93} \mathrm{Rh}$ decay and are indicated in figure 5.1. The four lines labelled 'unplaced' in figure 5.1 appear to be laser ionised but, $\gamma$ spectra gated the these lines fail to show any coincident $\gamma$ events. This is in comparison to the spectra shown in figure 5.2 where $\gamma$ lines of comparable intensity are clearly shown to be in coincidence. In view of this and the low
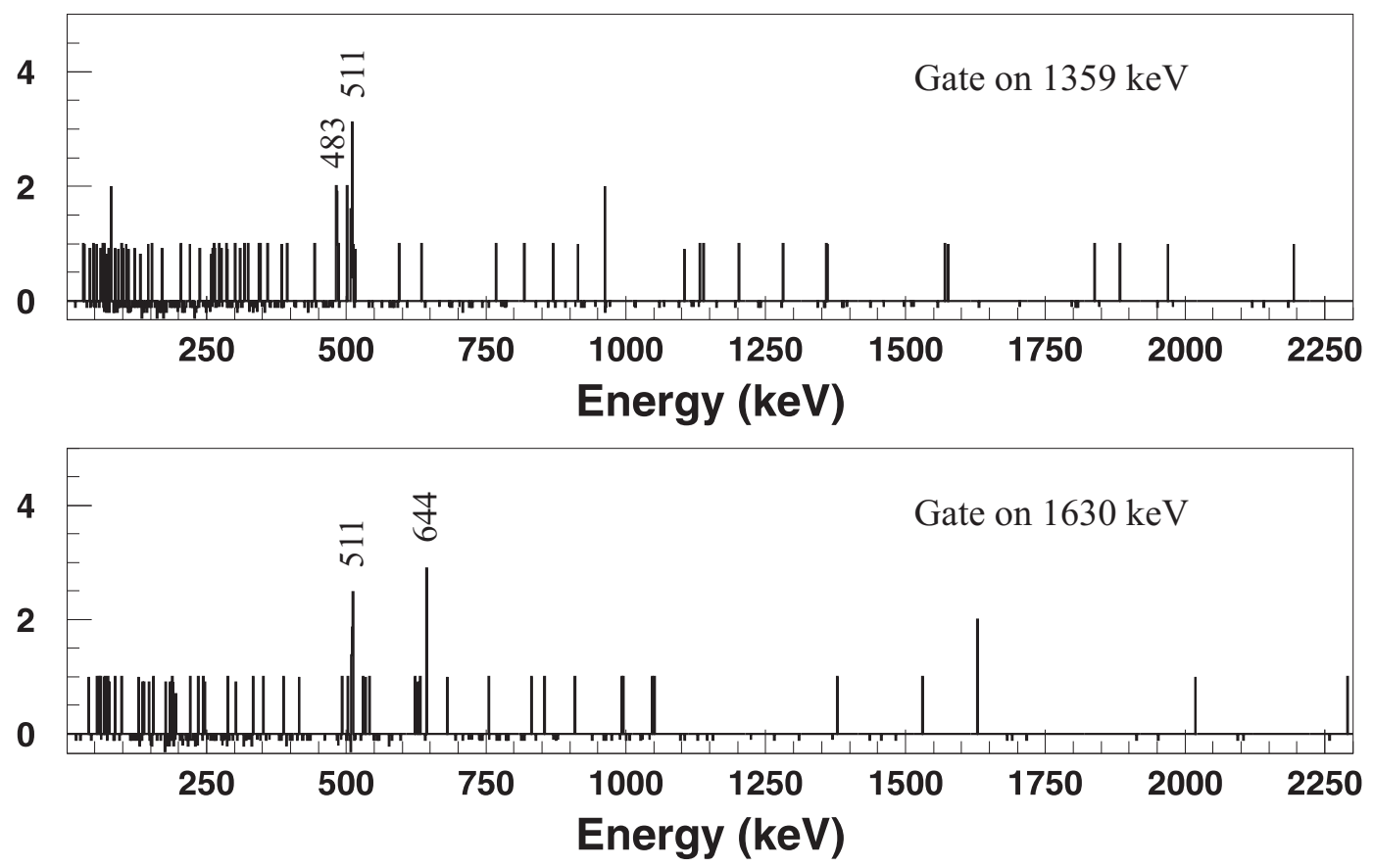

FIG. 5.2: Mass 93 Background subtracted coincidence spectra with gates on the 1359 and $1630 \mathrm{keV} \gamma$ lines.

statistics of these lines which make a half-life determination unreliable, it was considered unsafe to include these lines in the decay scheme of ${ }^{93} \mathrm{Rh}$. The energies and peak areas of these unplaced lines are however included in table 5.1 for reference along with the seven other $\gamma$ lines that were placed in the level scheme. Figure 5.3 shows the decay scheme resulting from the analysis of $\gamma-\gamma$ coincidence spectra. Beta branching $\left(\mathrm{I}_{\beta}\right)$ was determined using the $511 \mathrm{keV}$ annihilation line following the procedure described in section 4.3. Counts due to the decay of ${ }^{93} \mathrm{Ru}$ with its half-life of $59.7(6) \mathrm{s}$ were calculated using the $680.7(9) \mathrm{keV}$ line with $\mathrm{I}_{\beta}=5.9(4) \%$ [Lan76]. The calculated amount was then subtracted from the total $511 \mathrm{keV}$ area and the remainder attributed to ${ }^{93} \mathrm{Rh}$. The ${ }^{93} \mathrm{Rh}$ production, as determined using the $511 \mathrm{keV}$ line, was $31(7)$ at $/ \mu \mathrm{C}$. The half-life of $11.9(7) \mathrm{s}$ was 


\begin{tabular}{ccc}
\hline \hline $\mathrm{E}_{\gamma}(\mathrm{keV})$ & $\mathrm{A}_{\gamma}$ & Relative Intensity \\
\hline $482.6(3)$ & $70(23)$ & $20(7)$ \\
$643.6(1)$ & $118(16)$ & $42(8)$ \\
$1359.4(1)$ & $179(18)$ & 100 \\
$1393.3(2)$ & $130(16)$ & $72(14)$ \\
$1629.9(1)$ & $147(15)$ & $98(19)$ \\
$1842.4(6)$ & $45(18)$ & $31(13)$ \\
$2273.8(9)$ & $60(13)$ & $48(13)$ \\
unplaced $\gamma$ lines & \\
\hline $502.0(2)$ & $162(32)$ & \\
$1419.1(1)$ & $40(15)$ & \\
$1549.1(1)$ & $68(17)$ & \\
$2323.7(3)$ & $24(8)$ & \\
\hline
\end{tabular}

TABLE 5.1: Energies, peak areas and relative intensities of the seven $\beta$-gated $\gamma$ rays assigned to ${ }^{93} \mathrm{Rh}$ decay. Energies and peak areas of the four $\gamma$ lines not placed in the decay scheme of ${ }^{93} \mathrm{Rh}$ are also given.

calculated from a fit to the sum of the individual TDC spectra gated on each of the seven lines attributed to ${ }^{93} \mathrm{Rh}$ and is shown in figure 5.4. No evidence is seen of the ${ }^{93} \mathrm{Ru}\left(1 / 2^{-}\right) 10.8(3) \mathrm{s}$ isomeric decay as described in ref. [Lan76]; neither the M4 isomeric transition at $734 \mathrm{keV}$ nor any $\beta$-delayed $\gamma$ events. The $\left(1 / 2^{-}\right)$ state was thus either weakly or not populated in the $\left({ }^{40} \mathrm{Ar}, \mathrm{p} 4 \mathrm{n}\right)$ reaction. 


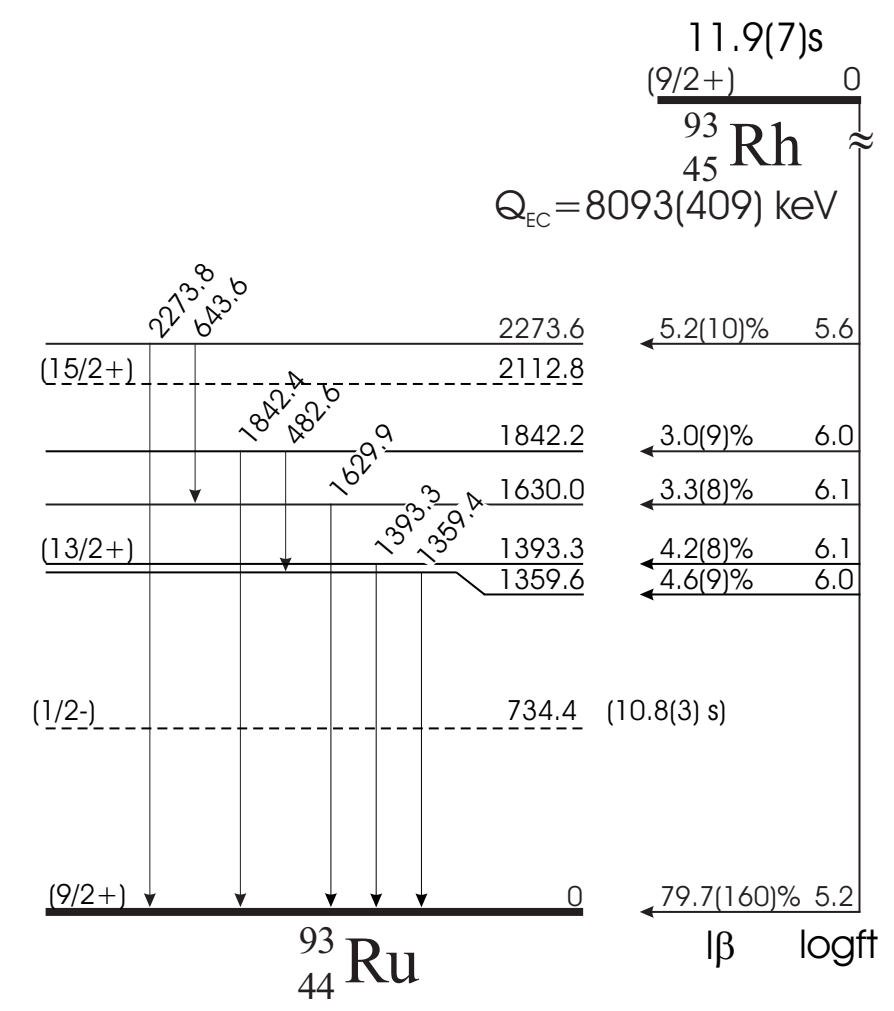

FIG. 5.3: The decay scheme of ${ }^{93} \mathrm{Rh}$. The $\left(1 / 2^{-}\right)$and $\left(15 / 2^{+}\right)$states detailed in refs. [Lan76] and [Arn94], although not seen in this study, are included for purposes of comparison. $\log f t$ values were calculated using the $\mathrm{Q}_{E C}$ values taken from ref. [Aud95] and, for reasons given in section 4.3, should be regarded as lower limits.

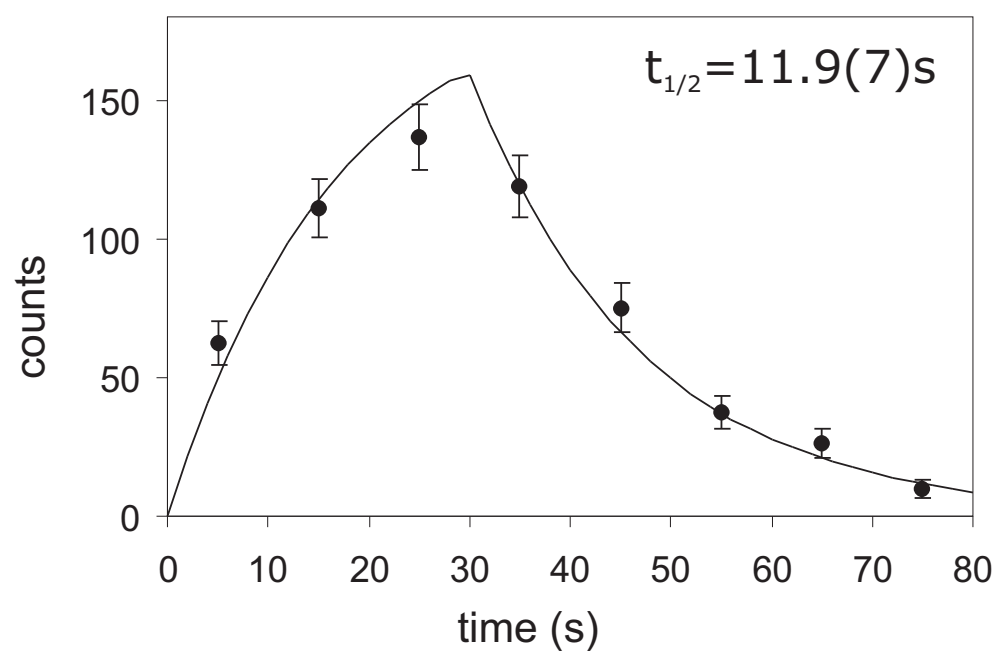

FIG. 5.4: Growing-in and decay fit to the time behaviour of the sum of the intensities of the seven lines placed in the decay scheme of ${ }^{93} \mathrm{Rh}$. 


\section{$5.1 .2 \quad{ }^{92} \mathrm{Rh}$}

The level structure of ${ }^{92} \mathrm{Ru}$ has been previously investigated by both in-beam [Nol80, Arn93b, Gór96, Lin97] and $\beta$-decay spectroscopy [Zho99]. The results presented here are in agreement with the most recent in-beam study [Lin97] except for the placement of the $919 \mathrm{keV}$ line and the inclusion here of a $340 \mathrm{keV}$ line (also reported in the earlier [Arn93b]). The level scheme reported by [Zho99] has been expanded and developed here by the addition of three $\gamma$ lines and their respective levels as well as feeding to these levels.

The ${ }^{58} \mathrm{Ni}\left({ }^{36} \mathrm{Ar}, \mathrm{pn}\right)$ reaction was used to produce ${ }^{92} \mathrm{Rh}$ nuclei which had a HIVAP calculated maximum cross section of $368 \mu \mathrm{b}$ at $120 \mathrm{MeV}$ which occurred close to the centre of the target. Beam ON/OFF times of $12 / 20 \mathrm{~s}$ were used for this measurement and figure 5.5 shows $\gamma$-ray spectra acquired at mass 92 . The time behaviour of the $\gamma$ lines attributed to the decay of ${ }^{92} \mathrm{Rh}$ is shown in figs. 5.6 and 5.7. Figure 5.8 gives an example of the $\gamma-\gamma$ coincidence spectra that were used to construct the decay scheme presented in figure 5.9.

\section{Indication of isomeric as well as ground state decay in ${ }^{92} \mathrm{Rh}$}

A calculation of feeding to the observed levels based on the $511 \mathrm{keV}$ annihilation line puts feeding to the ground state of ${ }^{92} \mathrm{Ru}\left(\mathrm{I}^{\pi}=0^{+}\right)$and the $2^{+} 866 \mathrm{keV}$ level at no less than 25 and $5 \%$ respectively. This is inconsistent with the assigned ground state spin and parity of $\left(\geq 6^{+}\right)$for ${ }^{92} \mathrm{Rh}$ [Zho99]. This apparent discrepancy may be explained by the decay of a low spin isomeric state in ${ }^{92} \mathrm{Rh}$. As figure 5.6 shows, there is evidence for two half-life components in the time behaviour of the $866 \mathrm{keV}$ line. The half-life of the longer living $\left(\geq 6^{+}\right)$state in the two-component fit has been fixed at 4.66(25) s; determined from the time behaviour of the intensities of the 163, 340, 818 and $919 \mathrm{keV}$ lines and shown in figure 5.7. This gives the low spin isomer a half-life of $0.53(37) \mathrm{s}$.

In view of this, and an examination of $\gamma-\gamma$ coincidence spectra, examples of which are presented in figure 5.8, the level scheme shown in figure 5.9 is proposed. The half-life of the $8^{+}$state was measured to be 100(14) ns [Nol80] and is also included in the level scheme. Because of the low energy of the $163 \mathrm{keV}$ line, electron conversion assuming an E2 transition has been taken into account in calculating the feeding to this level. It should be noted that although the $\left(\geq 6^{+}\right)$ state has been thus far referred to as the ground state, it is not yet apparent that this is indeed the case hence the energy values $(0+\mathrm{x}$ and $0+\mathrm{y})$ of the two states in figure 5.9. The $\left(2^{+}\right)$assignment for the second $\beta$-decaying state in ${ }^{92} \mathrm{Rh}$ will be 

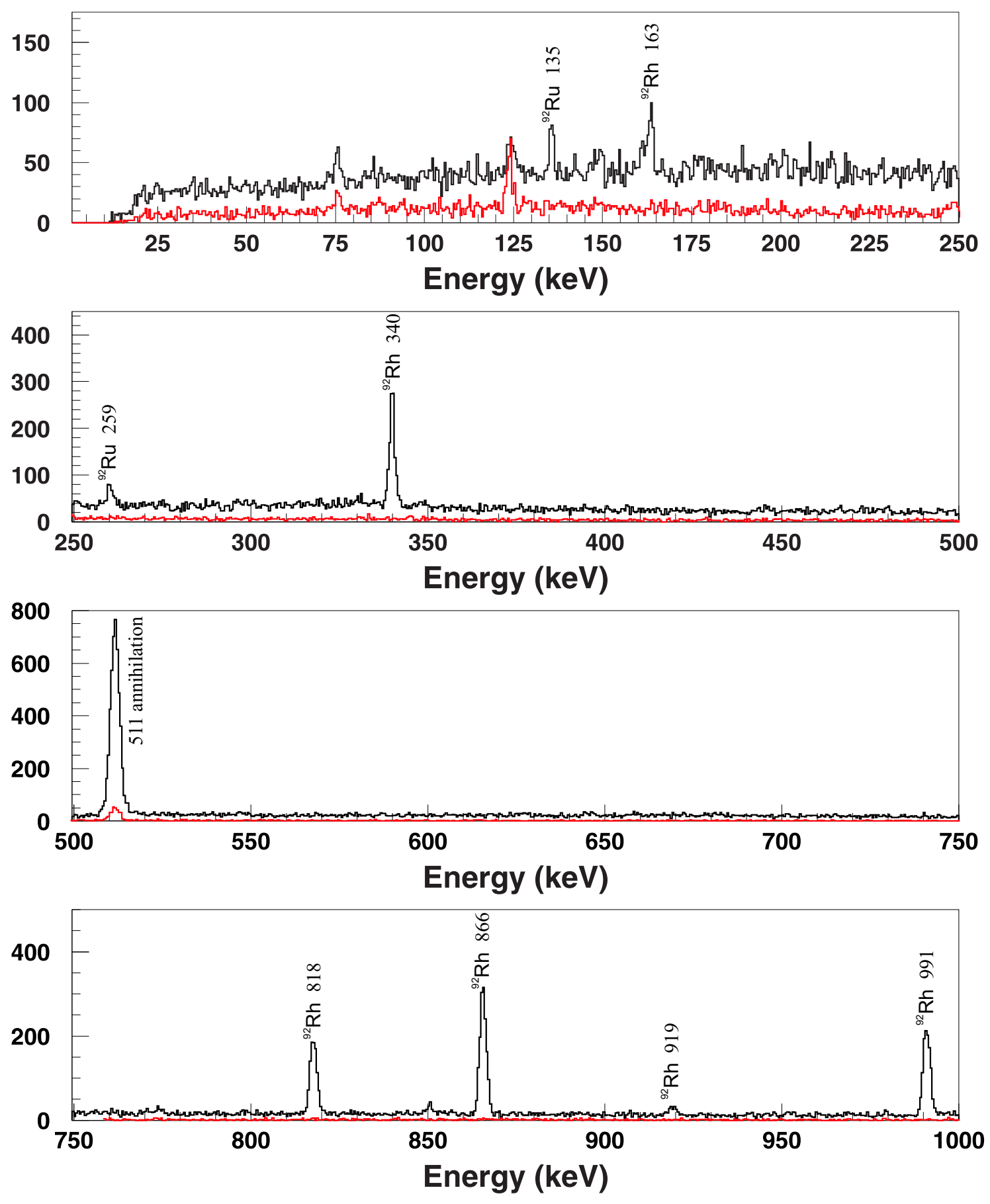

FIG. 5.5: Mass $92 \beta$ gated spectra with the lasers tuned to rhodium (black lines) and without lasers (gray lines). Energies labels are given in $\mathrm{keV}$. 


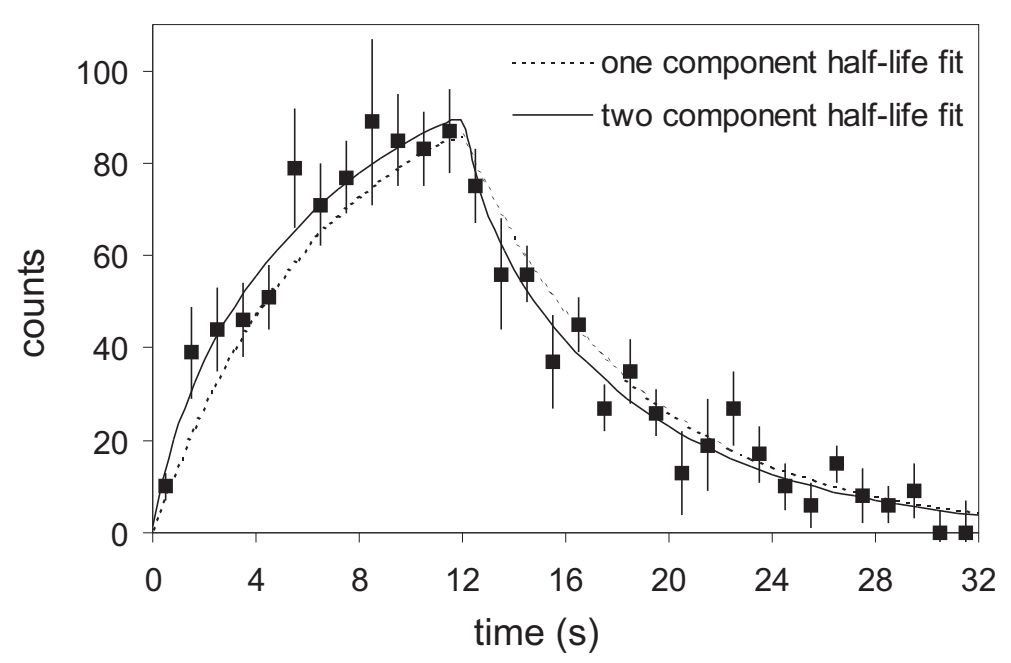

FIG. 5.6: A one half-life (dashed line) and two half-life (solid line) fit to the time behaviour of the intensity of the $866 \mathrm{keV} \gamma$ line. The longer half-life was fixed in both cases at $4.66 \mathrm{~s}$ which was determined from the fit in fig 5.7. This produces a $0.53(37) \mathrm{s}$ half-life for the shorter living state in the two component fit.

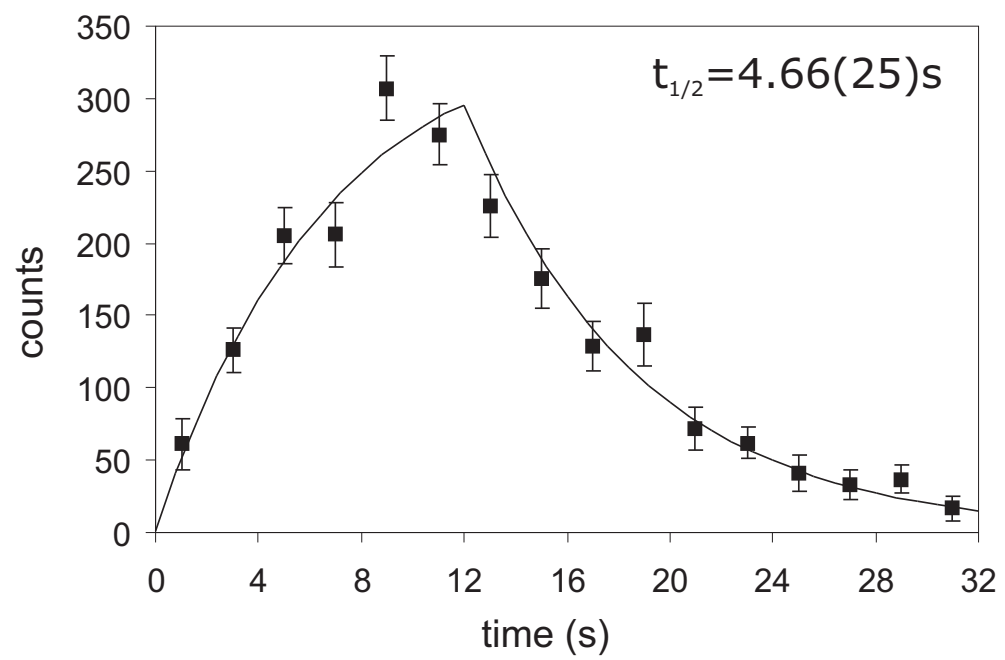

FIG. 5.7: Growing-in and decay fit to the time behaviour of the intensities of the 163, 340, 818 and $919 \mathrm{keV} \gamma$ lines.

discussed later in section 6.2.2. The properties of the individual lines attributed to the decay of ${ }^{92} \mathrm{Rh}$ are listed in table 5.2 . The $866 \mathrm{keV}$ line had a total area of 1426(34) and counts were apportioned between the low and high spin decays on the basis of the two component half-life fit shown in figure 5.6. 

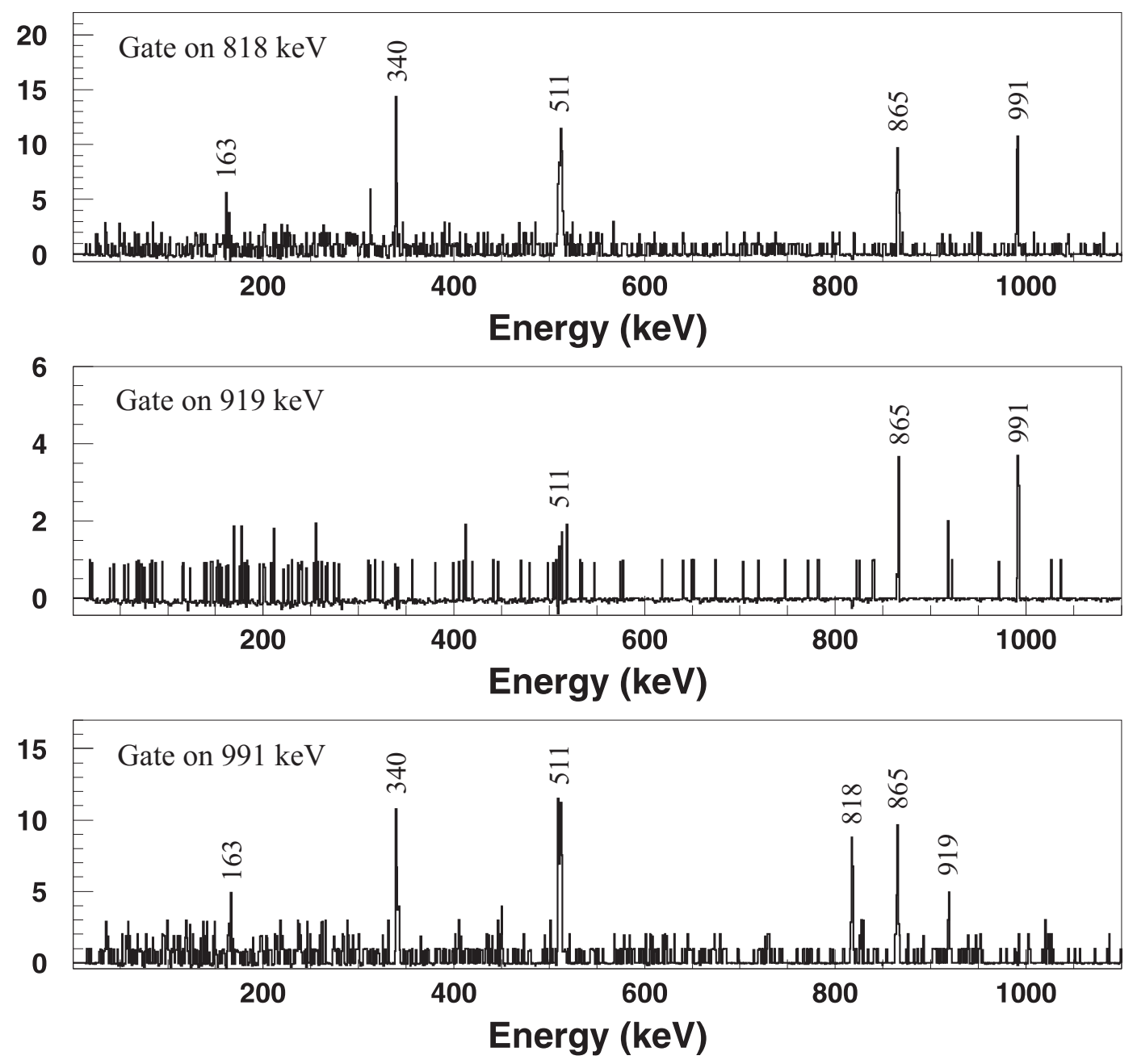

FIG. 5.8: Mass 92 Background subtracted coincidence spectra with gates on the 818, 918 and $991 \mathrm{keV} \gamma$ lines. 


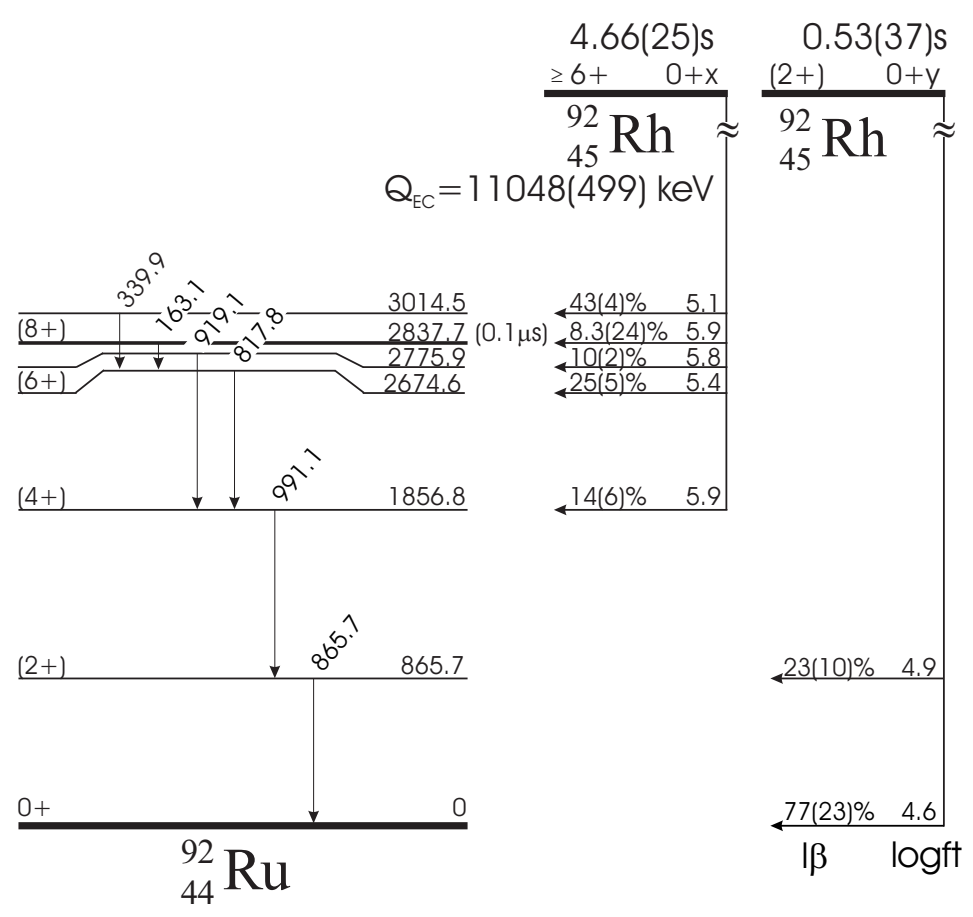

Fig. 5.9: The decay scheme of ${ }^{92} \mathrm{Rh}$. The $\left(2^{+}\right)$assignment for the low-spin isomeric state is discussed in section 6.2.2. Log $f t$ values were calculated using the $\mathrm{Q}_{E C}$ values taken from ref. [Aud95] and, for reasons given in section 4.3, should be regarded as lower limits.

\begin{tabular}{ccc}
\hline \hline $\mathrm{E}_{\gamma}(\mathrm{keV})$ & $\mathrm{A}_{\gamma}$ & $\begin{array}{c}\text { Relative Intensity } \\
92\end{array}$ \\
& & $6.8(20)$ \\
\hline $163.1(2)$ & $238(52)$ & $43(4)$ \\
$339.9(2)$ & $921(19)$ & $76(9)$ \\
$817.8(1)$ & $889(41)$ & $103(15)$ \\
$865.7(1)$ & $1207(85)$ & $10(2)$ \\
$919.1(1)$ & $120(25)$ & 100 \\
$991.1(3)$ & $1055(29)$ & 92 \\
& & 100 \\
\hline $865.7(1)$ & $219(78)$ & \\
\hline \hline
\end{tabular}

TABLE 5.2: Energies, peak areas and relative intensities of $\beta$-gated $\gamma$ rays assigned to ${ }^{92} \mathrm{Rh}$ decay. 


\subsection{3 ${ }^{91} \mathrm{Rh}$}

${ }^{91} \mathrm{Rh}$ nuclei were produced in the ${ }^{58} \mathrm{Ni}\left({ }^{36} \mathrm{Ar}, \mathrm{p} 2 \mathrm{n}\right)$ reaction allowing the $\beta$ decay of this nucleus to be studied for the first time. The argon beam, initially at $235 \mathrm{MeV}$, was degraded to $121 \mathrm{MeV}$ close to the centre of the target, overlapping with the maximum cross section of $11 \mu \mathrm{b}$ for this reaction channel as calculated by HIVAP. The five $\gamma$ lines indicated in the $\beta$-gated $\gamma$-ray spectra shown in figure 5.10, have been assigned to the decay of ${ }^{91} \mathrm{Rh}$ (see table 5.3). An examination of $\gamma-\gamma$ matrices gated on these transitions was unable to reveal any coincidences between the lines.

Apart from a recent half-life measurement [Kie01], ${ }^{91} \mathrm{Rh}$ was unknown experimentally prior to this study. A ground state of $9 / 2^{+}$is however favoured based on systematics and shall be adopted as a tentative assignment here. The better known ${ }^{91} \mathrm{Ru}$ has also been tentatively assigned to have a ground state with $\mathrm{I}^{\pi}=9 / 2^{+}$[Kom83] which would agree with the systematic properties of $\mathrm{N}=47$, $\mathrm{Z}=$ even nuclei in the vicinity. Both assignments are consistent with the $\beta$-decay branchings reported here.

Earlier in-beam experiments exploring the excited states of ${ }^{91} \mathrm{Ru}$ [Arn93a, Hee94] have attributed a $973 \mathrm{keV}$ line to a $\left(13 / 2^{+}\right)$to ground state transition and a very recent measurement [Rus04b] indicates a line at $890 \mathrm{keV}$ to result from an $\left(11 / 2^{+}\right)$to ground state transition. For this reason, and others that will be discussed in section 6.2.3, only these two $\gamma$ lines, out of the six listed in table 5.3, are placed in the level scheme shown in figure 5.11. Excepting the $\gamma$ line at $533 \mathrm{keV}$, half-lives based on the time behaviour of each of the lines were determined and are also included in table 5.3 along with their peak areas and intensities which have been normalised to the $438 \mathrm{keV}$ line.

The half-life attributed to ${ }^{91} \mathrm{Rh}$ ground state decay was established as $1.47(22) \mathrm{s}$ from the time behaviour of the 890 and $973 \mathrm{keV}$ lines over a 12/20 s grow-in and decay cycle. The fit is shown in figure 5.12. The half-life value is in agreement with the previous measurement of $1.7(2) \mathrm{s}$ [Kie01].

\section{The $387 \mathrm{keV} \gamma$ line}

The singles spectra in figure 5.13 reveal another feature of ${ }^{91} \mathrm{Rh}$ decay. The line at $387 \mathrm{keV}$ is not seen in $\beta$-gated spectra with or without lasers. It is however strongly produced in the singles spectra but only when the lasers are tuned to rhodium. This establishes an isomeric transition in either ${ }^{91} \mathrm{Rh}$ or ${ }^{91} \mathrm{Ru}$; the former being fed directly in the heavy-ion reaction and the latter populated 

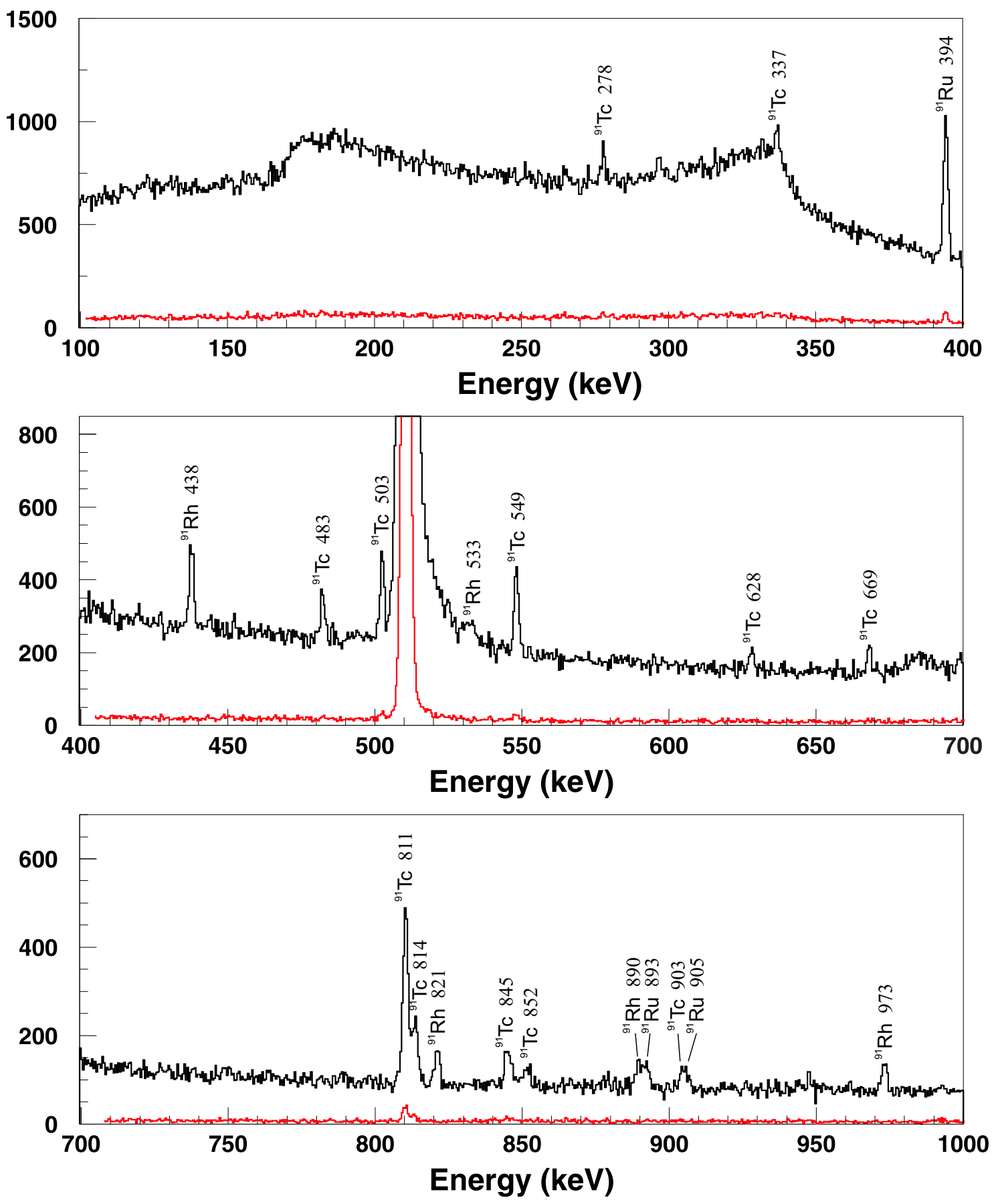

Fig. 5.10: Mass $91 \beta$ gated spectra with the lasers tuned to rhodium (black lines) and without lasers (gray lines). Energies labels are given in keV. 


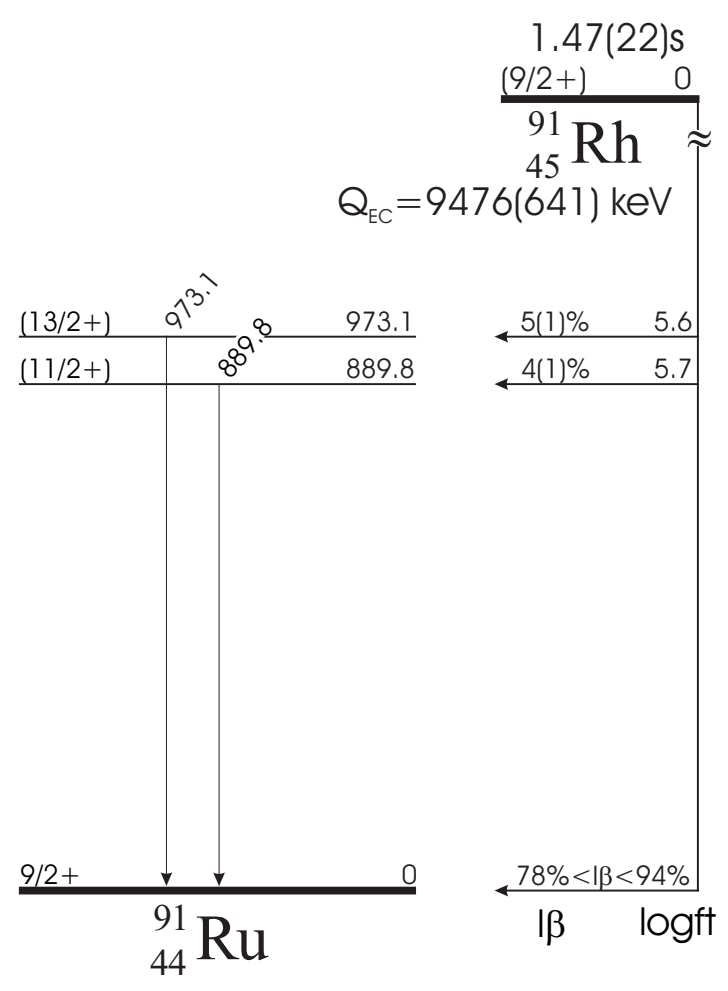

FIG. 5.11: The decay scheme of ${ }^{91} \mathrm{Rh}$ including only two of the six $\gamma$ lines associated with ${ }^{91} \mathrm{Rh}$ decay. The reasons for this and the limits on feeding to the ground state in ${ }^{91} \mathrm{Ru}$ are given in the text. Log $f t$ values were calculated using the $\mathrm{Q}_{E C}$ values taken from ref. [Aud95] and, for reasons given in section 4.3, should be regarded as lower limits.

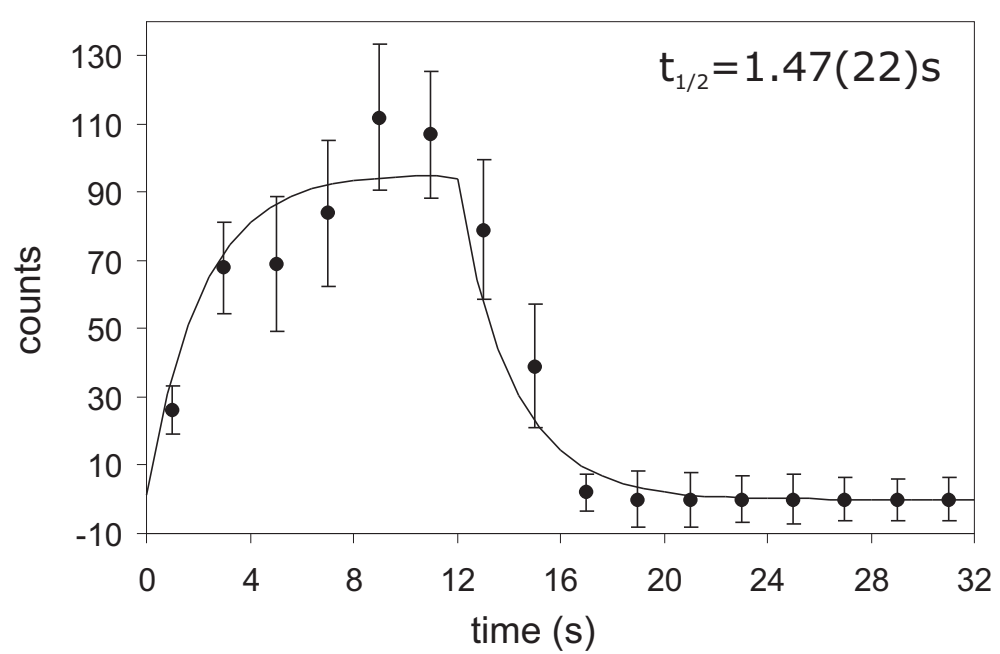

FIG. 5.12: Growing-in and decay fit to the time behaviour of the intensities of the 890 and $973 \mathrm{keV} \gamma$ lines. 


\begin{tabular}{cccc}
\hline \hline $\begin{array}{c}\mathrm{E}_{\gamma} \\
(\mathrm{keV})\end{array}$ & $\mathrm{A}_{\gamma}$ & $\begin{array}{c}\text { Relative } \\
\text { Intensity }\end{array}$ & $\begin{array}{c}\text { half-life } \\
(\mathrm{s})\end{array}$ \\
\hline $437.7(1)$ & $854(67)$ & 100 & $1.65(30)$ \\
$533.3(1)$ & $156(78)$ & $21(10)$ & \\
$821.1(1)$ & $334(32)$ & $63(9)$ & $1.84(35)$ \\
$889.8(2)$ & $268(49)$ & $52(11)$ & $1.40(33)$ \\
$973.1(1)$ & $297(43)$ & $61(11)$ & $1.52(29)$ \\
\hline $387.4(2)$ & $8066(242)$ & $351(39)$ & $1.46(11)$ \\
\hline \hline
\end{tabular}

TABLE 5.3: Energies, peak areas, relative intensities and half-lives of $\gamma$ rays assigned to ${ }^{91} \mathrm{Rh}$ decay. The proximity of the $511 \mathrm{keV}$ line meant that it was not possible to determine the half-life of the $533 \mathrm{keV}$ line; suffice to say it was short and similar to the others. The area of the $387 \mathrm{keV}$ line is taken from singles spectra due to its absence from coincidence data and its intensity has been normalised using the appropriate efficiency.

through the decay of ${ }^{91} \mathrm{Rh}$.

Collecting data in multiscaling mode allows the time behaviour of this $\gamma$ line to be determined. The size of the time bins is restricted to $4 \mathrm{~s}$ however the fit, shown in figure 5.14, produces a value of $1.46(11) \mathrm{s}$ which is very similar to that determined for ${ }^{91} \mathrm{Rh}$ ground state decay.

Assuming this line represents $100 \%$ intensity of the decay from which it originates, the production is then $4.0(8)$ at $/ \mu \mathrm{C}$. This can be compared with a production of $24(4)$ at $/ \mu \mathrm{C}$ as derived from the lines seen in $\beta$-gated spectra. The possible origins of this activity will be discussed in section 6.2.3. 


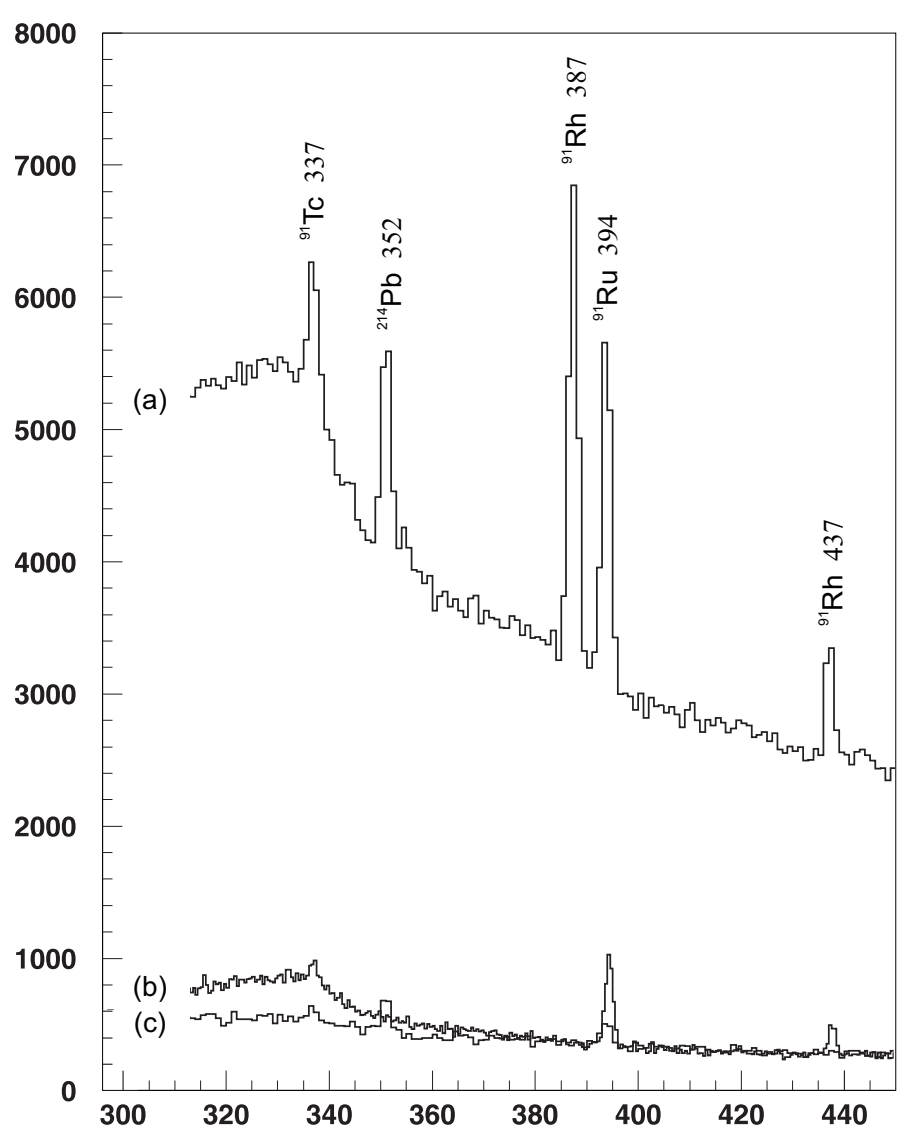

FIG. 5.13: $\gamma$ ray spectra for $A=91$ with (a) lasers tuned to rhodium in singles (b) $\beta$ gated and (c) singles without lasers. $N B$ The measurement time without lasers was much shorter (see table 3.2).

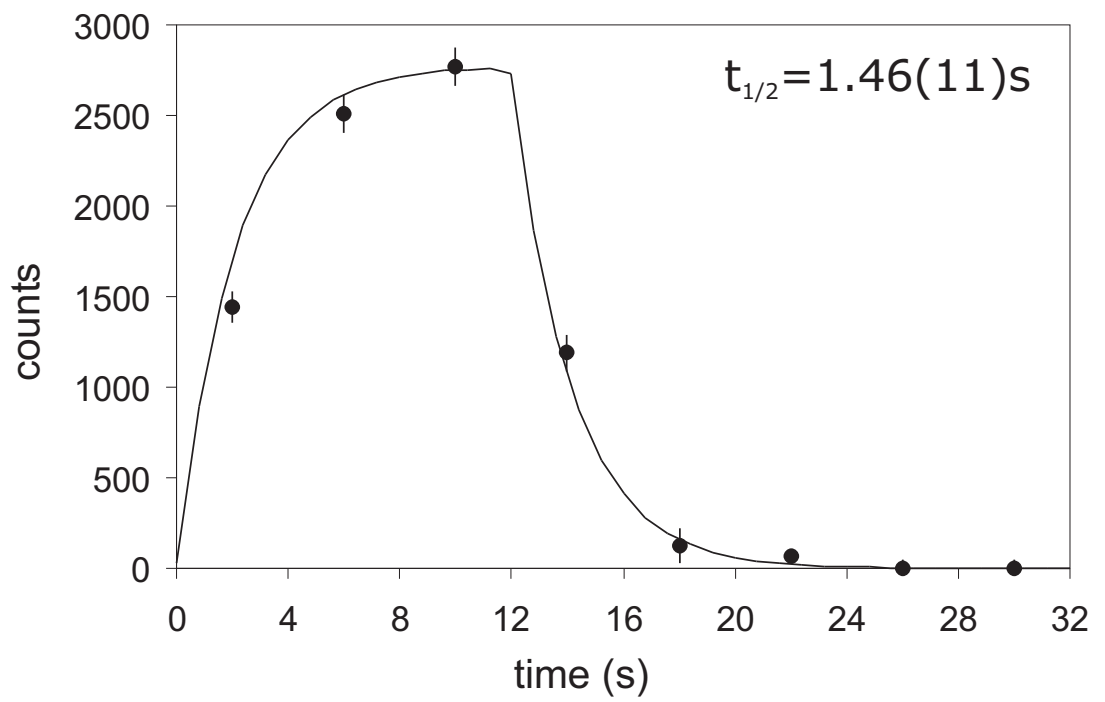

FIG. 5.14: Growing-in and decay fit to the time behaviour of the intensity of the $387 \mathrm{keV} \gamma$ line. 


\section{$\mathbf{5 . 1 . 4}{ }^{91} \mathrm{Ru}$}

Figures 5.15 and 5.16 show spectra resulting from 3.08 hours data acquisition on mass 91. Nuclei of ${ }^{91} \mathrm{Ru}$ were produced in the ${ }^{58} \mathrm{Ni}$ target using a ${ }^{36} \mathrm{Ar}$ beam incident at $158 \mathrm{MeV}$. From HIVAP calculations, a maximum cross section of $28 \mathrm{mb}$ is obtained from a beam energy of $130 \mathrm{MeV}$. The incident ${ }^{36} \mathrm{Ar}$ beam reaches this value close to the middle of the target.

As detailed in section 5.1.3, the ground state of ${ }^{91} \mathrm{Ru}$ has been tentatively assigned $9 / 2^{+}$. An isomeric $\left(1 / 2^{-}\right)$state with a half-life of $7.6(8) \mathrm{s}$ was identified as a $\beta$-delayed proton precursor by Hagberg et al. [Hag83]. The occurrence of an isomeric $1 / 2^{-}$state is in agreement with the systematic behaviour of odd, $N=47$ in this mass region. The excitation energy of this state is expected from systematics to be around 300-400 keV above a $9 / 2^{+}$ground state [Aud97]. The results of this work, examined in conjunction with other very recent measurements [Mar03b, Rus04b] have allowed us to place this level at $433 \mathrm{keV}$. See section 6.2 .3 for a full discussion.

A similar comparison with neighbouring nuclei also predicts a $1 / 2^{-}$isomeric state above a $9 / 2^{+}$ground state in the daughter nucleus ${ }^{91} \mathrm{Tc}$. The half-lives of these two states have been measured to be 3.14(2) and 3.3(1) min respectively [Lan76]. Comprehensive investigations of the high spin states in ${ }^{91} \mathrm{Tc}$ have been undertaken [Kom83, Arn93a, Rud94] with most recent study [Rud94] identifying a $\left(1 / 2^{-}\right)$state at $139 \mathrm{keV}$. Komninos et al. [Kom83] also measured the $\beta$ decay of ${ }^{91} \mathrm{Ru}$ observing four $\gamma$ transitions between low-lying $\left(7 / 2^{+}\right),\left(9 / 2^{+}\right)$, $\left(11 / 2^{+}\right)$and $\left(13 / 2^{+}\right)$states in ${ }^{91}$ Tc. In addition to these four known lines, eleven new $\gamma$ lines were attributed to the decay of ${ }^{91} \mathrm{Ru}$. Based on $\gamma-\gamma$ coincidence spectra such as those shown in figure 5.17 the decay scheme shown in figure 5.18 was established. The properties of all the observed $\beta$-delayed $\gamma$ lines are included in table 5.4.

Using a $12 / 20 \mathrm{~s}$ beam ON/OFF macrocycle, a half-life of 7.85(40) s was assigned to the decay of ${ }^{91} \mathrm{Ru}$ based on a fit to the time behaviour of the most intense $394 \mathrm{keV}$ line. The fit is shown in figure 5.19 and is in agreement with a previous measurement of 9(1) s [Kom83]. 

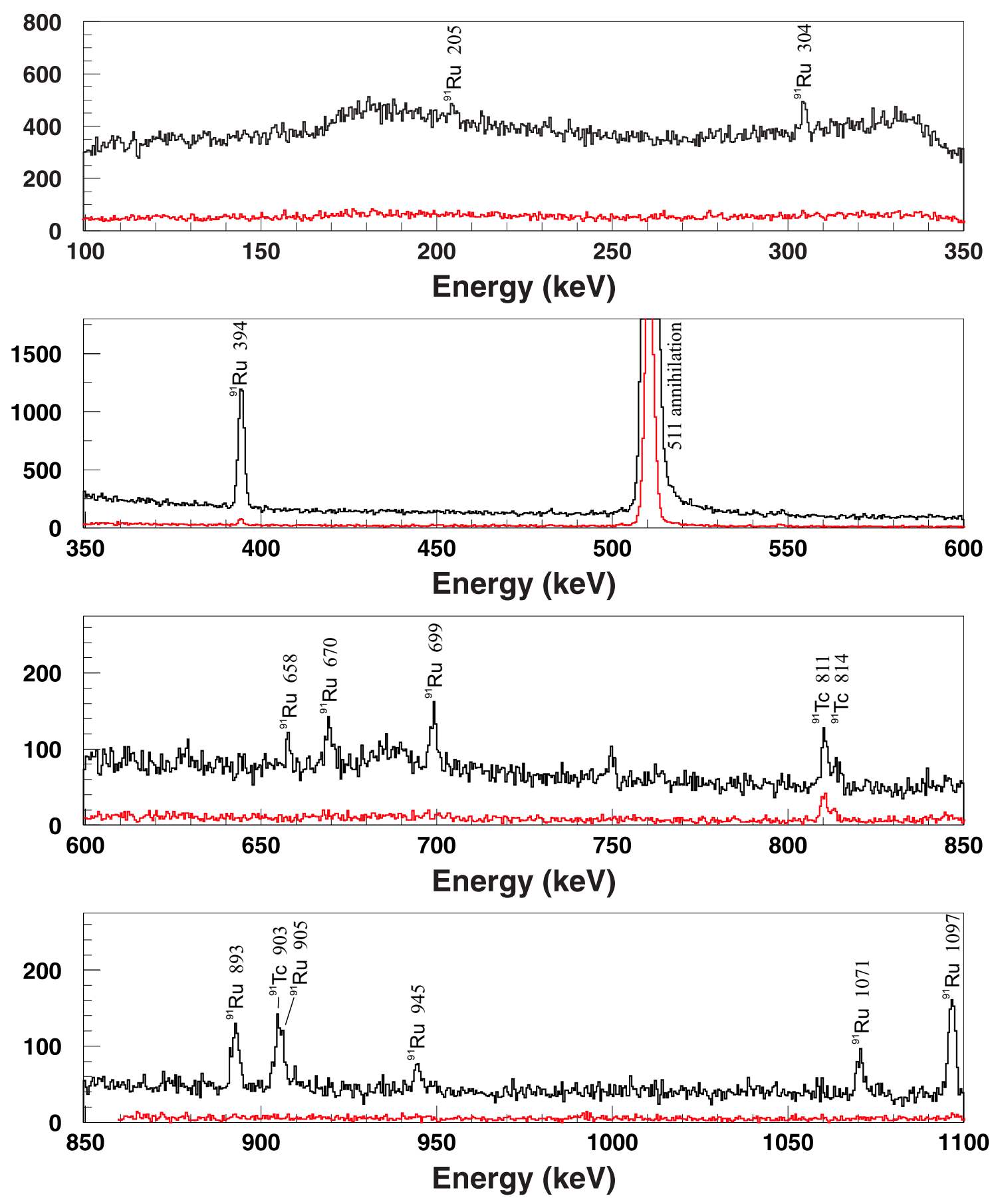

Fig. 5.15: Mass $91 \beta$ gated spectra with the lasers tuned to ruthenium (black lines) and without lasers (gray lines). Energies labels are given in keV. 

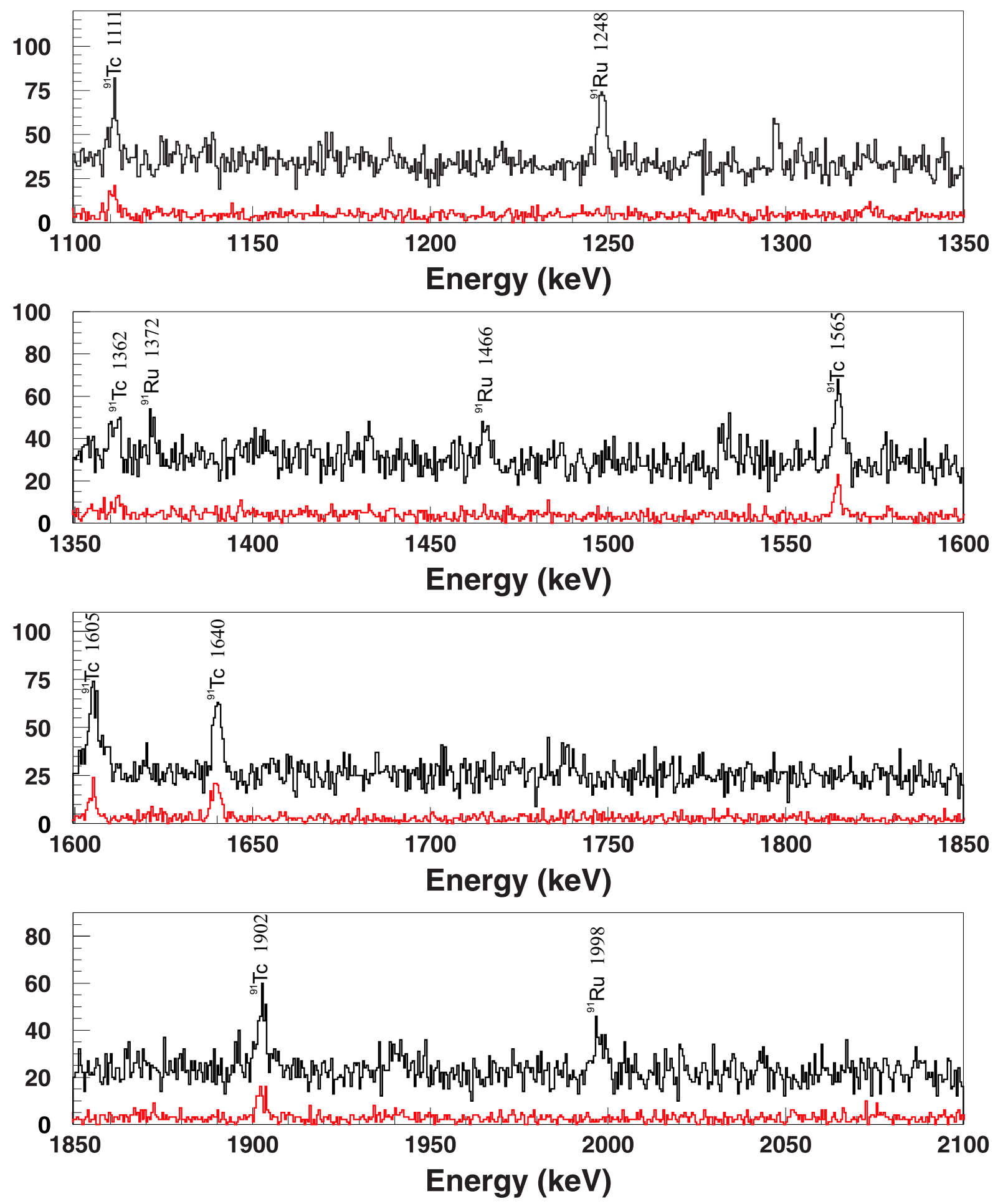

FiG. 5.16: Mass $91 \beta$ gated spectra with the lasers tuned to ruthenium (black lines) and without lasers (gray lines). Energies labels are given in keV. 

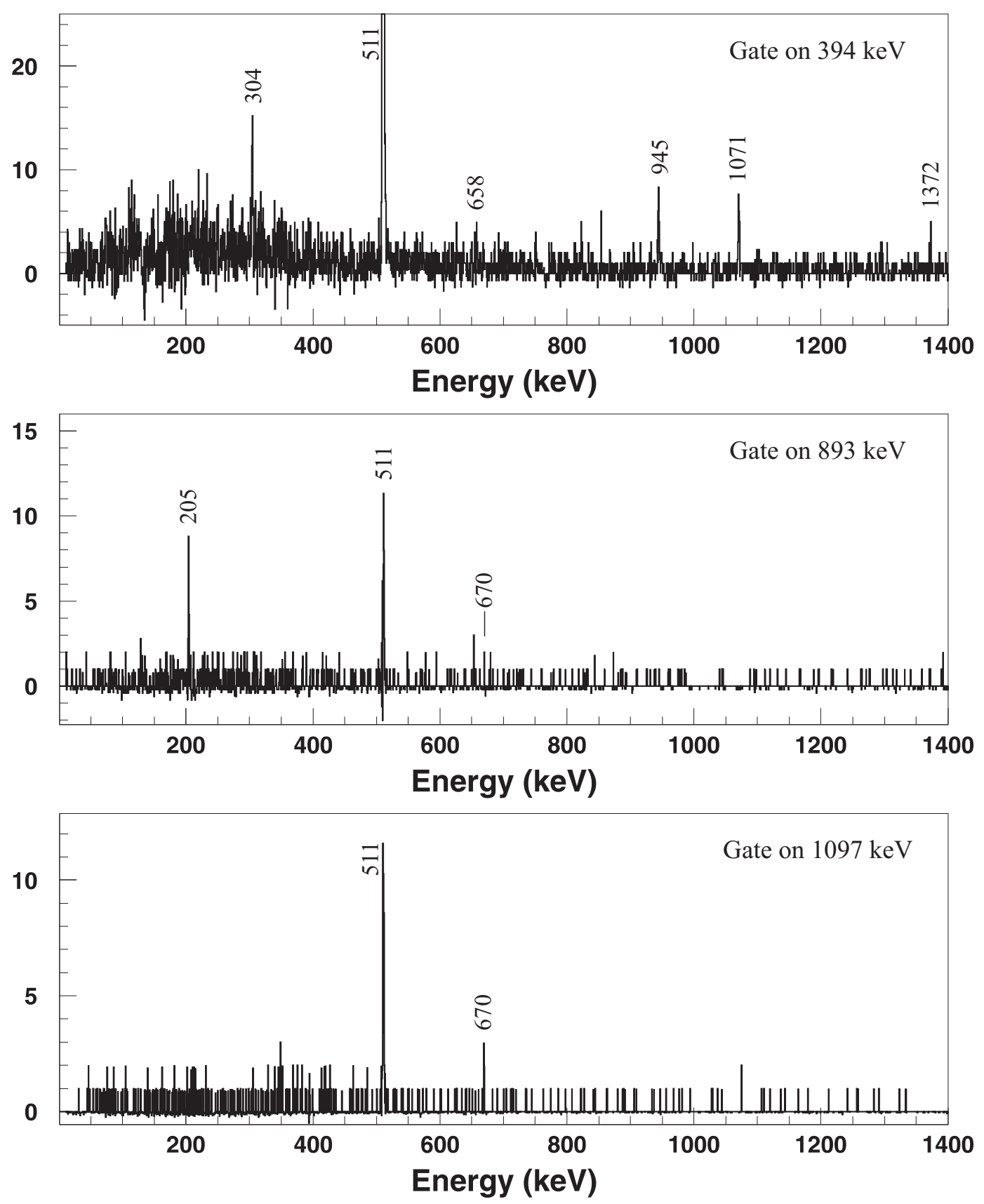

FIG. 5.17: ${ }^{91} \mathrm{Ru}$ background subtracted coincidence spectra with gates on the 394,893 and $1097 \mathrm{keV} \gamma$ lines. 


\section{$7.85(40) s$ \\ $\frac{\frac{(9 / 2+)}{91} \mathrm{Ru} \underset{44}{\approx}}{Q_{\mathrm{EC}}=7405(539) \mathrm{keV}}$}
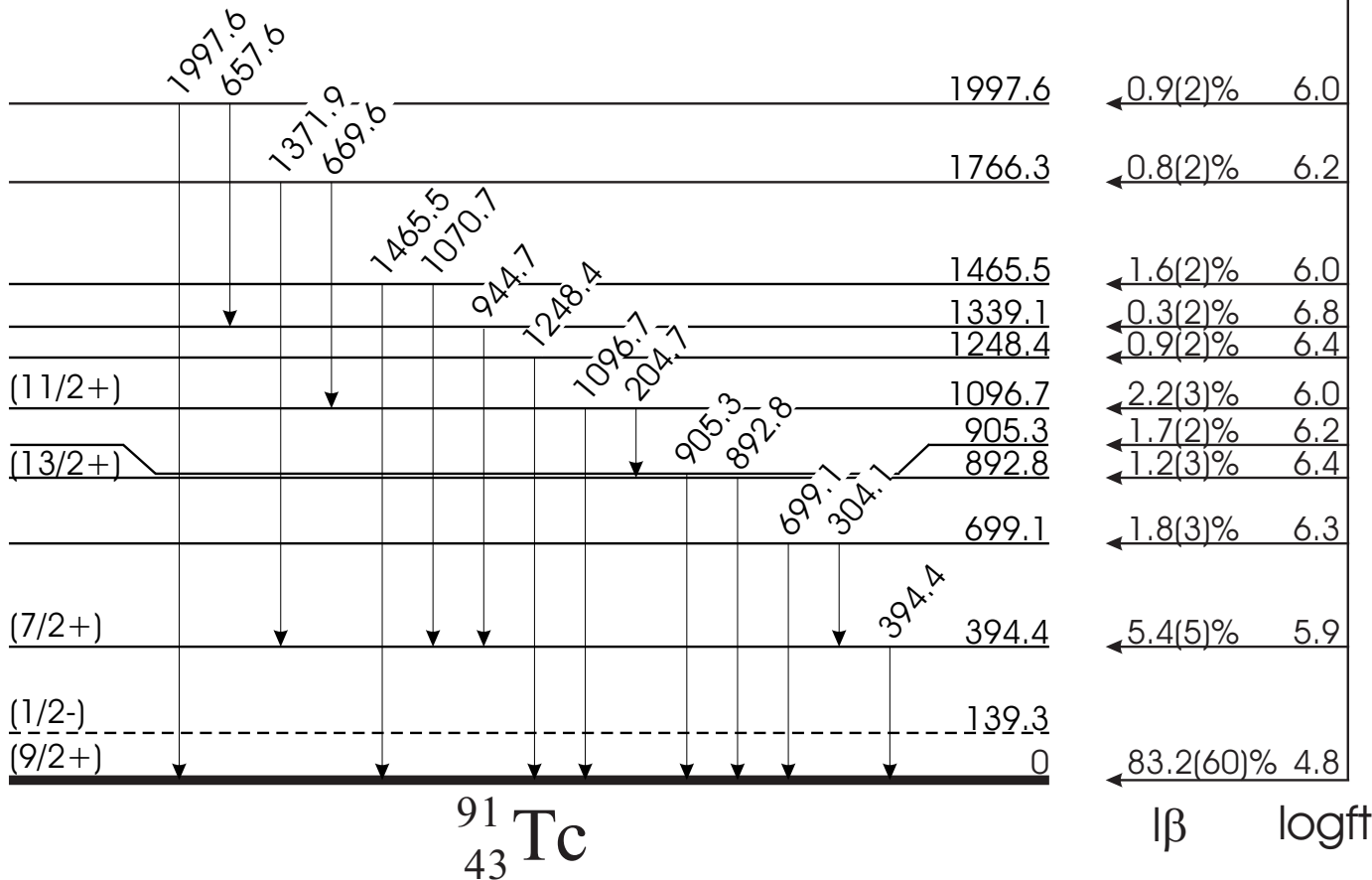

Fig. 5.18: The decay scheme of ${ }^{91} \mathrm{Ru}$. The $\left(1 / 2^{-}\right)$state identified in ref. [Rud94] was not observed in this study and is included for completeness. Log $f t$ values were calculated using the $\mathrm{Q}_{E C}$ values taken from ref. [Aud95] and, for reasons given in section 4.3, should be regarded as lower limits. 


\begin{tabular}{ccc}
\hline \hline $\mathrm{E}_{\gamma}(\mathrm{keV})$ & $\mathrm{A}_{\gamma}$ & Relative Intensity \\
\hline $204.7(3)$ & $246(97)$ & $3.9(23)$ \\
$304.1(1)$ & $364(70)$ & $11(2)$ \\
$394.4(1)$ & $4534(118)$ & 100 \\
$657.6(2)$ & $113(34)$ & $7.2(23)$ \\
$669.6(2)$ & $152(55)$ & $8.5(26)$ \\
$699.1(1)$ & $331(50)$ & $21(5)$ \\
$892.8(4)$ & $420(91)$ & $21(6)$ \\
$905.3(3)$ & $535(47)$ & $32(4)$ \\
$944.7(1)$ & $166(30)$ & $5.6(30)$ \\
$1070.7(1)$ & $246(25)$ & $19(3)$ \\
$1096.7(1)$ & $627(34)$ & $37(5)$ \\
$1248.4(1)$ & $226(32)$ & $17(3)$ \\
$1371.9(2)$ & $65(23)$ & $6.1(22)$ \\
$1465.5(3)$ & $110(36)$ & $9.5(33)$ \\
$1997.6(9)$ & $139(29)$ & $9.5(22)$ \\
\hline \hline
\end{tabular}

TABLE 5.4: Energies, peak areas and relative intensities of $\beta$-gated $\gamma$ rays assigned to ${ }^{91} \mathrm{Ru}$ decay.

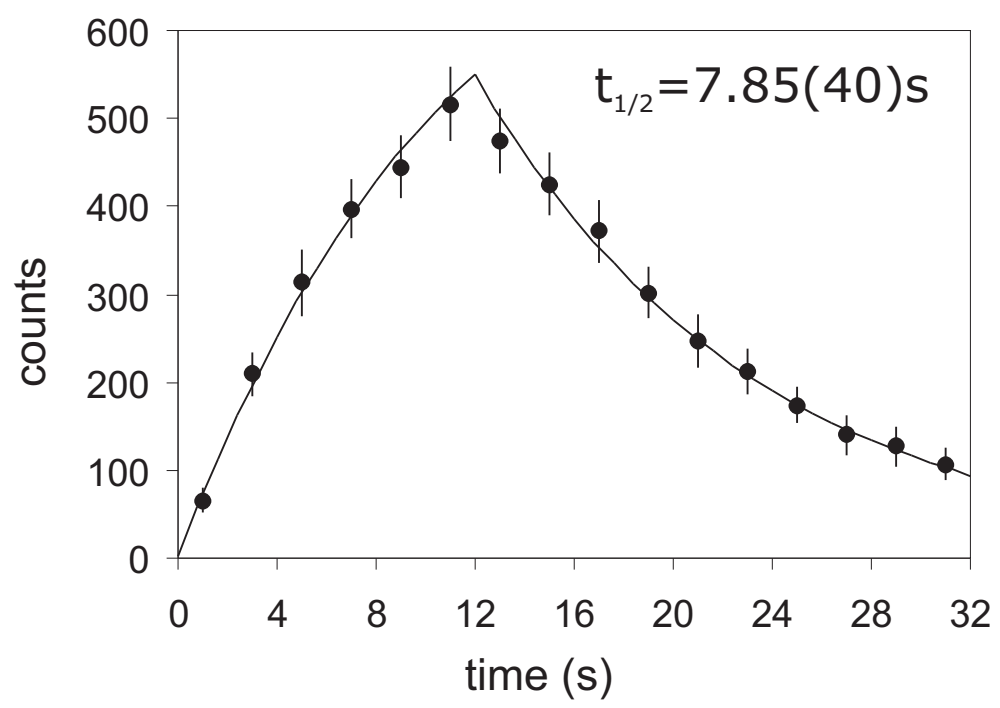

FIG. 5.19: Growing-in and decay fit to the time behaviour of the intensity of the $394 \mathrm{keV} \gamma$ line. 


\subsection{5 ${ }^{90} \mathrm{Ru}$}

A ${ }^{36} \mathrm{Ar}$ beam at $180 \mathrm{MeV}$ incident on target proved to be the energy best suited to production of ${ }^{90} \mathrm{Ru}$ agreeing with HIVAP calculations for a maximum cross section of $2.4 \mathrm{mb}$ at an energy $150 \mathrm{MeV}$ in the middle of the target. Figure 5.20 shows a selection of the data collected at mass 90 using a 32/32 s beam ON/OFF macrocycle.

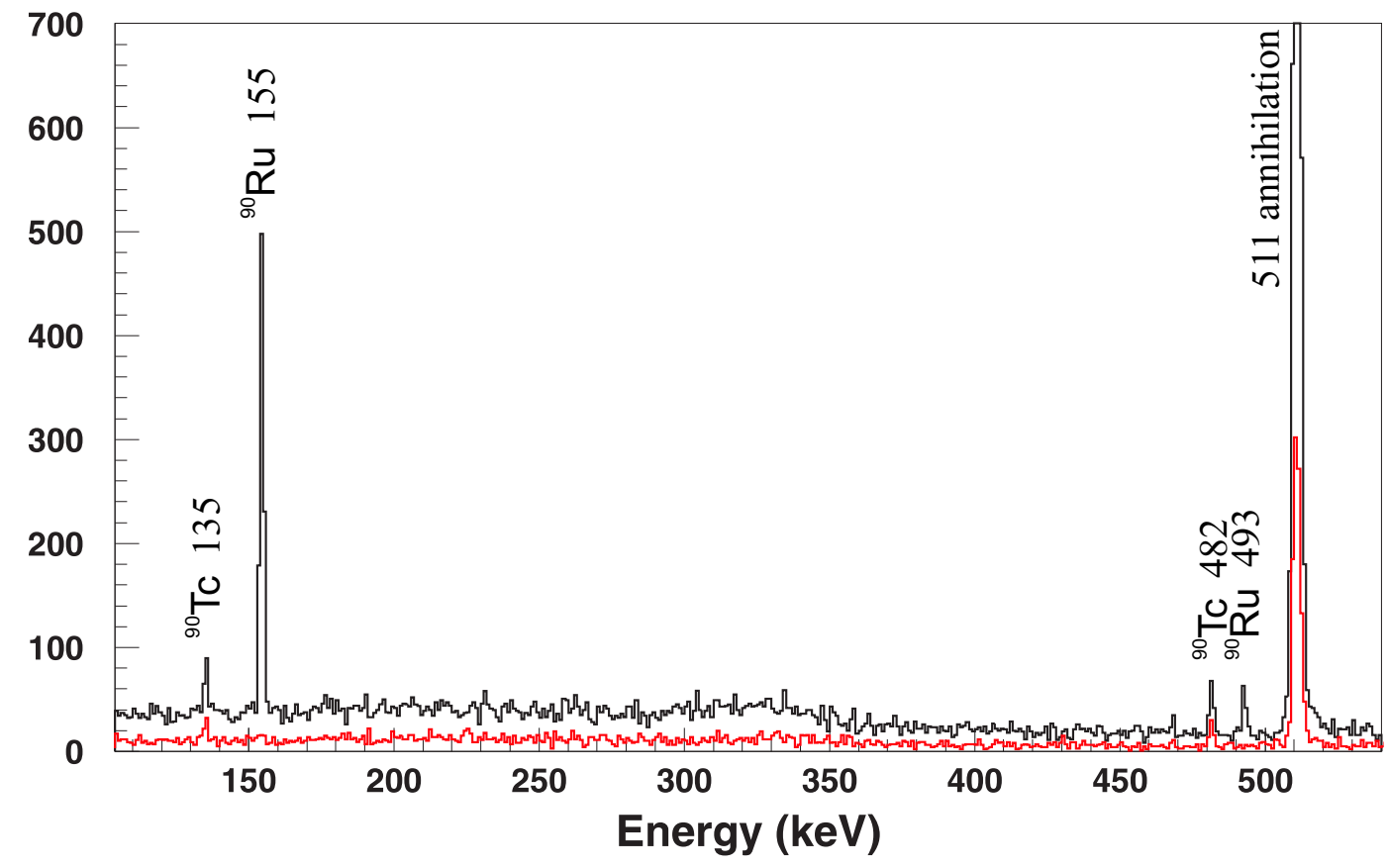

FiG. 5.20: Mass $90 \beta$ gated spectra with the lasers tuned to rhodium (black lines) and without lasers (gray lines). Energies labels are given in keV.

Prior to this work, measurements without the aid mass separation identified the line at $154.6 \mathrm{keV}$, along with 37 others, as belonging to the decay of ${ }^{90} \mathrm{Ru}$ [Zho94]. The line reported there at $491.8 \mathrm{keV}$ is probably that placed here at $492.8 \mathrm{keV}$. No evidence is seen of the remaining 36 lines. Examination of $\gamma-\gamma$ coincidence spectra show the two lines to be uncorrelated, they are thus placed as parallel transitions as shown in figure 5.21.

An early $\beta$-decay measurement of the daughter nucleus ${ }^{90} \mathrm{Tc}$ [Oxo81] identified two $\beta$-decaying states. A high spin $\left(6^{+}\right)$state with a half-life of $49.2(4) \mathrm{s}$ and a $\left(1^{+}\right)$ground state with a half-life of $8.7(2) \mathrm{s}$. A later in-beam measurement of the high-spin states in ${ }^{90} \mathrm{Tc}$ [Rud93] assigned the ground state $\mathrm{J}^{\pi}=8^{+}$and failed 


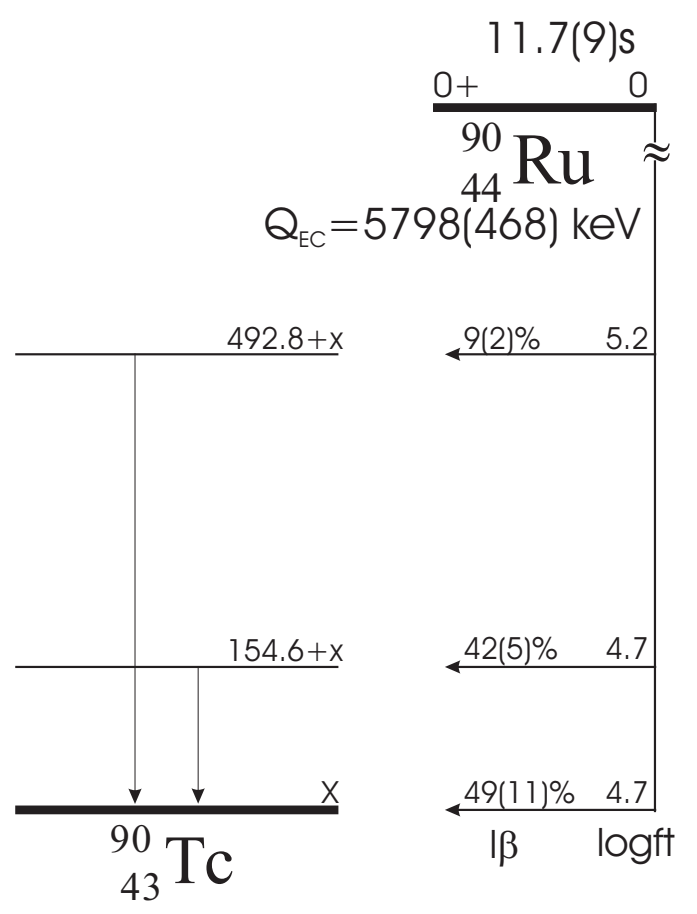

FIG. 5.21: The decay scheme of ${ }^{90} \mathrm{Ru}$. The level energies are quoted as relative to the lowest level populated for reasons given in the text. Log $f t$ values were calculated using the $\mathrm{Q}_{E C}$ values taken from ref. [Aud95] and, for reasons given in section 4.3, should be regarded as lower limits.

to observe any positive parity state with spin less than a tentatively assigned $6^{+}$at $104 \mathrm{keV}$. For this reason, the energy relation between the ground state of ${ }^{90} \mathrm{Tc}$ and the lowest state populated in ${ }^{90} \mathrm{Ru}$ decay cannot be established and the energies of the levels in figure 5.21 are given with the uncertainties shown.

The $\beta$ decay of ${ }^{90} \mathrm{Ru}$ was measured on two occasions, the first occasion using a higher beam energy produced a larger amount of isobaric contamination effectively obscuring the $493 \mathrm{keV}$ line which is clearly visible in figure 5.20. The $155 \mathrm{keV}$ line however, being more intense, was seen in the earlier measurement with an area of $1595(94)$ counts. This data is summed with data from the later experiment and is used to determine a half-life of $11.7(9) \mathrm{s}$ for ${ }^{90} \mathrm{Ru}$ which is in agreement with the previous measurement of 11(3) s [Zho94]. The fit is shown in figure 5.22. Branching to excited states was calculated from the data of the later experiment only and the properties of the $\gamma$ lines for that run only are included in table 5.5. 


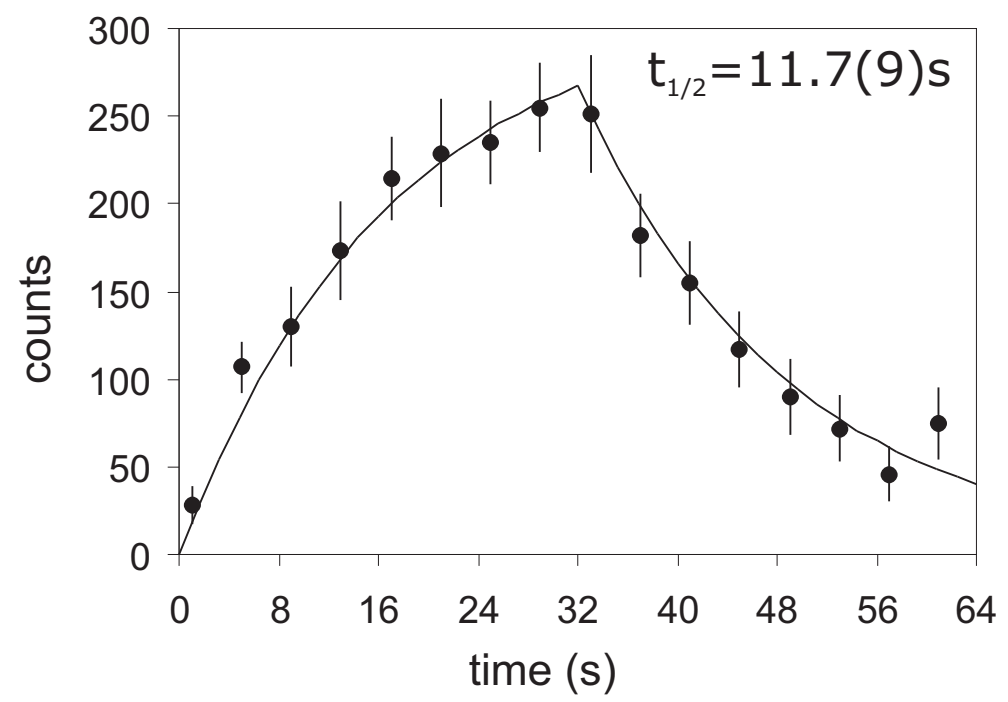

FIG. 5.22: Growing-in and decay fit to the time behaviour of the intensity of the $155 \mathrm{keV} \gamma$ line.

\begin{tabular}{ccc}
\hline \hline $\mathrm{E}_{\gamma}(\mathrm{keV})$ & $\mathrm{A}_{\gamma}$ & Relative Intensity \\
\hline $154.6(1)$ & $810(46)$ & 100 \\
$492.8(1)$ & $81(12)$ & $21(4)$ \\
\hline \hline
\end{tabular}

TABLE 5.5: Energies, peak areas and relative intensities of $\beta$-gated $\gamma$ rays assigned to ${ }^{90} \mathrm{Ru}$ decay. 


\subsection{Results of $\beta$-delayed proton measurements}

As a natural extension to this work, a study of $\beta$-delayed proton activity in the lighter nuclei in this region was investigated. Calculations of the energetics of such decays as well as supporting literature encouraged this enterprise. For this set of measurements, the mass separated beam was implanted into a thin carbon foil in front of a $\Delta \mathrm{E}$-E Si telescope system described more fully in section 3.

\subsection{1 $\quad{ }^{89} \mathrm{Ru}$}

The only experimental information available on ${ }^{89} \mathrm{Ru}$ at present, is a half-life measurement of $1.5(2) \mathrm{s}$ [Kie01]. A $9 / 2^{+}$ground state is predicted from systematics [Aud97] however, calculations by Hasegawa [Has04] and Möller [Möl97] predict the ground state of ${ }^{89} \mathrm{Ru}$ to be $1 / 2^{-}$and $5 / 2^{+}$respectively. The extreme sensitivity of decay rate to the orbital angular momentum of an emitted proton [Woo97] clearly adds more significance to the question of the ground state spin of this nucleus.

Five hours of data taken on ${ }^{89} \mathrm{Ru}$ failed to produce any protons. This result differs from that of an earlier measurement by $\mathrm{Li}$ and co-workers using the same reaction [Li99]. In that study, a $741 \mathrm{keV}$ line from the $2^{+} \rightarrow 0^{+}$transition in ${ }^{88} \mathrm{Mo}$ [Oda96] was seen in coincidence with events in a Si detector however, in the absence of mass separation and a particle identification setup, as was the case there, there is always the possibility that the $741 \mathrm{keV}$ line can result from $\beta$ decay of ${ }^{88} \mathrm{Tc}$.

No evidence of ${ }^{89} \mathrm{Ru}$ decay was seen either in $\gamma$-ray or proton spectra however, an upper limit on $\mathrm{I}_{p}$, the $\beta$-delayed proton branching, can still be calculated. The production of ${ }^{89} \mathrm{Ru}$ is derived by scaling the production of ${ }^{90} \mathrm{Ru}$ down by a factor $\sigma\left({ }^{90} R u\right) / \sigma\left({ }^{89} R u\right)$, where $\sigma\left({ }^{90} R u\right)$ and $\sigma\left({ }^{89} R u\right)$ are cross sections for ${ }^{90} \mathrm{Ru}$ and ${ }^{89} \mathrm{Ru}$ calculated using HIVAP. This results in $I_{p}<0.15 \%$ for ${ }^{89} \mathrm{Ru}$ in the one- $\sigma$ limit. No proton branchings ratios are available from ref. [Li99] for comparison. 


\subsection{2 ${ }^{90} \mathrm{Rh}$}

Two half-lives have been associated with the decay of the odd-odd, $N=Z$ nucleus ${ }^{90} \mathrm{Rh}$ by Kienle and co-workers [Kie01]. The shorter value of $12_{-4}^{+9} \mathrm{~ms}$ was associated with a $0^{+} \rightarrow 0^{+}$superallowed Fermi transition. The $0^{+}$state in ${ }^{90} \mathrm{Rh}$ is predicted to be the ground state [Her97] which leaves the larger measured value of $1.0_{-0.2}^{+0.3} \mathrm{~s}$ assigned to an isomeric decay.

The measurement of $\beta$-delayed proton emission from ${ }^{90} \mathrm{Rh}$ yielded three events in the expected energy region of a $\Delta \mathrm{E}-\mathrm{E}$ plot over a period of 2.7 hours. The results are shown in figure 5.23. A similar calculation to that in section 5.2.1

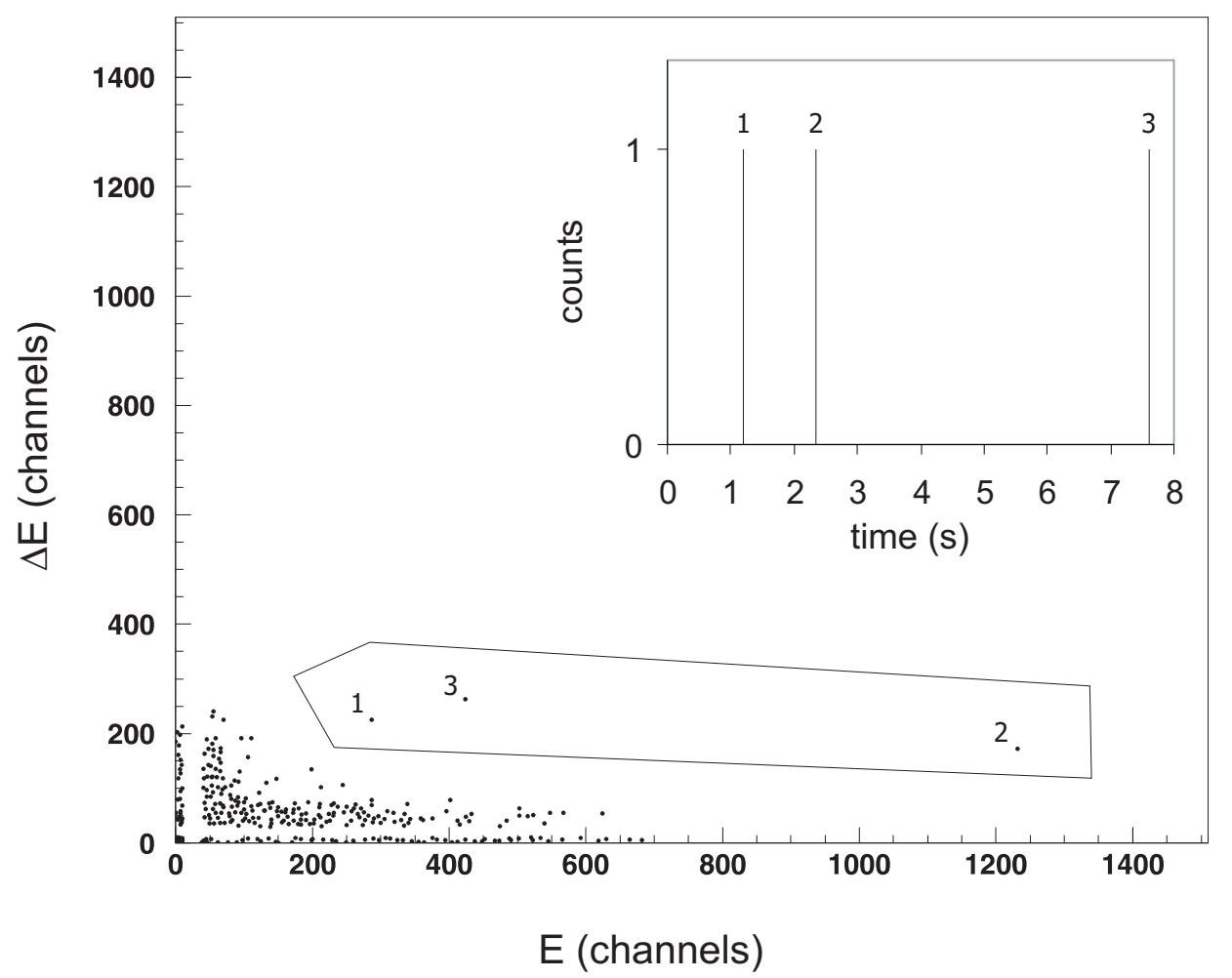

FIG. 5.23: Scatter plot of energy loss in the $\Delta \mathrm{E}$ section of the proton telescope versus the energy loss in the E section which shows up the three $\beta$-delayed proton events from the decay of ${ }^{90} \mathrm{Rh}$. The inset shows the time distribution of the three $\beta \mathrm{p}$ events over a $4 \mathrm{~s}$ beam-on followed by a $4 \mathrm{~s}$ beam off period.

and taking the three proton events as the upper limit gives $I_{p}<0.4 \%$. It was not possible to determine a half-life based on these three events however, based on their time distribution (see figure 5.23 inset), ${ }^{90} \mathrm{Rh}$ ground state decay can be ruled out. The timing of the observed particles is however consistent with decay of a longer living isomeric state. 


\section{Chapter 6}

\section{Discussion}

The results presented in the previous chapter will be discussed in the following sections. The excited states of the measured nuclei are discussed in terms of the shell model and are compared to shell model calculations. The details of these calculations, which were performed with the shell-model code ANTOINE [Cau99], have been discussed earlier in section 2.1.2. The calculations indicated 'GF' use the empirical two-body matrix elements of the residual interaction and the four single particle energies taken from Gross and Frenkel [Gro76]. Here proton and neutron particles are restricted to the $\left(\mathrm{p}_{1 / 2}, \mathrm{~g}_{9 / 2}\right)$ single-particle orbits. The parameters for this interaction were calculated from a fit to the energy levels in ten nuclei with $\mathrm{N}=48,49,50$. The levels labelled ' $\mathrm{S}$ ', refer to calculations performed using the interaction parameters of Sinatkas et al. [Sin92a, Sin92b] who assume a ${ }^{100} \mathrm{Sn}$ inert core and consider proton and neutron holes distributed in the $\mathrm{g}_{9 / 2}$, $\mathrm{p}_{1 / 2}, \mathrm{p}_{3 / 2}$ and $\mathrm{f}_{5 / 2}$ orbitals of that many body system. The model spaces used for each interaction are indicated schematically in figure 6.1. The following section

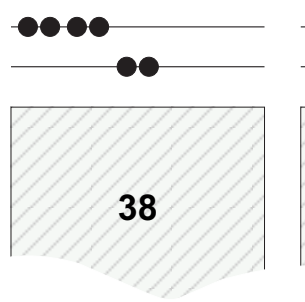

$\pi$

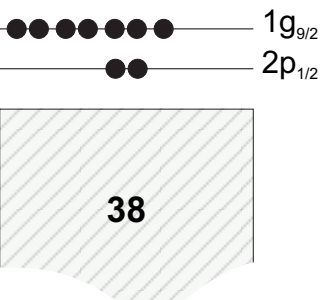

V

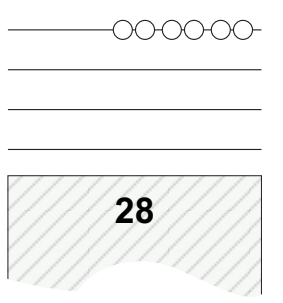

$\pi$

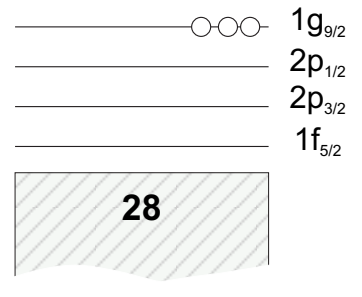

V

Gross-Frenkel

Sinatkas

FIG. 6.1: Model spaces used for shell-model calculations. The ground-state configuration for ${ }_{44}^{91} \mathrm{Ru}_{47}$ is shown in both cases. 
shows a comparison between the half-lives determined in this work and those predicted from the shell-model of Herndl and Brown [Her97]

\subsection{Half-lives}

Proton rich nuclei in the range $\mathrm{A}=86-100$ have also been investigated by Herndl and Brown [Her97] within the $\left(\mathrm{p}_{1 / 2}, \mathrm{~g}_{9 / 2}\right)$ space using the SLGT0 interaction taken from ref. [Ser76] which is essentially identical to that of Gross and Frenkel. Halflives were determined from the calculated Gamow-Teller matrix elements reduced by an orbit-dependent quenching factor $\mathrm{q}=0.4$ where, $(\sigma \tau)_{\text {reduced }}=(1-q)(\sigma \tau)$. The resulting values along with those determined experimentally are included in table 6.1. With the exception of ${ }^{90} \mathrm{Ru}$ and ${ }^{92} \mathrm{Rh}$, the predicted half-lives are in

\begin{tabular}{cccc}
\hline & Present study & Previous work & Theory[Her97] \\
\hline${ }^{93} \mathrm{Rh}$ & $11.9(7)$ & $13.9(16)[\mathrm{Kie} 01]$ & 14.9 \\
${ }^{92} \mathrm{Rh}\left(2^{+}\right)$ & $0.53(37)$ & & 4.30 \\
${ }^{92} \mathrm{Rh}\left(\geq 6^{+}\right)$ & $4.66(25)$ & $5.6(5)[\mathrm{Kie} 01]$ & \\
${ }^{91} \mathrm{Rh}\left(9 / 2^{+}\right)$ & $1.47(22)$ & $1.7(2)[\mathrm{Kie} 01]$ & 1.68 \\
${ }^{91} \mathrm{Rh}\left(1 / 2^{-}\right)$ & $1.46(11)$ & & \\
${ }^{91} \mathrm{Ru}$ & $7.85(40)$ & $9(1)[\mathrm{Kom} 83]$ & 12.3 \\
${ }^{90} \mathrm{Ru}$ & $11.7(9)$ & $11(3)[\mathrm{Zho} 94]$ & 41.5 \\
\hline
\end{tabular}

TABLE 6.1: Experimental half-lives determined in this study along with previous measurements and theoretical predictions where available. All values are in seconds.

remarkably good agreement with those measured although, a general tendency to overestimate the experimental values should be noted. The predicted half-life for ${ }^{92} \mathrm{Rh}\left(2^{+}\right)$state shows a much better agreement with the measured half-life for ${ }^{92} \mathrm{Rh}\left(\geq 6^{+}\right)$than it does with the shorter living $\left(2^{+}\right)$state. 


\subsection{Large scale shell model calculations}

\subsection{1 ${ }^{93} \mathrm{Rh}$ decay}

The unpaired $g_{9 / 2}$ proton is expected to determine the main properties of ${ }^{93} \mathrm{Rh}$. Allowed Gamow-Teller decays from the $9 / 2^{+}$ground state will populate $11 / 2^{+}$, $9 / 2^{+}$and $7 / 2^{+}$states in ${ }^{93} \mathrm{Ru}$. The decay scheme of ${ }^{93} \mathrm{Rh}$ shown in figure 5.3 however shows a $4.2 \%$ feeding to the $\left(13 / 2^{+}\right)$state in ${ }^{93} \mathrm{Ru}$. This apparent forbidden decay was explained briefly in section 4.3 as the result of allowed decays to higher-lying excited states in ${ }^{93} \mathrm{Ru}$ that subsequently decay by $\gamma$ emission down to the states where the de-excitation is observed. The fact that $\beta$ decay of ${ }^{93} \mathrm{Rh}$ proceeds predominantly to the ground state of ${ }^{93} \mathrm{Ru}$ and, that several of the subsequent $\gamma$ lines are already close to their observational limit, as figure 5.1 shows, suggests that $\gamma$ decays feeding the $\left(13 / 2^{+}\right)$state would not necessarily be visible. The shell model calculations seen in figure 6.2 support this explanation. Both the GF and $\mathrm{S}$ calculations show a much higher density of levels accessible in $\beta$ decay than are observed experimentally. In common with two other known $A=$ odd
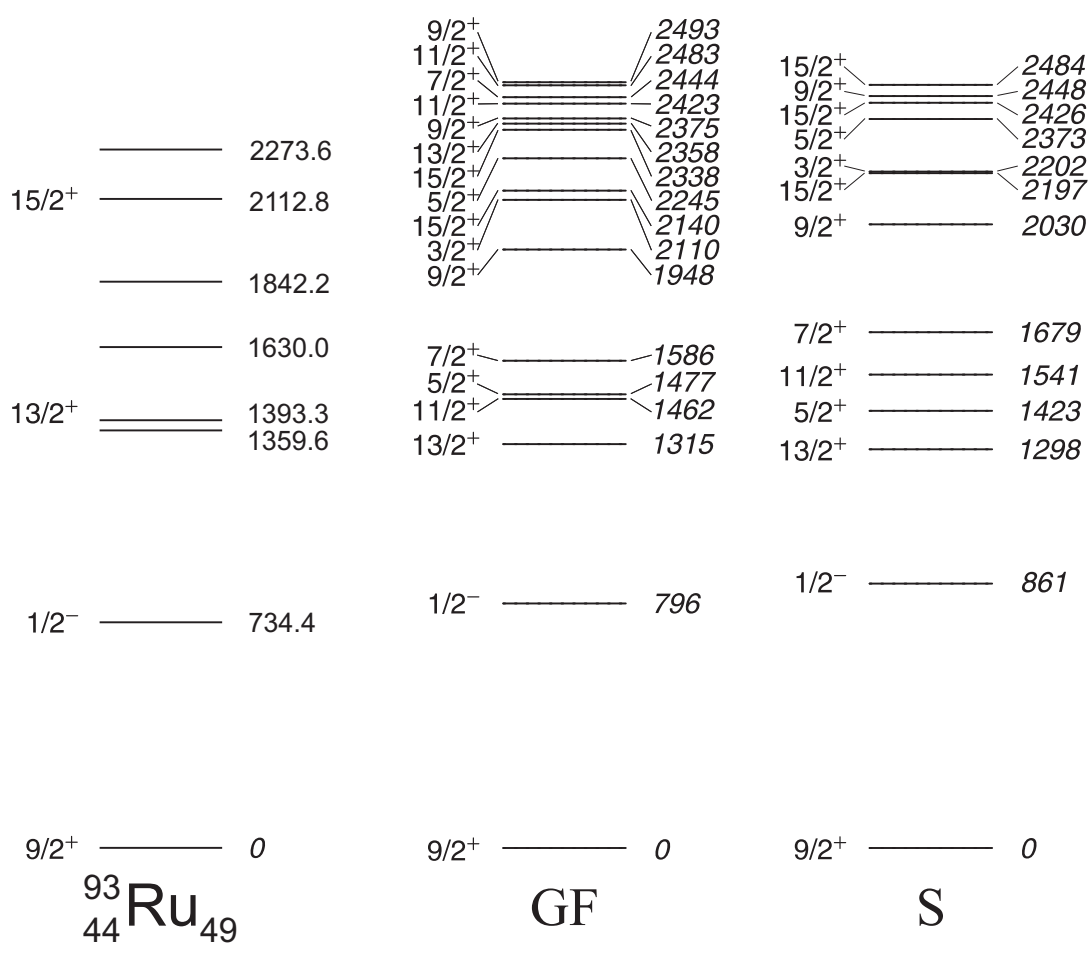

FIG. 6.2: Experimental excited states in ${ }^{93} \mathrm{Ru}$ with shell model predictions. The calculated states include only those with $\mathrm{I}^{\pi} \leq 15 / 2^{+}$below $2.5 \mathrm{MeV}$. The $1 / 2^{-}$and $15 / 2^{+}$ states were not observed in this study. 
$Z \geq 40, N=49$ nuclei ${ }^{89} \mathrm{Zr}$ and ${ }^{91} \mathrm{Mo},{ }^{93} \mathrm{Ru}$ has a $9 / 2^{+}$ground state and an isomeric $1 / 2^{-}$state at less than $1 \mathrm{MeV}$ higher. The experimental level schemes of these nuclei along with the recently measured ${ }^{95} \mathrm{Pd}$ are shown in figure 6.3. The
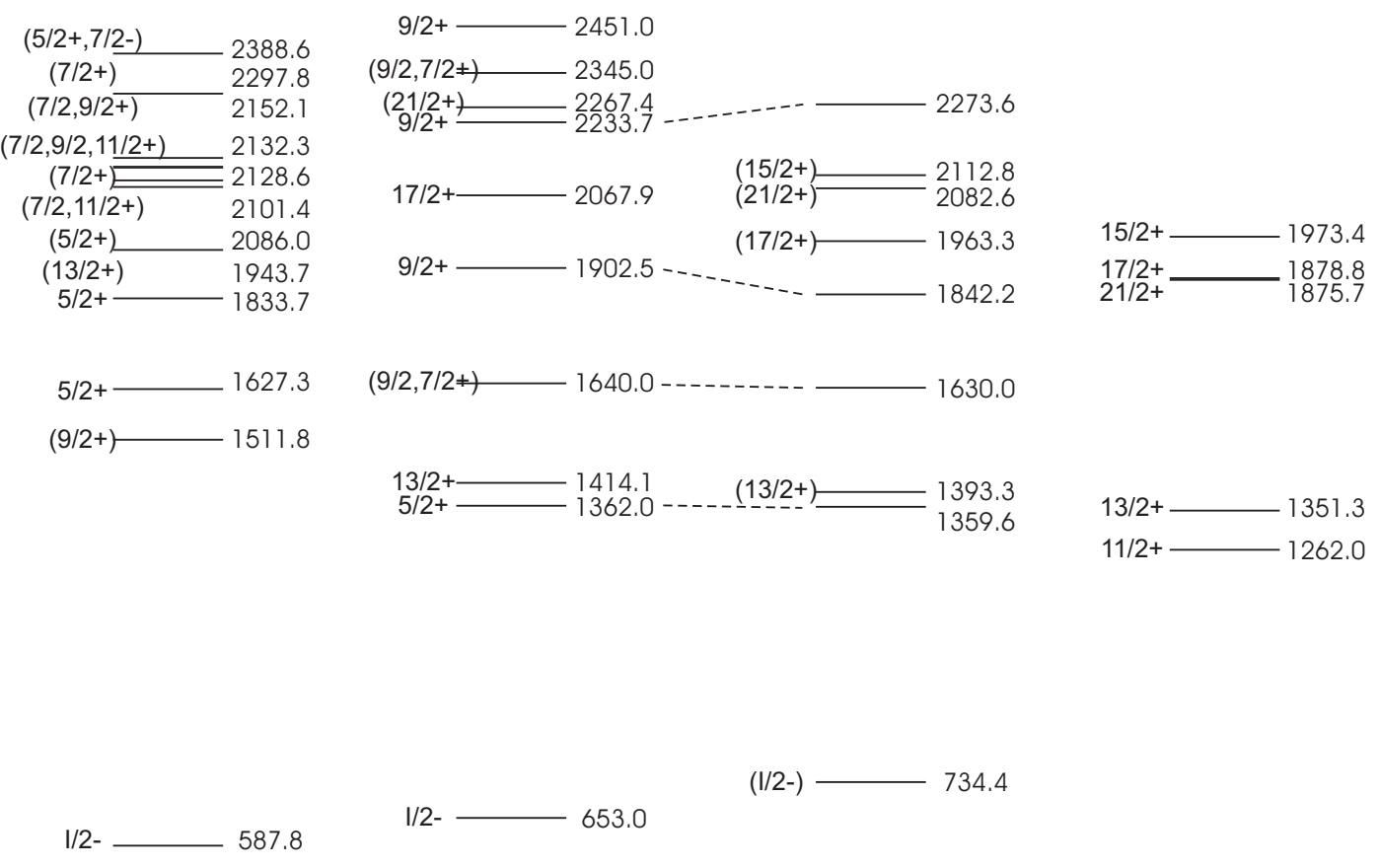

$(\mathrm{I} / 2-)-734.4$

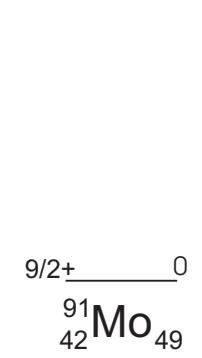

${ }^{9 / 2+}{ }_{44} \mathrm{Ru}_{49}$

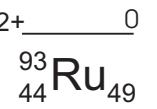

Fig. 6.3: Comparison of the measured level schemes of the $N=49$ isotones with $\mathrm{Z} \geq 40$ : ${ }^{89} \mathrm{Zr}$ [Sin98], ${ }^{91} \mathrm{Mo}$ [Bag99] and ${ }^{95} \mathrm{Pd}$ [Mar03a]. Only positive parity states less than $2.5 \mathrm{MeV}$ and the first excited $1 / 2^{-}$state are included.

lowest-lying states can be understood most simply in terms of the coupling of a $g_{9 / 2}$ and a $p_{1 / 2}$ neutron hole to the $0^{+}$ground state in the corresponding $N=50$ nucleus. The calculated multiplet of states resulting from the single $g_{9 / 2}$ neutron hole coupled to proton $2^{+}$excitations in ${ }^{94} \mathrm{Ru}$ at $1431 \mathrm{keV}$ [Fir96] correspond well with the four states observed between 1 and $2 \mathrm{MeV}$. Because of missing feeding, the $\log f t$ values do not allow too much speculation of the spin assignments for the observed levels however the information in Figs. 6.2 and 6.3 suggest that the $1360 \mathrm{keV}$ state is most likely to have $\mathrm{I}^{\pi}=5 / 2^{+}$or $11 / 2^{+}$. 
The state at $2273 \mathrm{keV}$ with its lower log $f t$ value is a likely candidate for the first excited $9 / 2^{+}$state calculated in both model spaces to lie around $2 \mathrm{MeV}$. A second excited $9 / 2^{+}$, state corresponding to the coupling between the neutron hole and a $0^{+}$state at $2995 \mathrm{keV}$ in ${ }^{94} \mathrm{Ru}$ may also be expected to lie in the vicinity. The remarkable similarity between the level schemes of ${ }^{91} \mathrm{Mo},{ }^{93} \mathrm{Ru}$ and ${ }^{95} \mathrm{Pd}$ in figure 6.3 indicate a conservation of seniority in the $g 9 / 2$ proton shell. Indeed a one-to-one correspondence between the states in ${ }^{91} \mathrm{Mo}$ and ${ }^{93} \mathrm{Ru}$ can be made between the states indicated which differ by no more than $40 \mathrm{keV}$.

The idea that the $\mathrm{p}_{1 / 2}$ and $\mathrm{g}_{9 / 2}$ orbitals are the major players in the construction of the observed excited states is supported by the remarkable similarity between the two shell model calculations. Neither valence space predicts any positive parity state at a lower energy than the $13 / 2^{+}$. The $1 / 2^{-}$and $15 / 2^{+}$states, unobserved in this study, are included in the decay scheme and shell model calculation for comparison. 


\subsection{2 ${ }^{92} \mathrm{Rh}$ decay}

The level scheme of ${ }^{92} \mathrm{Rh}$ as observed by Kast et al. [Kas97] is shown in figure 6.4 with predicted values. The lowest energy excited state observed was assigned by

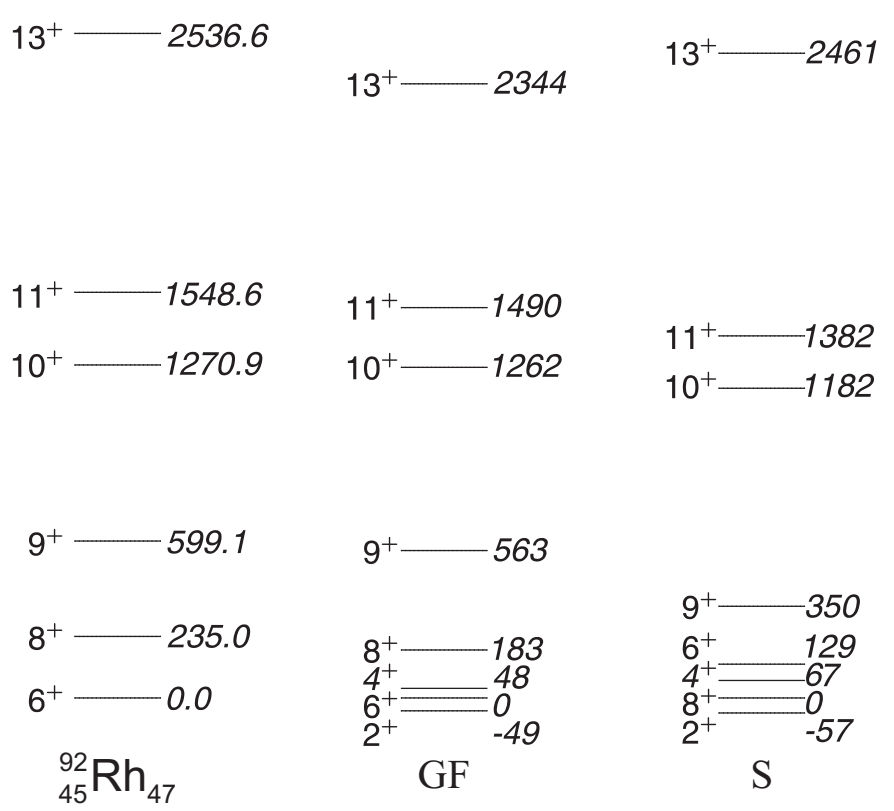

Fig. 6.4: The experimental high-spin level scheme of ${ }^{92} \mathrm{Rh}$ up to $13^{+}$[Kas97] alongside shell model calculations of the yrast states up to the same spin.

these authors as $\left(6^{+}\right)$based on a comparison with shell model calculations using the parameterisation of Gross and Frenkel. The feeding pattern seen in the $\beta$ decay of ${ }^{92} \mathrm{Rh}$ shown in figure 5.9 certainly agrees with a high-spin assignment. However, in view of the fact that the $\left(8^{+}\right)$state in ${ }^{92} \mathrm{Ru}$ at $2838 \mathrm{keV}$ was populated in $\beta$ decay, and that the $\mathrm{S}$ calculation in figure 6.4 shows the lowest high-spin state to be $8^{+}$, the $\beta$ decaying high-spin state in ${ }^{92} \mathrm{Rh}$ has been assigned $\left(\geq 6^{+}\right)$. It should also be noted that two of the nearest neighbours, ${ }^{94} \mathrm{Rh}$ and the $N=47$ isotone ${ }^{90} \mathrm{Tc}$, both have established $8^{+}$ground states [Oxo80, Rud93].

Shell-model calculations for excited states in ${ }^{92} \mathrm{Ru}$ are presented in figure 6.5 and are in good agreement with energies of the experimentally observed states. The agreement is particularly good for the GF calculation where the difference between observed and calculated excitation energy does not exceed $200 \mathrm{keV}$. The calculation using the Sinatkas interaction although still satisfactory, tends to overestimate the excitation energy of all the experimental levels by about $250 \mathrm{keV}$. 


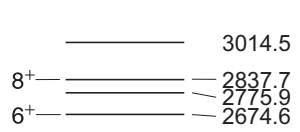

$4^{+} \longrightarrow \quad 1856.8$
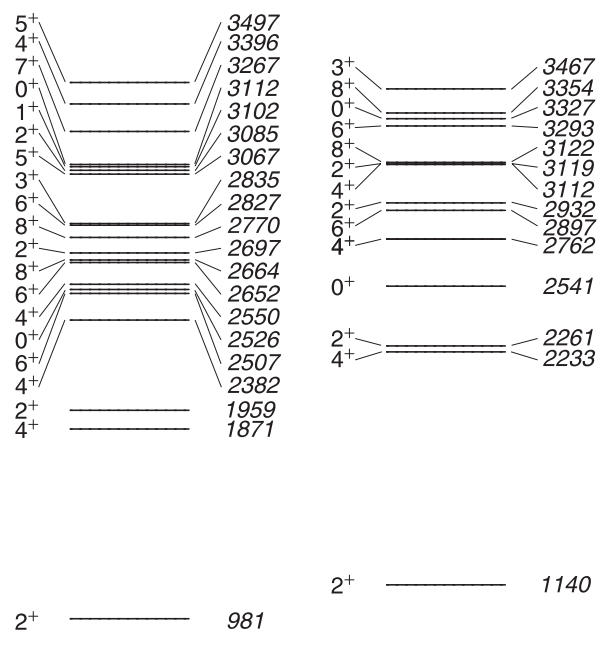

$2^{+}$

865.7

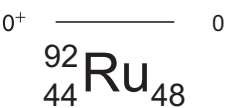

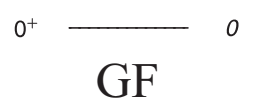

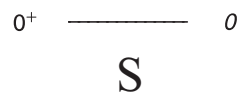

FIG. 6.5: Experimental excited states in ${ }^{92} \mathrm{Ru}$ with shell model predictions. All calculated levels below $3.5 \mathrm{MeV}$ with $\mathrm{I}^{\pi} \leq 10^{+}$are included.

Similar to the $\mathrm{N}=49$ isotones, the systematic behaviour of the known $\mathrm{N}=48$ isotones, shown in Fig 6.6, shows a rather slow evolution in the energies of yrast states with increasing proton number. The behaviour of yrare states is more erratic or rather it appears to be. This may be a result of incomplete level schemes and does not offer any candidates for the two new levels in ${ }^{92} \mathrm{Ru}$ at 2276 and $3014 \mathrm{keV}$. The larger $\log f t$ value for the $2776 \mathrm{keV}$ state and the fact that it is close to the value for the $(4+)$ state at $1857 \mathrm{keV}$, suggests this could be a second $4^{+}$state. A similarly argument suggests the $3014 \mathrm{keV}$ level may be a second $6^{+}$state. The predictions shown in figure 6.5 while they do not support these conjectures, the large density of different spin states means that they cannot be ruled out.

\section{Low-spin isomeric decay in ${ }^{92} \mathrm{Rh}$}

The experimental evidence for a second $\beta$-decaying state in ${ }^{92} \mathrm{Rh}$ presented in section 5.1.2 is corroborated by the shell model calculations shown in figure 6.4. Both calculations predict a $2^{+}$ground state about $50 \mathrm{keV}$ below the high-spin state. This state would be a good candidate for the observed low-spin $\beta$-decaying state. 

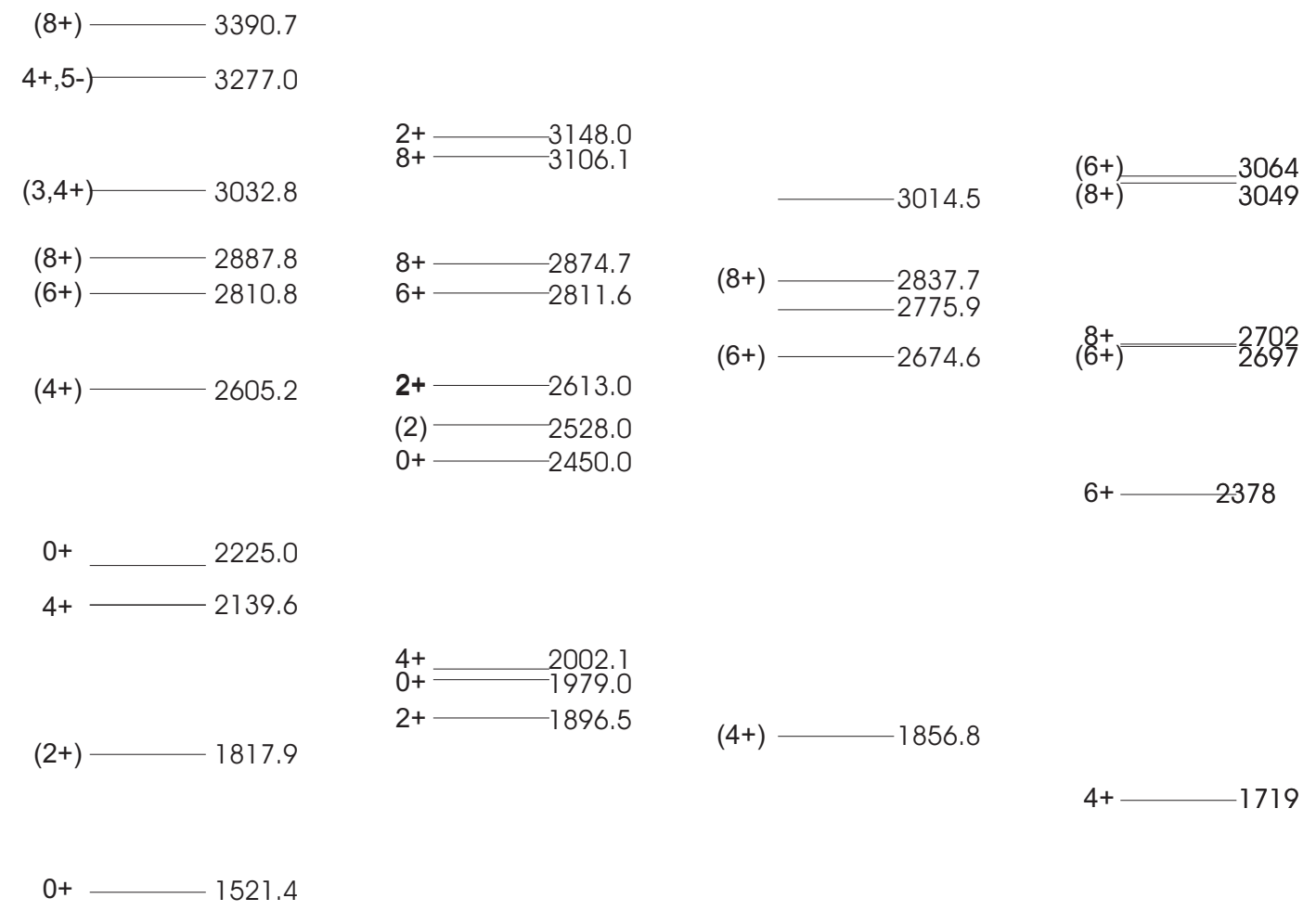

$2+\square 1057.0$

$2+\longrightarrow 948.0$

$(2+) \longrightarrow 865.7$

$2+\square 14$

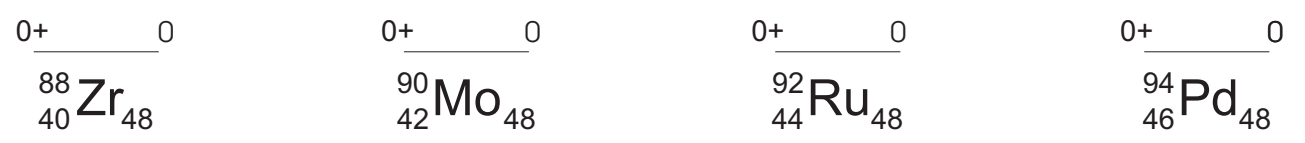

Fig. 6.6: The $\mathrm{A}=$ even, $\mathrm{N}=48$ isotones ${ }^{88} \mathrm{Zr}$ [Mul88], ${ }^{90} \mathrm{Mo}$ [Bro97], ${ }^{94} \mathrm{Pd}$ [Ple04]. Only positive parity states less than $3.4 \mathrm{MeV}$ are shown. 


\subsection{3 ${ }^{91} \mathrm{Rh}$ decay}

Moving further from stability, shell model predictions for levels in ${ }^{91} \mathrm{Ru}$, as shown in 6.8 are less convincing. Configurations of the $\left(\nu g_{9 / 2}\right)^{-3}$ type provide the simplest low lying single particle excitations available to this nucleus. The $\left(13 / 2^{+}\right)$
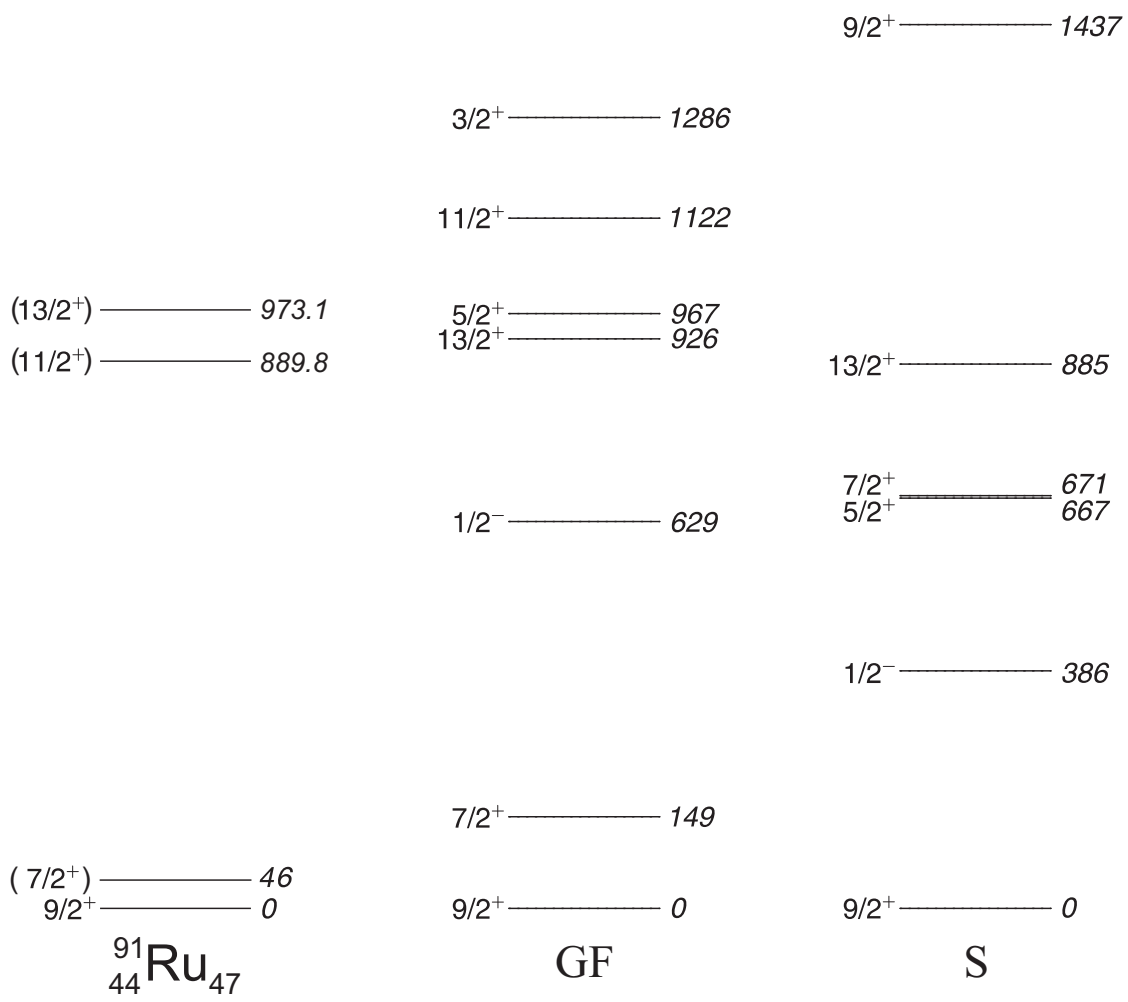

FIG. 6.7: Experimental excited states in ${ }^{91} \mathrm{Ru}$ with shell model predictions. Calculations levels include only those with $\mathrm{I}^{\pi} \leq 15 / 2^{+}$below $1.5 \mathrm{MeV}$.

level at $973 \mathrm{keV}$ which is the only one of the observed lines to be reported in literature prior to this study [Arn93a, Hee94], is well reproduced by both calculations. The line at $890 \mathrm{keV}$, if it is assumed to be the $11 / 2^{+}$seen in the very recent and unpublished data in ref. [Rus04b], is reasonably well reproduced by the GF calculation whereas the $\mathrm{S}$ calculation fails. The energy of the $1 / 2^{-}$isomeric state is expected, on the basis of mass evaluations, to lie around $400 \mathrm{keV}$ above the ground state [Aud97]. The calculation using the parameters of Sinatkas predicts such a state at $386 \mathrm{keV}$ and the GF calculation at $629 \mathrm{keV}$.

The larger discrepancy between experimental and calculated values in this case could be due to the fact that the effective interaction as determined by Sinatkas et al. from $\mathrm{N}=48-50$ nuclei in not correctly applicable in the case of 
this $\mathrm{N}=47$ nucleus. In the more restricted model space, the effect of admixtures to the state wavefunctions from configurations outside the space should not be discounted. There is also the possibility that further from the $\mathrm{N}=50$ closed shell, collective excitations can become important and may influence low lying excited states.

\section{The $387 \mathrm{keV} \gamma$ line}

The first question to be answered regarding the $387 \mathrm{keV}$ line seen in ${ }^{91} \mathrm{Rh}$ singles data is, to which nucleus does it belong? The fact that the line is seen only with the lasers tuned to the excitation scheme of rhodium (figure 5.13(a)) and not ruthenium (fig 5.15) would tend to associate the $387 \mathrm{keV}$ line with rhodium. Following this assumption, the shell model calculations of ${ }^{91} \mathrm{Rh}$, shown in figure 6.8 were performed to explore the possible origins of this decay.

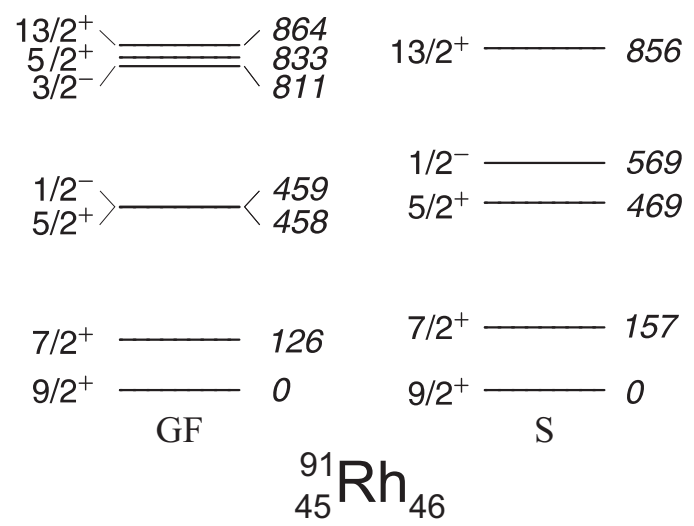

FIG. 6.8: Shell model calculations of excited negative and positive parity states in ${ }^{91} \mathrm{Rh}$ with $\mathrm{I}^{\pi} \leq 15 / 5$ below $1 \mathrm{MeV}$.

A study using the two-body matrix elements of Gross and Frenkel [Gal00] of the $\mathrm{N}=46$ isotones with $\mathrm{Z}=40-44$ show good overall agreement between measured and calculated states. This together with similarity between the two different calculations shown in figure 6.8 may add weight to any conclusions. Both calculations show $1 / 2^{-}$states at around $500 \mathrm{keV}$ above a $9 / 2^{+}$ground state. A number of possibilities thus present themselves; an M4 transition directly to the ground state or an E3 via the $7 / 2^{+}$intermediate state calculated to lie at 126 and $157 \mathrm{keV}$. The slow rate of an M4 transition as predicted by the Weisskopf formula (>70 min) and similar transitions in neighbouring nuclei rules out the first proposition. An E3 transition would be faster, the Weisskopf formula predicts $20 \mu \mathrm{s}-2 \mathrm{~ms}$ however, similar transitions in the neighbouring nuclei show that 
these predictions can grossly underestimate measured values and a wide range of partial half-lives from ms to seconds is observed. The $387 \mathrm{keV}$ line could thus be a candidate for the $\left(1 / 2^{-}\right) \rightarrow\left(7 / 2^{+}\right)$transition with the subsequent $\left(7 / 2^{+}\right) \rightarrow\left(9 / 2^{+}\right)$ transition being too low in energy to be observed. An alternative scenario, that the $387 \mathrm{keV}$ line belongs to a similar de-excitation in ${ }^{91} \mathrm{Ru}$ involves the production of a ${ }^{91} \mathrm{Rh} 1 / 2^{-}$isomeric state which then $\beta$ decays followed by $\gamma$ de-excitation to a $1 / 2^{-}$state in ${ }^{91} \mathrm{Ru}$.

Recent measurements [Rus04b, Mar03b] would appear to offer a way out of this predicament. A negative parity band feeding a $\left(1 / 2^{-}\right)$state in ${ }^{91} \mathrm{Rh}$ at a energy too low to accommodate a $387 \mathrm{keV}$ transition was seen in ref. [Mar03b] effectively ruling out the first proposition that the $387 \mathrm{keV}$ isomeric transition occurs in ${ }^{91} \mathrm{Rh}$. Secondly, a low-lying $\left(7 / 2^{+}\right)$state was seen in ${ }^{91} \mathrm{Ru}$ [Rus04b], indicating the GF calculations in figure 6.8 to be the more reliable and enabling a $\left(1 / 2^{-}\right) \rightarrow\left(7 / 2^{+}\right) \rightarrow\left(9 / 2^{+}\right)$cascade of which, because of its low energy, the $\left(7 / 2^{+}\right) \rightarrow\left(9 / 2^{+}\right)$transition would go unseen in our detection setup. This explanation is illustrated in figure 6.9 .

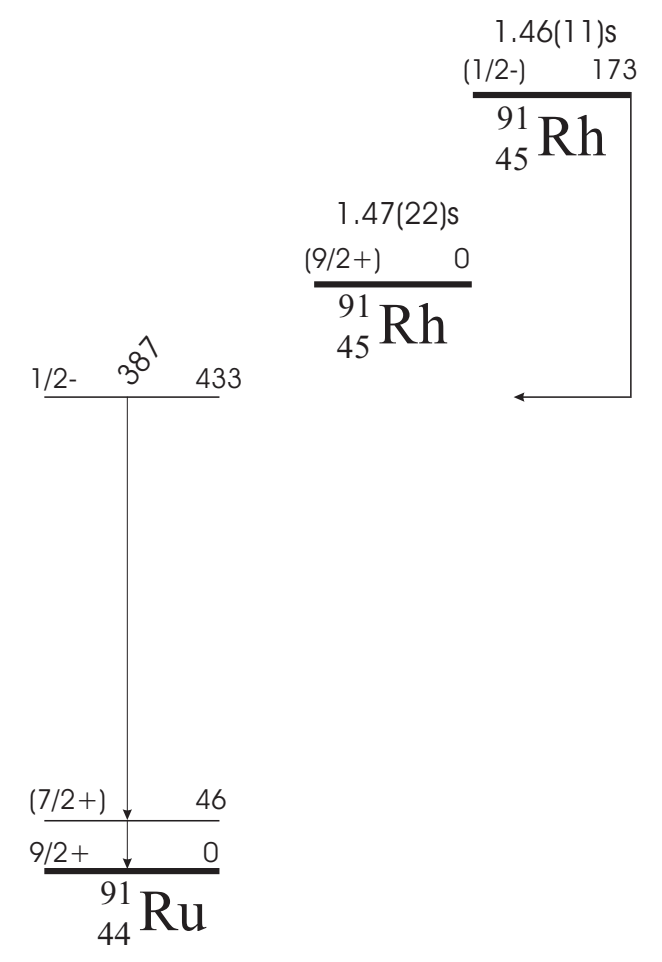

FIG. 6.9: The most likely explanation for the $387 \mathrm{keV}$ line. The $\left(1 / 2^{-}\right)$state in ${ }^{91} \mathrm{Rh}$ was observed in ref. [Mar03b] and the $\left(7 / 2^{+}\right)$state in ${ }^{91} \mathrm{Ru}$ in ref. [Rus04b]. The $1 / 2^{-}$ state at $433 \mathrm{keV}$ has not been observed but is implied by the energies of the observed states. See text for details. 
This leads to the conclusion that the $\left(1 / 2^{-}\right)$isomer in ${ }^{91} \mathrm{Rh}$ is indeed populated in the heavy-ion fusion evaporation reaction and subsequently $\beta$ decays to negative parity states in ${ }^{91} \mathrm{Ru}$. The half-life of this $\left(1 / 2^{-}\right)$state in ${ }^{91} \mathrm{Ru}$ has to be less than $\sim 200 \mathrm{~ms}$ [Kud96, Kud01] as the isomeric transition of $387 \mathrm{keV}$ was not observed when the lasers were tuned to ruthenium (see figure5.15). Furthermore, considering 100 counts to be statistically significant as a peak area in $\beta$-gated spectra around $400 \mathrm{keV}$, the half-life for the $\left(1 / 2^{-}\right)$state must be $\gtrsim 20 \mu \mathrm{s}$. The apparent half-life $(1.46(11) \mathrm{s})$ must originate from the $\beta$ decay of the $\left(1 / 2^{-}\right)$isomer in ${ }^{91} \mathrm{Rh}$. This half-life does not differ significantly from the $\left(9 / 2^{+}\right)$value of $1.47(22) \mathrm{s}$, the three remaining $\gamma$ lines from table $5.3(438,533$ and $821 \mathrm{keV}$ ) cannot therefore be attributed uniquely to either the $\beta$ decay of the $\left(9 / 2^{+}\right)$or the $\left(1 / 2^{-}\right)$isomer. From an extreme shell-model picture, $\operatorname{direct} \beta$ decay to a $1 / 2^{-}$isomer in ${ }^{91} \mathrm{Ru}$ is forbidden, involving as it does the transition $\pi\left(\mathrm{p}_{1 / 2}^{-1}, \mathrm{~g}_{9 / 2}^{6}\right) \nu \mathrm{g}_{9 / 2}^{6} \rightarrow \pi \mathrm{g}_{9 / 2}^{4} \nu\left(\mathrm{p}_{1 / 2}^{-1}, \mathrm{~g}_{9 / 2}^{8}\right)$. As a consequence, limits for the allowed $\left(9 / 2^{+}\right)$ground state to $\left(9 / 2^{+}\right)$ground state decay have been determined depending on whether the three unplaced $\gamma$ rays are assumed to feed either the $\left(1 / 2^{-}\right)$ or the $\left(9 / 2^{+}\right)$states in ${ }^{91} \mathrm{Ru}$ (see figure 6.8 ). Note that these limits could change due to unobserved $\gamma$ rays (see sec. 4.3 ).

Shown alongside its $\mathrm{N}=47$ neighbours in figure 6.10, the proposed energy of $433 \mathrm{keV}$ for a $1 / 2^{-}$state in ${ }^{91} \mathrm{Ru}$ is certainly not incongruous. The $46 \mathrm{keV}$ $\left(7 / 2^{+}\right)$state measured by Rusu et al. [Rus04b] is also consistent with the smooth decrease in the energy of the first excited $7 / 2^{+}$state. 


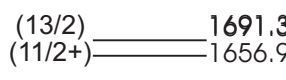

$(11 / 2+) \longrightarrow 1645.8$
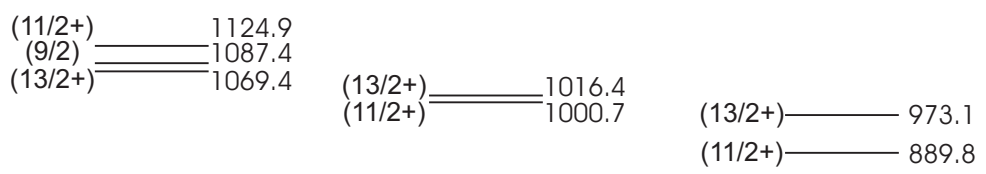

$(13 / 2+)-983.5$

$(7 / 2+) \longrightarrow 801.5$

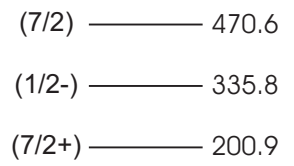

(1/2-)

$-387.5$

(1/2-) -------- 433

${ }^{(9 / 2+)} \frac{}{{ }_{40}^{87} \mathrm{Zr}_{47}} 0$
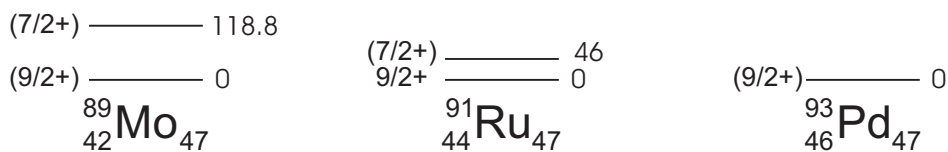

Fig. 6.10: Comparison of the measured level schemes of the $N=47$ isotones with $\mathrm{Z} \geq 40$ : ${ }^{87} \mathrm{Zr}$ [Hel02], ${ }^{89} \mathrm{Mo}$ [Sin98], ${ }^{93} \mathrm{Pd}$ [Rus04a]. Only positive parity states less than $2 \mathrm{MeV}$ and the first excited $1 / 2^{-}$states are included. 


\subsection{4 ${ }^{91} \mathrm{Ru}$ decay}

As was mentioned in section 5.1.3 the ground state of ${ }^{91} \mathrm{Ru}$ has been assigned $\left(9 / 2^{+}\right)$with an isomeric $\left(1 / 2^{-}\right)$state. In an extreme single particle picture, these states result from $\nu g_{9 / 2}^{-3}$ and $\nu p_{1 / 2}^{-1}$ neutron configurations.

The lack of agreement between excited states in ${ }^{91} \mathrm{Ru}$ and shell model predictions has already been discussed in section 6.2.3. The situation for excited states in its daughter ${ }^{91} \mathrm{Tc}$ is somewhat clearer. Due to the close proximity of the $N=50$ closed shell, the structure of states in ${ }^{91} \mathrm{Tc}$ populated in the $\beta$ decay of ${ }^{91} \mathrm{Ru}$ are expected to be readily accounted for in terms of the shell model. A comparison of experimental levels with shell model calculations which is presented in figure 6.11 show that this does indeed appear to be the case.

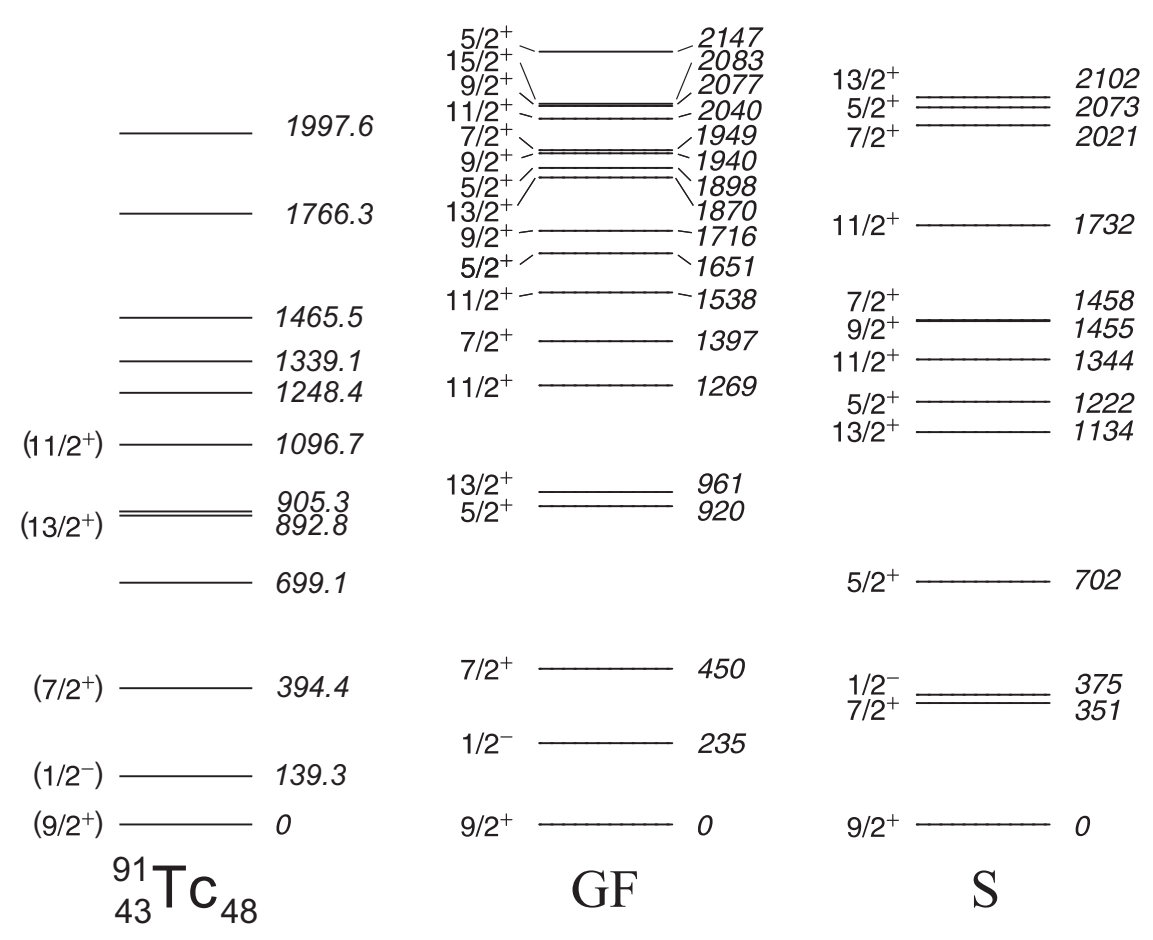

FIG. 6.11: Experimental excited states in ${ }^{91} \mathrm{Tc}$ with shell model predictions. The calculated states include those with $\mathrm{I}^{\pi} \leq 15 / 2^{+}$below $2.2 \mathrm{MeV}$.

The two shell-model calculations both predict the next positive parity state above a $7 / 2^{+}$state to be a $5 / 2^{+}$state. A comparison between the closest $\mathrm{N}=48$ neighbours, presented in figure 6.12, shows a rather smooth evolution of energies with respect levels with proposed spin assignments. The state at $699 \mathrm{keV}$ in ${ }^{91} \mathrm{Tc}$ is thus likely to be a $5 / 2^{+}$state. Regarding the remainder of the unassigned 


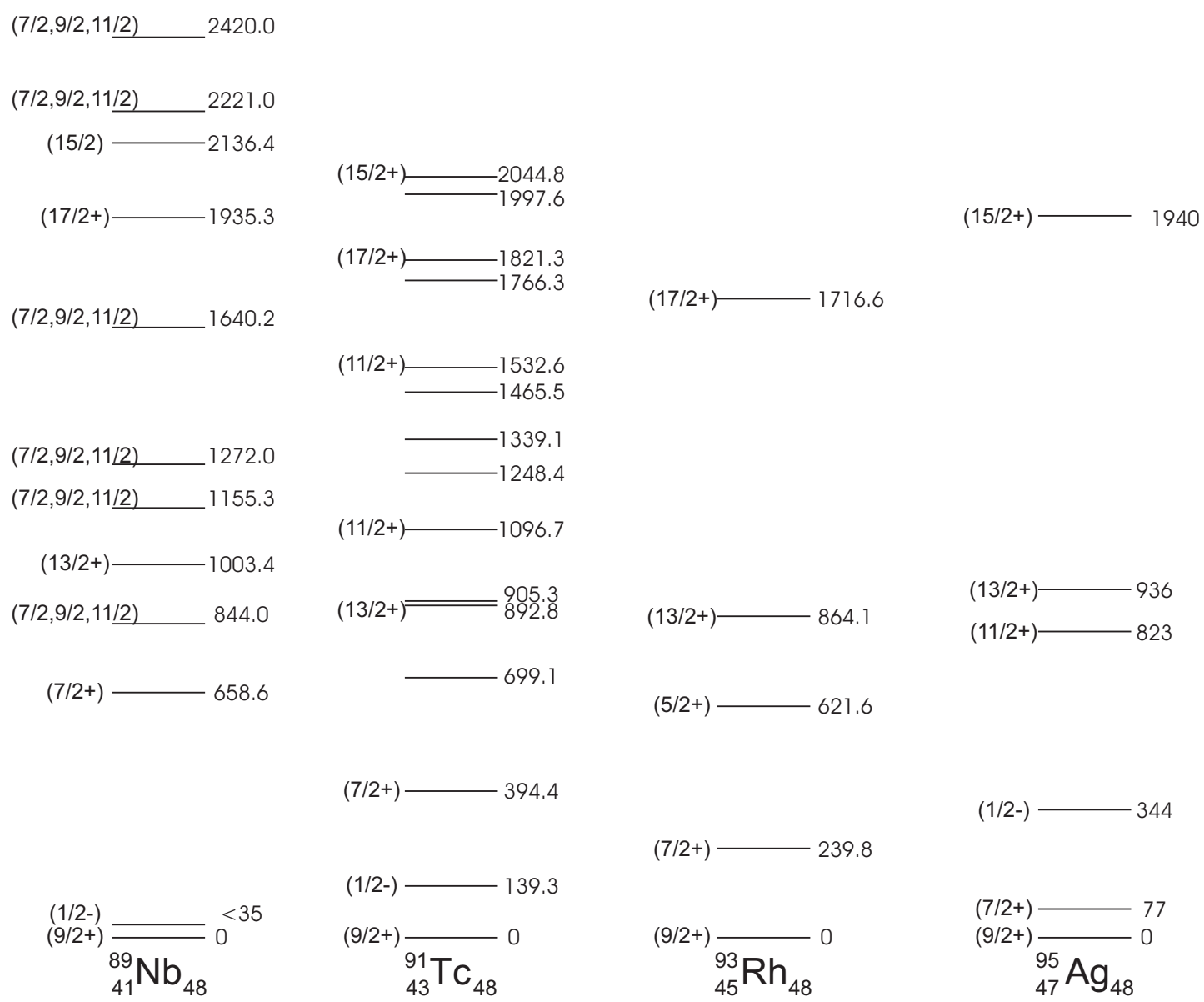

FIG. 6.12: Comparison of the measured level schemes of the $\mathrm{A}=\mathrm{odd}, \mathrm{N}=48$ isotones with $\mathrm{Z} \geq 40:{ }^{89} \mathrm{Nb}$ [Sin98], ${ }^{93} \mathrm{Rh}$ [Rot95][Sch00(a)], ${ }^{95} \mathrm{Ag}$ [Dör03]. Only positive parity states less than $2.5 \mathrm{MeV}$ and the first excited $1 / 2^{-}$states are included.

states in ${ }^{91} \mathrm{Tc}$, inconsistencies between the two shell-model calculations as well as rather sparse information on the neighbouring isotopes make further speculation unsafe. 


\subsection{5 ${ }^{90} \mathrm{Ru}$ decay}

Regarding the odd-odd nucleus ${ }^{90} \mathrm{Tc}$, the first property to be discussed is its ground state spin. The $\pi g_{9 / 2}$ and $\nu g_{9 / 2}$ can couple to spins $\mathrm{I}^{\pi}=0^{+}$to $9^{+}$of which it is argued, $8^{+}$is the ground state [Rud93]. A study by Oxorn and Mark [Oxo81] identified two $\beta$-unstable states, a $1^{+}$and a $\left(6^{+}\right)$of which they claim the $1^{+}$to be the ground state. The shell model calculations in figure 6.13 reproduce well the experimental data of Rudolph et al. [Rud93] for excited states in ${ }^{90} \mathrm{Tc}$ below $2 \mathrm{MeV}$.

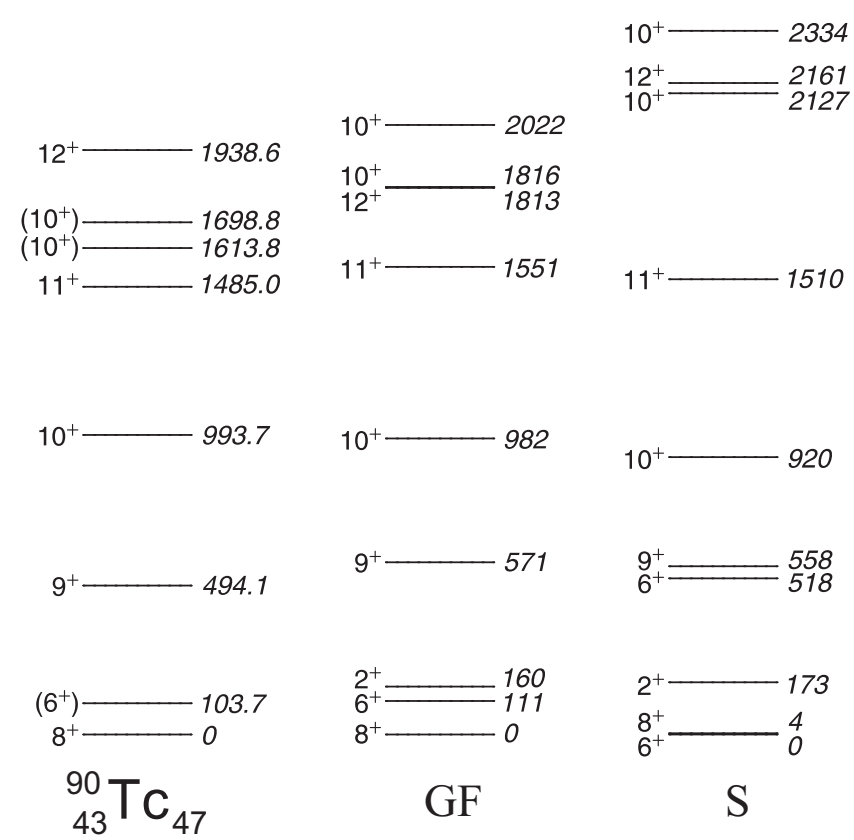

FiG. 6.13: The experimental high-spin level scheme of ${ }^{90} \mathrm{Tc}$ up to $12^{+}$[Rud93] together with shell model calculations. Only yrast states from the calculations are included with the exception of the $10^{+}$where addition states are added to correspond with the observed levels. The calculated low lying $2^{+}$states are included to show their position with respect to the ground state ( $c f$ figure 6.14).

All observed states are accounted for in the calculation with a difference, in most cases, of less than $100 \mathrm{keV}$. Both calculations favour a high spin ground state and proffer a $2^{+}$at around $160 \mathrm{keV}$ as a candidate for a low spin isomer. However the apparent strong feeding to this state conflicts with a $2^{+}$assignment. Clearly more experimental data is needed for this nucleus.

The good agreement between theory and experiment at high spin makes the situation at low spin all the more uncertain. The calculations shown next to the 

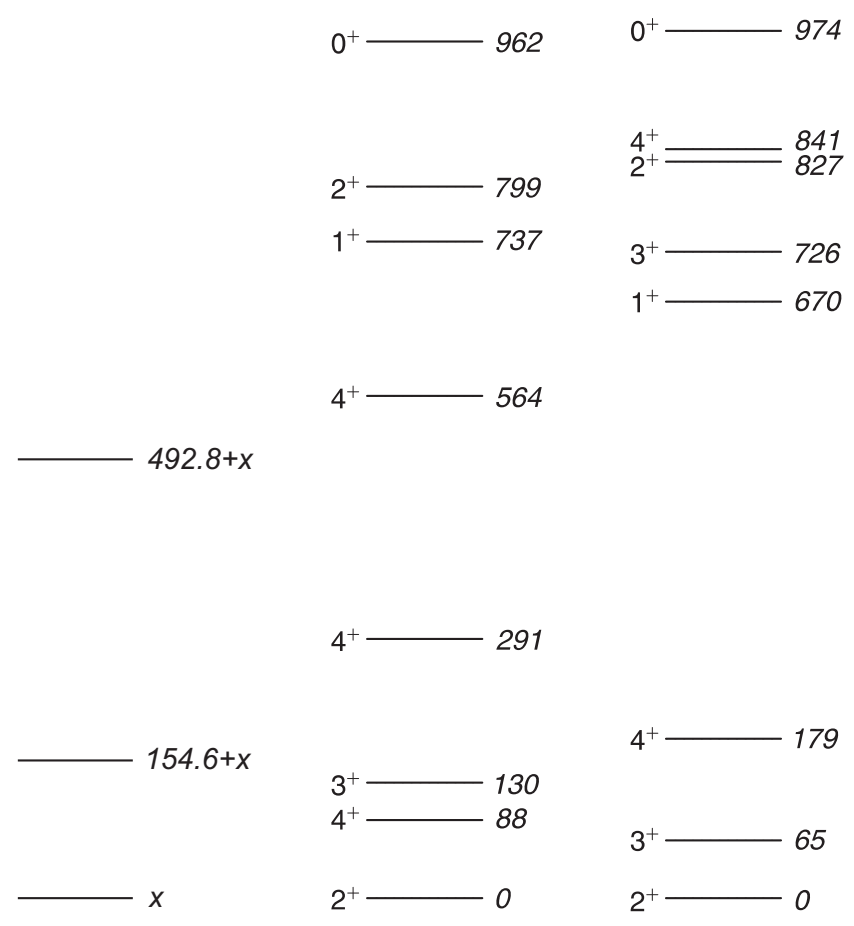

${ }_{43}^{90} \mathrm{TC}_{47}$

GF

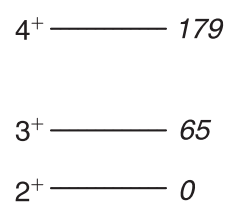

$\mathrm{S}$

FIG. 6.14: Experimental excited states in ${ }^{90} \mathrm{Tc}$ alongside shell model calculations. The calculated levels include only those with $\mathrm{I}^{\pi} \leq 4^{+}$below $1 \mathrm{MeV}$. The lowest lying observed level is aligned to the $2^{+}$states seen in figure 6.13 and since this is almost certainly not the ground state, the observed level energies are quoted as relative to ' $\mathrm{x}$ '.

decay scheme in figure 6.14 include levels with $\mathrm{I}^{\pi} \leq 4^{+}$with energies below $1 \mathrm{MeV}$. The lowest lying $2^{+}$levels are those in figure 6.13 at $\sim 160 \mathrm{keV}$. The $1^{+}$levels calculated to lie around $700 \mathrm{keV}$ may correspond to the observed $492.8+\mathrm{x} \mathrm{keV}$ level however, the calculated lower levels are unable to provide a candidate for the $154.6+\mathrm{x} k \mathrm{kV}$ level which the observed feeding suggests has a spin and parity no greater than $2^{+}$. The large discrepancy indicates a major weakness in the shellmodel description of the low-spin states in ${ }^{90} \mathrm{Tc}$. It is at present not apparent what the cause of this might be. 


\section{$6.3 \beta$-delayed proton activity}

Moving closer to the proton drip line, $\beta$-delayed proton emission becomes more energetically favourable. Based on the large amount of energy available for $\beta$ delayed proton emission in ${ }^{89} \mathrm{Ru}$ and ${ }^{90} \mathrm{Rh}$ which is calculated in table 6.2 significant feeding to proton emitting states in the daughter nucleus is expected for these nuclei,

\begin{tabular}{ccccc}
\hline \hline & $\begin{array}{c}\mathrm{t}_{1 / 2}(\mathrm{~s}) \\
{[\text { Kie01] }}\end{array}$ & $\begin{array}{c}\mathrm{Q}_{E C} \\
(\mathrm{keV})\end{array}$ & $\begin{array}{c}\mathrm{S}_{p} \\
(\mathrm{keV})\end{array}$ & $\begin{array}{c}\mathrm{Q}_{E C}-\mathrm{S}_{p} \\
(\mathrm{keV})\end{array}$ \\
\hline${ }^{89} \mathrm{Ru}$ & $1.5 \pm 0.2$ & 7980 & 2080 & 5900 \\
${ }^{90 m} \mathrm{Rh}$ & $1.0_{-0.2}^{+0.3}$ & 12190 & 5200 & 6990 \\
\hline \hline
\end{tabular}

TABLE 6.2: Measured half-lives and energies involved in the $\beta$-delayed proton emission of ${ }^{89} \mathrm{Ru}$ and ${ }^{90} \mathrm{Rh} . \mathrm{Q}_{E C}$ and $\mathrm{S}_{p}$ values are calculated from mass excesses taken from ref. [Aud97].

\subsection{1 ${ }^{89} \mathrm{Ru}$ decay}

The fact that no protons were observed from the decay of ${ }^{89} \mathrm{Ru}$ may indicate that the greater part of the $\beta$ decay of this nucleus does not proceed to highly excited proton emitting states in the daughter nucleus ${ }^{89} \mathrm{Tc}$. The data in ref. [Li99] would appear to suggest population of the $2^{+}$and $4^{+}$states in ${ }^{88} \mathrm{Mo}$ which would tend to identify the $9 / 2^{+}$predicted ground state of ${ }^{89} \mathrm{Ru}$ [Aud97] as the precursor.

\subsection{2 ${ }^{90} \mathrm{Rh}$ decay}

Two half-lives have been identified with the decay of ${ }^{90} \mathrm{Rh}$ in ref. [Kie01]. The data collected in this work indicate decay of the longer living $1.0_{-0.2}^{+0.3} \mathrm{~s}$ isomeric state as opposed to the shorter $12_{-4}^{+9} \mathrm{~ms}$ state that the authors claim as a fast superallowed Fermi transition. Shell model calculations of states in ${ }^{90} \mathrm{Rh}$ in ref. [Her97] and this work do indeed predict a $0^{+}$ground state with the next excited state being a $2^{+}$at $\sim 900 \mathrm{keV}$ higher. The search for candidates for the $\beta$-decaying isomeric state may centre on a $5^{+}, 7^{+}, 9^{+}$group of states above the $2^{+}$state at energies between 1.1 and $1.6 \mathrm{MeV}$ in each of the calculations. 


\section{Chapter 7}

\section{Conclusions and outlook}

To summarise, elemental laser ionisation of reaction products, from heavy-ion fusion evaporation, thermalised within a gas cell has been employed to produce the neutron deficient ${ }^{91,92,93} \mathrm{Rh}$ and ${ }^{90,91} \mathrm{Ru}$ isotopes. The decay schemes have been determined from measurement of $\beta$-delayed $\gamma$ decays and are discussed in terms of the shell model. Calculations were performed using the shell model code ANTOINE and with the interactions parameters of Gross and Frenkel as well as those in the larger model space of Sinatkas. With the exceptions of ${ }^{90} \mathrm{Tc}$ and to a lesser extent ${ }^{91} \mathrm{Ru}$, the observed excited states are well reproduced by the calculations. Addition data on ${ }^{90} \mathrm{Tc}$ and ${ }^{91} \mathrm{Ru}$ would certainly elucidate the situation however, the considerable discrepancy between the GF and S calculations may be improved with the inclusion of new experimental information especially on the low-spin nonyrast states. The half-lives of the measured nuclei have been determined from fits to the time behaviour of their $\gamma$ lines. Feature measurements include the lifetime and decay scheme of a low-spin $\beta$-decaying state in ${ }^{92} \mathrm{Rh}$. By combining our data with recent in-beam measurements [Rus04b, Mar03b], the $\beta$ decay of a $\left(1 / 2^{-}\right)$isomer populating eventually a $387 \mathrm{keV}$ isomeric transition in ${ }^{91} \mathrm{Ru}$ has been observed.

As a complement to the measurements on $\beta$-delayed $\gamma$ activity, a study of $\beta$ delayed proton activity was undertaken. These measurements were taken during a later experimental run in which technical difficulties led to rather low productions. However, upper limits for the branchings to proton emitting states in their daughter nuclei were determined for the ${ }^{90} \mathrm{Rh}$ and ${ }^{89} \mathrm{Ru}$ precursors.

This work has demonstrated the successful application of on-line separation in combination with isotope production inside a gas cell to the neutron deficient nuclei described here. The advent of high-efficiency detector technology [Hab97] 
along with developments in radioactive ion beams anticipates continued work in this region and possible access to more exotic species in the direction of ${ }^{100} \mathrm{Sn}$. 


\section{Samenvatting}

\section{Inleiding en motivatie}

De doelstelling van de hedendaagse kernfysica is het verkrijgen van een volledige beschrijving van de interacties tussen de nucleonen, deze zou alle eigenschappen van atomaire kernen moeten uitleggen die we experimenteel observeren. De eigenschappen van de atoomkeren zijn een combinatie van de elektromagnetische, sterke en zwakke interacties die plaatsvinden binnen een eindig deeltjessysteem. Door verschillende gebieden van de kernkaart te onderzoeken kunnen een aantal aspecten van deze interacties versterkt of verzwakt worden.

Fysische systemen willen steeds een punt bereiken waarop ze de laagste energie hebben, en atoomkernen vormen hierop geen uitzondering. Er zijn twee manieren waarop atoomkernen de meest stabiele configuratie kunnen bereiken. Een geëxciteerde kern kan fotonen uitsturen in de vorm van $\gamma$ stralen en zodoende door elektromagnetische de-excitatie de laagst energetische toestand, de grondtoestand, bereiken. Ook kan een atoomkern door het uitsturen van een aantal deeltjes veranderen in een andere, meer stabiele atoomkern. In dit werk vervallen exotische atoomkernen, die geproduceerd worden in hetzij de grondtoestand of een metastabiele toestand, door het uitsturen van betadeeltjes naar toestanden in de dochterkern. De halfwaardetijden, energieniveaus, vervalschema's en vertakkingswaarschijnlijkheden werden voor elk van de bestudeerde kernen bepaald.

Studies van kernen dichtbij dubbel-magische schillensluitingen vormen belangrijke testgebieden voor kernmodellen zoals het schillenmodel aangezien de eigenschappen van deze kernen vaak kunnen beschreven worden in termen van een koppeling van een beperkt aantal valentiedeeltjes aan een inerte dubbelmagische kern. De nabijheid van ${ }^{100} \mathrm{Sn}$ voor de kernen bestudeerd in dit werk maakt schillenmodelberekeningen mogelijk, dit laat toe om een volledige vergelijking te maken van niet enkel de niveauschema's maar ook van elektromagnetische transitiesnelheden en Gamow-Teller sterktes die beduidend kleiner zijn dan verwacht.

In de meeste atoomkernen bezetten de valentieprotonen en -neutronen ver- 
schillende schillen, bijgevolg worden de paringsinteracties tussen de protonen en neutronen onderdrukt. Echter, in het gebied rond $N=Z$ bezetten de valentiedeeltjes dezelfde orbitalen en men verwacht verhoogde deeltjesinteracties ten gevolge van deze hoge ruimtelijke overlap tussen de ééndeeltjesgolffuncties. De belangrijkste interactie is de paringsinteractie waarover we het meest kennen uit de studie van atoomkernen met een vrij groot neutronoverwicht waar n-n en p-p paren gekoppeld tot totale isospin $T=1$ (spins antiparallel georiënteerd), domineren. Twee identieke deeltjes kunnen onmogelijk dezelfde set van quantumnummers hebben en zodoende moeten nucleonen met hetzelfde angulair moment tegengestelde spins hebben. Deze beperkingen gelden niet voor niet-identieke nucleonen en dus voor kernen dicht bij de $N=Z$ lijn, in deze kernen verwacht men competitie tussen de valentiedeeltjes gekoppeld tot isospin $T=0$ (spins parallel georiënteerd) en de gebruikelijke $T=1$ paring tussen gelijkaardige nucleonen. De effecten van verhoogde $T=0$ paring manifesteren zich op een aantal manieren. De grotere interactiesterkte van een $T=0$ paar in vergelijking met die van een $T=1$ paar kan leiden tot een $T=0$ toestand voor de grondtoestand van oneven-oneven $N=Z$ atoomkernen in het gebied van ${ }^{100} \mathrm{Sn}$. Bij hogere spinwaarden doet de Coriolis interactie, die een verschillende kracht uitoefent op elk van de twee deeltjes gekoppeld tot $J=0^{+}$, een nucleonenpaar opbreken door beide nucleonspins langs de rotatie-as op te lijnen. De parallelle spinoriëntatie van het $T=0$ paar resulteert erin dat deze configuratie tot hogere waarden van angulair moment kan overleven, hierdoor wordt het fenomeen van 'backbending' uitgesteld tot hogere spinwaarden. Met meer informatie over deze p-n interacties en over de paringsinteractie tussen nucleonen van dezelfde soort kunnen we een beter inzicht verkrijgen in de residuele interactie in de atoomkern.

De studie van neutronarme atoomkernen in dit gebied heeft ook belangrijke gevolgen voor de astrofysica. Het snelle protonvangst (rp) proces dat een pad volgt langsheen atoomkernen in de buurt van $N=Z$ voor $A=60-100$, speelt een cruciale rol gedurende het proces van waterstofverbranding bij hoge temperaturen en dichtheden aan het oppervlak van neutronensterren.De halfwaardetijden van atoomkernen in dit gebied zijn belangrijke factoren voor het bepalen van de tijdschaal van dit rp proces, het voortbrengen van energie en de resulterende overvloed van atoomkernen. De halfwaardetijden bepaald in deze studie werden vergeleken met de theoretische berekeningen van Herndl en Brown waar ze afgeleid zijn van berekende Gamow-Teller sterktes. 


\section{Experimentele methoden en resultaten}

\section{De productie van exotische atoomkernen}

De neutronarme rhodium en ruthenium kernen bestudeerd in dit werk werden geproduceerd in de ${ }^{58} \mathrm{Ni}\left({ }^{36,40} \mathrm{Ar}, \mathrm{x} n \mathrm{y} p\right)$ fusie-evaporatie reactie aan de Louvain-laNeuve cyclotron faciliteit in België. Ze werden vervolgens naar massa gescheiden aan de Lisol opstelling. Bundels van ${ }^{36(40)} \mathrm{Ar}^{10+(11+)}$ met een stroomsterkte van typisch $1 \mathrm{e} \mu \mathrm{A}$ verlaten het cyclotron met een energie tussen 235 en $255 \mathrm{MeV}$. Een set van tantalum folies van variabele dikte kan in de bundellijn geplaatst worden om de uiteindelijke bundelenergie te tunen. Een nikkel trefschijf wordt in de gascel geplaatst en reactieproducten die teruggestoten worden uit de trefschijf worden gestopt en geneutaliseerd binnenin de cel door het argon buffergas. Twee kleurstoflasers schijnen door de gascel om op een selectieve manier het element van interesse te ioniseren door het exciteren van atomaire elektronen. De inhoud van de gascel wordt dan richting uitgang getrokken en de laser geïonizeerde kernen en de overige overlevende kernen worden naar de massascheider geleid door een sextupool ionengeleider. De resulterende bundel wordt vervolgens geïmplanteerd in een beweegbare tape in het centrum van de detectie-opstelling. Deze laatste bestaat uit twee germanium detectoren van een hoge zuiverheidsgraad voor het detekteren van $\gamma$ stralen, deze staan opgesteld rond $\beta$-gevoelige plastic $\Delta \mathrm{E}$ detectoren. Data werden verzameld in singles en coïncidentie mode door middel van macrocyclussen, een bundel-aan periode gevolgd door een bundel-af periode om zo nauwkeurig mogelijk halfwaardetijden te kunnen bepalen. Geant simulaties werden gebruikt om de detectie-efficiëntie van de germanium detectoren te bepalen voor verschillende $\gamma$-straal energieën.

Een vergelijking van data genomen met en zonder lasers werd in eerste instantie gebruikt om $\gamma$-straal overgangen te bepalen die toebehoren aan het verval van atoomkernen die resonant geproduceerd zijn. $\gamma$ lijnen werden vervolgens geassocieerd aan het verval van een bepaald isotoop op basis van hun halfwaardetijdgedrag, en indien mogelijk op basis van $\gamma$ - $\gamma$ coïncidenties. Betavervalvoeding naar de grondtoestand van de dochterkern werd bepaald met behulp van de 511 $\mathrm{keV}$ annhiliatielijn.

Voor het meten van $\beta$-vertraagd protonverval werd de naar massa gescheiden bundel geimplanteerd in dunne koolstoffolies geplaatst voor een $\Delta \mathrm{E}-\mathrm{E}$ Si telescoopsysteem geleend van het GSI. De hoge efficiëntie van dergelijke detectiesystemen gecombineerd met de toenemende waarschijnlijkheid van dit type verval naargelang men de druppellijn nadert maakt van deze methode een krachtig mid- 
del om kernstruktuurinformatie te bekomen in gevallen waar de huidige productieaantallen $\gamma$-straalspectroscopie uitsluiten. Het telescoopsysteem werd geplaatst in een vacuümkamer verbonden met de bundellijn, een hoog-zuivere Ge-detector werd er onmiddellijk achter opgesteld.

\section{Resultaten van de $\beta$-verval metingen}

Bovenop een toestand gekend van in-bundelstudies, voegde deze eerste $\beta$-vervalmeting van ${ }^{93} \mathrm{Rh}$ zes bijkomende $\gamma$ lijnen toe aan het schema van ${ }^{93} \mathrm{Ru}$. Een halfwaardetijd van 11.9(7) s werd berekend van een fit van het tijdsgedrag van alle zeven lijnen. Het niveauschema van ${ }^{92} \mathrm{Ru}$ werd in deze studie uitgebreid en verder ontwikkeld door het toevoegen van drie $\gamma$ lijnen en hun respectievelijke niveaus evenals de voeding naar deze niveaus. Tegenstrijdigheden in de geobserveerde voeding naar de $2^{+}$toestand in ${ }^{92} \mathrm{Ru}$ evenals het halfwaardegedrag van de $2^{+} \rightarrow$ grondtoestand transitie leidde tot het bepalen van een lage spin $\beta$-vervallende toestand in ${ }^{92} \mathrm{Rh}$ met een halfwaardetijd van $0.53(37) \mathrm{s}$.

De eerste $\beta$-verval meting van ${ }^{91} \mathrm{Rh}$ leverde vijf $\gamma$ lijnen op in het $\beta$-gated spectrum. Twee van deze transities werden geobserveerd in een eerdere inbundelstudie en de halfwaardetijd van het verval van de grondtoestand van ${ }^{91} \mathrm{Rh}$ werd bepaald op 1.47(22) s gebaseerd op deze twee transities. Enkelvoudige spectra vertoonden een isomere transitie op $387 \mathrm{keV}$ die gevoed werd door een $1.46(11)$ s verval dat niet gezien werd in de $\beta$-gated spectra of zonder de lasers getuned op rhodium.

Elf nieuwe $\gamma$ lijnen werden toegevoegd aan het vervalschema van ${ }^{91} \mathrm{Ru}$. Een halfwaardetijd van 7.85(40) s werd toegewezen op basis van een fit aan het tijdsverloop van de meest intense $394 \mathrm{keV}$ lijn.

Metingen van het $\beta$ verval van ${ }^{90} \mathrm{Ru}$ naar ${ }^{90} \mathrm{Tc}$ produceerden twee lijnen in de $\beta$-gated spectra. Een vorig experiment zonder massascheiding zag deze twee lijnen tesamen met 36 andere. De onzekerheid op de grondtoestand van ${ }^{90} \mathrm{Tc}$ en zijn relatie tot de laagste toestand bevolkt in het verval van ${ }^{90} \mathrm{Ru}$ konden niet vastgesteld worden en de energieniveaus konden enkel relatief ten opzichte van elkaar bepaald worden.

\section{Resultaten van de $\beta$-vertraagde protonemissiemetingen}

Data genomen op ${ }^{89} \mathrm{Ru}$ faalden voor het produceren van protonen, dit resultaat is inconsistent met een vorige meting uitgevoerd zonder massascheiding. Een bovenlimiet voor de $\beta$-vertraagde protonvertakkingswaarschijnlijkheid werd bepaald op 
$I_{p}<0.15 \%$ gebruik makend van de ${ }^{89} \mathrm{Ru}$ productiesnelheid afgeleid van de voorspelde werkzame doorsnede. De meting van de $\beta$-vertraagde protonemissie van ${ }^{90} \mathrm{Rh}$ leverde drie gebeurtenissen op over een periode van 2.7 uur. Indien men de drie gebeurtenissen als een bovenlimiet neemt geeft dit $I_{p}<0.4 \%$. Twee halfwaarden werden geassocieerd met het verval van ${ }^{90} \mathrm{Rh}$ en de tijdsverdeling van de drie gebeurtenissen is consistent met het verval van de langer levende isomere toestand.

\section{Discussie}

Schillenmodelberekeningen werden uitgevoerd met de ANTOINE code gebruik makend van de interactieparameters van Gross en Frenkel die empirisch bepaald werden voor de $p_{1 / 2}$ en $g_{9 / 2}$ orbitalen. Een realistische interactie afgeleid van nucleon-nucleon verstrooiingsmetingen en geëvalueerd in de grotere $f_{5 / 2}, p_{3 / 2}, p_{1 / 2}, g_{9 / 2}$ ruimte door Sinatkas en medewerkers werd ook gebruikt. Deze berekeningen werden vergeleken met de experimentele resultaten.

De laagst-gelegen toestanden bevolkt in het verval van ${ }^{93} \mathrm{Rh}$ kunnen het makkelijkst geïnterpreteerd worden in termen van de koppeling van een $g_{9 / 2}$ en een $p_{1 / 2}$ neutrongat aan de $0^{+}$grondtoestand in de overeenstemmende $N=50$ atoomkern. Het berekende multiplet van toestanden resulterend van de koppeling van een enkel $g_{9 / 2}$ neutrongat aan een $2^{+}$excitatie in ${ }^{94} \mathrm{Ru}$ op $1431 \mathrm{keV}$ is in goede overeensteming met de vier toestanden geobserveerd tussen 1 en $2 \mathrm{MeV}$. De idee dat de $\mathrm{p}_{1 / 2}$ en $\mathrm{g}_{9 / 2}$ orbitalen de belangrijkste bijdrage leveren tot de constructie van de geobserveerde geëxciteerde toestanden wordt gesteund door de opvallende gelijkenis tussen de twee schillenmodelberekeningen. Geen van beide valentieruimtes voorspelt een positieve pariteit toestand op een lagere energie dan de $13 / 2^{+}$.

Schilenmodelberekeningen voor ${ }^{92} \mathrm{Ru}$ stemmen goed overeen met de energieën van de experimenteel geobserveerde toestanden. De overeenkomst is in het bijzonder goed voor de Gross-Frenkel berekening. De berekening met de Sinatkas interactie is nog steeds tevredenstellend, maar neigt tot een overschatting van de excitatie-energie van alle experimentele niveaus. De experimentele evidentie voor een tweede $\beta$-vervallende toestand in ${ }^{92} \mathrm{Rh}$ wordt ondersteund door de schillenmodelberekeningen. Beide interacties voorspellen een $2^{+}$grondtoestand op ongeveer $50 \mathrm{keV}$ beneden de hoge-spin toestand, dit is een goede kandidaat voor de geobserveerde lage-spin $\beta$-vervallende toestand. 
Verder weg van de stabiliteitslijn zijn de schillenmodelvoorspellingen voor energieniveaus in ${ }^{91} \mathrm{Ru}$ minder overtuigend. Configuraties van het type $\left(\nu \mathrm{g}_{9 / 2}\right)^{-3}$ verschaffen de meest eenvoudige lage-energie ééndeeltjesexcitaties voor deze atoomkern. De energie van de gekende $\left(13 / 2^{+}\right)$toestand wordt goed weergegeven in beide berekeningen hoewel de Sinatkas formulering faalt voor de $\left(11 / 2^{+}\right)$toestand. Verder weg van de $\mathrm{N}=50$ gesloten schil wordt ook de mogelijkheid van collectieve excitaties belangrijk en deze kunnen de laag gelegen geëxciteerde toestanden beïnvloeden. Wat de $387 \mathrm{keV} \gamma$ lijn betreft, recente metingen beperken deze overgang tot een $1 / 2^{-}$naar $7 / 2^{+}$transitie in ${ }^{91} \mathrm{Ru}$. De voorgestelde energie van $433 \mathrm{keV}$ voor de $1 / 2^{-}$toestand stemt mooi overeen met de systematiek van de $1 / 2^{-}$toestanden in de $\mathrm{N}=47$ buurkernen. Deze toestand wordt bevolkt na het $\beta$ verval van een $1 / 2^{-}$isomere toestand in ${ }^{91} \mathrm{Rh}$. De halfwaardetijd van $1.46(11) \mathrm{s}$ voor deze toestand verschilt niet veel van de $\left(9 / 2^{+}\right)$waarde van $1.47(22) \mathrm{s}$. Zodoende kunnen de drie overblijvende $\gamma$ lijnen die geassocieerd werden met dit verval, niet éénduidig toegekend worden aan het $\beta$ verval van hetzij de $\left(9 / 2^{+}\right)$of de $\left(1 / 2^{-}\right)$isomeer.

De nabijheid van de $N=50$ gesloten schil voorspelt dat de structuur van de toestanden in ${ }^{91} \mathrm{Tc}$ bevolkt in het $\beta$ verval van ${ }^{91} \mathrm{Ru}$ regelrecht kan verklaard worden in termen van het schillenmodel, dit blijkt inderdaad het geval. Een vergelijking met de dichtste $\mathrm{N}=48$ buurkern vertoont een redelijk vloeiende evolutie van de energieën van de niveaus met de voorgestelde spintoewijzingen. Evenwel maken inconsistenties tussen beide schillenmodelberekeningen en de vrij beperkte informatie over de naburige isotopen een speculatie over de identiteit van de niet onderbrachte toestanden in ${ }^{91} \mathrm{Tc}$ gevaarlijk.

Aangeslagen toestanden met hoge spinwaarde in in ${ }^{90} \mathrm{Tc}$ worden goed gereproduceerd door de schillenmodelberekeningen. Voor de lage-spin toestanden, zoals deze bevolkt in het $\beta$ verval van ${ }^{90} \mathrm{Ru}$ is de situatie minder bevredigend. De berekeningen zijn niet in staat om een uitleg te verschaffen voor de twee geobserveerde $\gamma$ lijnen. Een groot verschil tussen de twee berekeningen duidt op een zwakheid in de schillenmodelbeschrijving van de lage-spin toestanden in ${ }^{90} \mathrm{Tc}$. Momenteel is het niet duidelijk wat de oorzaak hiervan kan zijn, het is duidelijk dat meer experimentele data nodig zijn voor deze atoomkern.

Twee halfwaardetijden werden toegekend aan het verval van ${ }^{90} \mathrm{Rh}$, de data bestudeerd in dit werk vertonen het verval van een langlevende $1.0_{-0.2}^{+0.3} \mathrm{~s}$ isomere toestand in tegenstelling tot de korter levende $12_{-4}^{+9} \mathrm{~ms}$ toestand waarvan men beweert dat het een snel toegelaten Fermi transitie is. Schillenmodelberekeningen voor de toestanden in ${ }^{90} \mathrm{Rh}$ voorspellen inderdaad een $0^{+}$grondtoestand met een 
eerste aangeslagen toestand met spin $2^{+}$op $\sim 900 \mathrm{keV}$ hoger in energie. De zoektocht voor kandidaten voor de $\beta$-vervallende isomere toestand concentreert zich op een groep van $5^{+}, 7^{+}, 9^{+}$toestanden bovenop de $2^{+}$toestand bij energieën tussen 1.1 en $1.6 \mathrm{MeV}$ in beide berekeningen.

\section{Samenvatting en vooruitzichten}

Elementaire laserionisatie van reactieproducten gevormd in zware-ionen fusieevaporatiereacties en gethermalizeerd binnen een gascel, werd toegepast voor het produceren van de neutronarme ${ }^{91,92,93} \mathrm{Rh}$ en ${ }^{90,91} \mathrm{Ru}$ isotopen. De vervalschema's werden bepaald van de meting van $\beta$-vertraagde $\gamma$ vervallen en werden bediscuteerd in het raamwerk van het schillenmodel. Berekeningen werden uitgevoerd met behulp van de schillenmodelcode ANTOINE en met de interactieparameters van Gross en Frenkel, evenals voor de grotere modelruimte van Sinatkas.

Met uitzondering van ${ }^{90} \mathrm{Tc}$ en in mindere mate van ${ }^{91} \mathrm{Ru}$, worden de geobserveerde aangeslagen toestanden goed gereproduceerd door de theoretische berekeningen. Bijkomende data op ${ }^{90} \mathrm{Tc}$ and ${ }^{91} \mathrm{Ru}$ zouden zeker de situatie verduidelijken, ook het aanzienlijke verschil tussen de Gross-Frenkel en Sinatkas berekeningen zou kunnen verbeterd worden door het inbrengen van nieuwe experimentele informatie in het bijzonder over de lage-spin niet-yrast toestanden.

De halfwaardetijden voor de bestudeerde atoomkernen werden bepaald van fits van het tijdsgedrag van hun $\gamma$ lijnen. Een studie van $\beta$-vertraagde protonverval werd ook ondernomen. Deze metingen vonden plaats tijdens een later experiment tijdens hetwelk technische problemen aanleiding gaven tot een vrij lage productie-opbrengst. Evenwel werden bovenlimieten bepaald voor de vertakkingswaarschijnlijkheden naar de toestanden in de dochterkernen die protonen uisturen, en dit voor de ${ }^{90} \mathrm{Rh}$ en ${ }^{89} \mathrm{Ru}$ moederkernen.

Dit werk toonde de succesvolle toepassing aan van on-line scheiding in combinatie met isotoopproductie binnenin een gascel voor de neutronarme kernen hierboven beschreven. De komst van hoogefficiënte detectortechnologie gecombineerd met ontwikkelingen in radioactieve ionenbundels verwacht vervolgstudies in dit gebied en mogelijks toegang tot meer exotische kernen in de richting van ${ }^{100} \mathrm{Sn}$. 


\section{Bibliography}

[And00] A. Andreyev, et al. Nature 405, 430 (2000)

[Arf85] G. Arfken, Mathematical Methods for Physicists, Academic Press, Inc. (London) Ltd., 1985

[Ari98] A. Arima, et al. Phys. Lett. B499, 104 (1998)

[Arn93a] S. E. Arnell, et al. Phys. Scr. 47, 355 (1993)

[Arn93b] S. E. Arnell, et al. Z. Phys. A346, 111 (1993)

[Arn94] S. E. Arnell, et al. Phys. Rev. C49, 51 (1994)

[Aud95] G. Audi and A.H. Wapstra, Phys. A595, 409 (1995)

[Aud97] G. Audi, et al. Nucl. Phys. A624, 1 (1997)

[Bag99]Ｃ. M. Baglin, Nucl. Data Sheets 861 (1999)

[Bag97]Ｃ. M. Baglin, Nucl. Data Sheets 801 (1997)

[Boh98] A. Bohr and R. B. Mottelson, Nuclear Structure World Scientific, 1998

[Bro85] B. A. Brown and B. H. Wildenthal, Atomic data and nuclear data tables,33, 347 (1985)

[Bro88] B. A. Brown, A. Etchegoyen, W. D. M. Rae, Code OXBASH, MSU Cyc. Lab. Report No. 524 (1988)

[Bro97] E. Brown, Nucl. Data Sheets 82379 (1997)

[Bru77] P. G. Brussaard and P.W.M. Glaudemans, Shell-model applications in nuclear spectroscopy North-Holland publishing company, Amsterdam, 1977 
[Cas00] R. F. Casten, Nuclear structure from a simple perspective Oxford University Press, 2000

[Cau99] E. Caurier and F. Nowacki, Acta Physica Polonica B30, 705 (1999)

[Cho93] W.-T. Chou, et al. Phys. Rev. C47, 163 (1993)

[Col95] G. Colò, et al. Phys. Rev. C52, R1175 (1995)

[Dob95] J. Dobaczewski and I. Hamamoto, Phys. Lett. B345, 181 (1995)

[Dör03] J. Döring, et al. Phys. Rev. C68, 034306 (2003)

[Fac04a] M. Facina, Ph.D. Thesis, University of Leuven, in preparation. To be published

[Fac04b] M. Facina, et al. submitted to Nucl. Instr. and Meth. B

[Fey58] R. P. Feynman and M. Gell-Mann, Phys. Rev. 109 (1958) 193

[Fir96] R. B. Firestone and V. S. Shirley (eds), Table of Isotopes (New York: Wiley 1996)

[Fra99] S. Frauendorf and J. A. Sheikh, Phys. Rev. C59, 1400 (1999)

[Gal00] E. Galindo, et al. Eur. Phys. J. A9, 439 (2000)

[Gea] http://wwwinfo.cern.ch/asd/geant/

[Gib80] W. M. Gibson and B. R. Pollard, Symmetry principles in elementary particle physics, Cambridge University Press, 1980

[Gie03] M. Gierlik, et al. Nucl. Phys. A724, 313 (2003)

[Goo80] C. D. Goodman, et al. Phys. Rev. Lett. 44, 1755 (1980)

[Goo01] C. D. Goodman, et al. Nucl. Instr. and Meth. A462, 545 (2001)

[Goo99] A. L. Goodman, Phys. Rev. C60, 014311 (1999)

[Gor01] S. Goriely, et al., Atomic data and nuclear data tables,77, 311 (2001)

[Gór96] M. Górska, et al. Acta Physica Polonica B27, 165 (1996)

[Gro76] R. Gross and A. Frenkel, Nucl. Phys. A267, 85 (1976) 
[Gro90] K. Grotz and H. V. Klapdor, The weak interaction in nuclear, particle and astrophysics, IOP Publishing Ltd. (1990)

[Hab97] D. Habs, et al. Prog.Part.Nucl.Phys. 38, 111 (1997)

[Hag83] E. Hagberg, et al. Nucl. Phys. A395, 152 (1983)

[Hag02] K. Hagiwara, et al.(Particle Data Group) Phys. Rev. D66, 010001 (2002)

[Ham93] I. Hamamoto and H. Sagawa, Phys. Rev. C48, R960 (1993)

[Har98] J. C. Hardy and I. S. Towner, Conf. Proc. ENAM98, AIP Conf. Proc. 38 (1998)733

[Has04] M. Hasegawa, et al. Phys. Rev. C69, 034324 (2004)

[Hee94] J. Heese, et al. Phys. Rev. C49, 1896 (1994)

[Hel02] R. G. Helmer, Nucl. Data Sheets 95543 (2002)

[Her97] H. Herndl and B. A. Brown, Nucl. Phys. A627, 35 (1997)

[Hey90] K. L. G. Heyde, The nuclear shell model, Springer-Verlag, 1900

[Hjo95] M. Hjorth-Jensen, et al. Phys. Rep. 261, 125 (1995)

[Hu99] Z. Hu, Phys. Rev. C60, 024315 (1999)

[Ike63] K. Ikeda, et al. Phys. Lett. 3, 271 (1963)

[Jan00] Z. Janas, et al. Proc. Int. Workshop PINGST 2000, Lund, Sweden, p99

[Kan99] K. Kaneko and M. Hasegawa, Phys. Rev. C60, 024301 (1999)

[Kas97] D. Kast, et al. Z. Phys. A356, 363 (1997)

[Kie01] P. Kienle, et al. Prog.Part.Nucl.Phys. 46, 73 (2001)

[Kom83] P. Komninos, et al. Z. Phys. A314, 135 (1983)

[Kra88] K. Krane, Introductory nuclear physics, John Wiley \& Sons, Inc. (1988)

[Kud96] Y. Kudryavtsev, et al. Nucl. Instr. and Meth. B 114, 350 (1996) 
[Kud01] Y. Kudryavtsev, et al. Nucl. Instr. and Meth. B 179, 412 (2001)

[Lan76] J. C. de Lange, et al. Z. Phys. A279, 79 (1976)

[Li99] Li Zhankui, et al. Eur. Phys. J. A5, 351 (1999)

[Lin97] C. lingk, et al. Phys. Rev. C56, R2349 (1997)

[Mar03a] N. Marginean, et al. Phys. Rev. C67, 61301 (2003)

[Mar03b] N. Marginean, et al., private communication

[Mar96] G. Martinez-Pinedo, et al. Phys. Rev. C53, R2602 (1996)

[Maz02] C. Mazzocchi, Ph.D. Thesis, Universität Mainz,

[Min] http://wwwinfo.cern.ch/asdoc/minuit/minmain.html

[Mö197] P. Möller, et al., Atomic data and nuclear data tables,66, 131 (1997)

[Mul88] H.-W. Muller, Nucl. Data Sheets 541 (1988)

[Nav03] P. Navrátil and W.E. Ormand, Phys. Rev. C68, 034305 (2003)

[Naz98] W. Nazarewicz, Nucl. Phys. A630, 239c (1998)

[Nil73] A. Nilsson and M. Grecescu, Nucl. Phys. A212, 448 (1973)

[Nol80] E. Nolte, et al. Z. Phys. A298, 191 (1980)

[nndc] http://www.nndc.bnl.gov/nndc/physco/

[Oda96] A. Odahara, et al. Z. Phys. A354, 231 (1996)

[Oxo80] K. Oxorn, et al. Z. Phys. A294, 389 (1980)

[Oxo81] K. Oxorn and S. K. Mark, Z. Phys. A303, 63 (1981)

[Pie01] S. C. Pieper and R. B. Wiringa, Ann. Rev. Nucl. Part. Sci. 51, 53 (2001)

[Pie02] S. C. Pieper, et al. Phys. Rev. C66, 044310 (2002)

[Ple04] C. Plettner et al., Nucl. Phys. A733, 20 (2004)

[Rap94] J. Rapaport and E. Sugarbeker, Ann. Rev. Nucl. Part. Sci. 44, (1994) 109 
[Rei81] W. Reisdorf, Z. Phys. A300, 227 (1981)

[Rot95] H. A. Roth, et al. J. Phys. G: Nucl. Part. Phys. 21, (1995) L1

[Rud93] D. Rudolph, et al. Phys. Rev. C47, 2574 (1993)

[Rud94] D. Rudolph, et al. Phys. Rev. C49, 66 (1994)

[Rus04a] C. Rusu, et al. Phys. Rev. C69, 024307 (2004)

[Rus04b] C. Rusu, et al., in preparation

[Sch95] R. Schubart, Nucl. Phys. A591, 515 (1995)

[Sch98] H. Schatz, et al. Phys. Rep. 294, 167 (1998)

[Sch00(a)] K. Schmidt, et al. Eur. Phys. J. A8, 303 (2000)

[Sch00(b)] P. Schuurmans, Nucl. Phys. A672, 89 (2000)

[Ser76] F. J. D. Serduke, et al. Nucl. Phys. A256, 45 (1976)

[Sha63] A. de Shalit and I. Talmi, Nuclear Shell Theory Academic Press, London 1963

[Sin98] B. Singh, Nucl. Data Sheets 851 (1998)

[Sin92a] J. Sinatkas, et al. J. Phys. G: Nucl. Part. Phys. 18, (1992) 1377

[Sin92b] J. Sinatkas, et al. J. Phys. G: Nucl. Part. Phys. 18, (1992) 1401

[Soh04] D. Sohler, et al. Eur. Phys. J. A19, 169 (2004)

[Sri] http://www.srim.org/

[Tad87] T. N. Taddeucci, et al. Nucl. Phys. A469, 125 (1987)

[Tow85] I. S. Towner, Nucl. Phys. A444, 402 (1985)

[Van97(a)] P. Van den Bergh, et al. Nucl. Instr. and Meth. B 126, 194 (1997)

[Van97(b)] P. Van Isacker and D.D. Warner, Phys. Rev. Lett. 78, 3266 (1997)

[Van00] P. Van Duppen, et al. Hyperfine Interactions 127(1), 401 (2000)

[Van02] J. Van Roosbroeck, Ph.D. Thesis, University of Leuven (2002) 
[Wei99] L. Weissman, et al. Nucl. Instr. and Meth. A 423, 328 (1999)

[Wil83] B. H. Wildenthal, et al. Phys. Rev. C28, 1343 (1983)

[Wil73] D.H. Wilkinson, Phys. Rev. C7, 930 (1973)

[Woo97] P. J. Woods and C. N. Davids, Ann. Rev. Nucl. Part. Sci. 47, 451 (1997)

[Wys01] R. A. Wyss and W. Satula, Acta Physica Polonica B9, 2457 (2001)

[Zho94] Zhou Shuhua, et al. Z. Phys. A350, 7 (1994)

[Zho99] S-H. Zhou, et al. Chin. Phys. Lett. 16, 18 (1999) 